FINAL REPORT

U.S. Department of Energy

\title{
BASIC ENGINEERING RESEARCH FOR D\&D OF R REACTOR STORAGE POND \\ SLUDGE: ELECTROKINETICS, CARBON DIOXIDE EXTRACTION, AND SUPERCRITICAL WATER OXIDATION
}

\author{
Project Director: Edward A. Hamilton \\ Institution: South Carolina Universities Research and Education Foundation \\ Principal Investigator: Dr. Michael A. Matthews \\ Institution: University of South Carolina \\ Co-Principal Investigators \\ Dr. David Bruce \\ Dr. Thomas Davis \\ Dr. Mark Thies \\ Dr. John Weidner \\ $\underline{\text { Institution }}$ \\ Dr. Ralph White \\ Clemson University \\ University of South Carolina \\ Clemson University \\ University of South Carolina \\ University of South Carolina \\ Collaborators \\ Ms. Nancy Lowry \\ Dr. Lawrence Oji \\ Dr. John Pickett \\ Institution \\ Westinghouse Savannah River Company \\ Savannah River Technology Center \\ Westinghouse Savannah River Company
}

Project Number: 64979-SC

Grant Number: DE-FG07-98ER 14923

Grant Project Officers:

Robert E. Price, Ph.D.

Chester (Chet) Miller

Project Duration: September 18, 1998 - December 31, 2001 


\section{TABLE OF CONTENTS}

1. Executive Summary

2. Research Objectives

3. Method and Results

3.1 Supercritical CO2 for Extraction of PCBs

3.1.1 Objectives

3.1.2 Background

3.1.3 Methodology

3.1.4 Results and Discussion

3.2 Electrochemical Superoxide Chemistry Destruction of PCBs

3.2.1 Objectives

3.3 Solubility of PCBs in Hot Water

3.3.1 Objectives

3.4 Supercritical Water Oxidation of PCBs

3.4.1 Objectives

4. Relevance, Impact and Technology Transfer

5. Project Productivity

6. Personal Supported

7. Publications

8. Interactions

9. Patents

10. Future work

10.1 Extraction of PCBs Using Supercritical CO2 or Hot Water 10.2 Solubility of PCBs in Near-Critical Water

10.3 Kinetic Analysis of Supercritical Water Oxidation

11. Literature cited

12. Feedback

13. Appendices 


\section{EXECUTIVE SUMMARY}

Large quantities of mixed low level waste (MLLW) that fall under the Toxic Substances Control Act (TSCA) exist and will continue to be generated during D\&D operations at DOE sites across the country. Currently, the volume of these wastes is approximately $23,500 \mathrm{~m}^{3}$, and the majority of these wastes (i.e., almost $19,000 \mathrm{~m}^{3}$ ) consist of PCBs and PCB-contaminated materials. Further, additional PCB-contaminated waste will be generated during D\&D operations in the future. The standard process for destruction of this waste is incineration, which generates secondary waste that must be disposed, and the TSCA incinerator at Oak Ridge has an uncertain future. Beyond incineration, no proposed process for the recovery and/or destruction of these persistent pollutants has emerged as the preferred choice for DOE cleanup.

The main objective of the project was to investigate and develop a deeper understanding of the thermodynamic and kinetic reactions involved in the extraction and destruction of polychlorinated biphenyls (PCBs) from low-level mixed waste solid matrices in order to provide data that would permit the design of a combined-cycle extraction/destruction process. The specific research objectives were to investigate benign dense-fluid extraction with either carbon dioxide (USC) or hot water (CU), followed by destruction of the extracted PCBs via either electrochemical (USC) or hydrothermal (CU) oxidation. Two key advantages of the process are that it isolates and concentrates the PCBs from the solid matrices (thereby reducing waste volume greatly and removing the remaining low-level mixed waste from TSCA control), and little, if any, secondary solvent or solid wastes are generated.

This project was a collaborative effort involving the University of South Carolina (USC), Clemson University (CU), and Westinghouse Savannah River Company (WSRC) (including the Savannah River Technology Center, Facilities Decommissioning Division and Regulatory Compliance). The project was directed and coordinated by the South Carolina Universities Research and Education Foundation (SCUREF), a consortium of the four public research universities in South Carolina.

The original plan was to investigate two PCB extraction processes (supercritical carbon dioxide and hot, pressurized water) and two PCB destruction processes (electrochemical oxidation and hydrothermal oxidation). However, at approximately the mid-point of the threeyear project, it was decided to focus on the more promising extraction process (supercritical carbon dioxide) and the more promising destruction process (supercritical water oxidation). This decision was taken because the investigation of two processes simultaneously by each university was stretching resources too thin, and because the electrochemical oxidation process needed more concentrated research before it would be ready for application to PCB destruction.

The solid matrix chosen for experimental work was Toxi-dry, a commonly used adsorbent made from plant material that is used in cleanup of spills and/or liquid solvents. The Toxi-dry was supplied by the research team member from the Facilities Decommissioning Division, WSRC. This adsorbent is a major component of job control waste.

The project team designed and built two supercritical $\mathrm{CO}_{2}$ extraction apparatuses for investigation of the effects of temperature, pressure and cosolvents on 1,2,4-trichlorobenzeneze (TCB) or 2-chlorobiphenyel (2CBP) extraction efficiency and compared the results of supercritical fluid extraction (SFE) with Soxhlet extraction and sonication. The Toxi-dry was spiked with PCB surrogates, and numerous runs were completed using 5\% ethanol-modified 
carbon dioxide as a cosolvent. The experimental pressures were 2,000 and 4,000 psi, and the temperatures were $40{ }^{\circ} \mathrm{C}$ and $80{ }^{\circ} \mathrm{C}$. These experiments showed that supercritical $\mathrm{CO}_{2}$ extraction using ethanol as a modifier is a very promising technology for extracting chlorinated aromatics from job control waste and other DOE matrices.

The project team also constructed a continuous-flow supercritical water oxidation (SCWO) apparatus in which to conduct hydrothermal oxidation of PCBs. Chemical analysis was performed with a new GC/electron capture detector system. The team conducted SCWO screening tests with methanol as a tuning compound for the continuous-flow supercritical water oxidation reactor. Methanol was chosen not only because it is easy to work with, but also because the supercritical water oxidation behavior of methanol is well documented in the literature. Hydrogen peroxide was chosen as the oxidant, as it outperforms oxygen as indicated by the literature. The reactor has obtained conversions of methanol and PCBs in excess of $99 \%$.

This EMSP project provided support for two Masters theses and the experimental data for two $\mathrm{PhD}$ dissertations (in progress).

This research is highly relevant to the needs of DOE/EM. As indicated above, within the entire weapons complex there are approximately $19,000 \mathrm{~m}^{3}$ of PCB-contaminated low-level mixed waste and job control waste, and more will be generated during ongoing and future D\&D operations. The only approved disposal path is incineration, and the only approved incinerator for this type waste, at Oak Ridge, has been shut down, perhaps permanently. This process can be a viable, safe and relatively inexpensive alternative to incineration.

This project has produced the data necessary to understand the reaction kinetics and thermodynamics of the technologies involved. Within two more years, the project can produce the data necessary for prototype design and a larger-scale demonstration. Further research and development would include (1) fine tuning the $\mathrm{CO}_{2}$ /ethanol extraction process to achieve higher rates of extraction; (2) additional lab-scale tests comparing hot water and $\mathrm{CO}_{2}$ as the extraction solvent, and extracting PCBs from additional solid matrices of interest to SRS and DOE; (3) performing additional experiments and kinetic analysis of the SCWO process; (4) obtaining additional phase equilibrium data for PCBs in support of extraction and oxidation modeling; and (5) modeling and consolidating all technical data so that a prototype combined-cycle apparatus could be built and a larger-scale demonstration could be considered for implementation by DOE. 


\section{RESEARCH OBJECTIVES}

The Toxic Substances Control Act (TSCA) regulates the handling, storage, and destruction of wastes containing polychlorinated biphenyls (PCBs). Because of stringent TSCA disposal requirements and a shortage of disposal capacity, storage and disposal of radioactive PCB wastes is a major waste management problem for the entire DOE complex. Since 1979, regulations implementing the Toxic Substances Control Act (TSCA) have required that wastes within 50 parts-per-million (ppm) PCBs be disposed within one year of generation. However, until the TSCA Incinerator at the DOE Oak Ridge facility began operations in 1991, no facility in the United States could dispose radioactive PCBs. Further, incineration is not an ideal solution to the problem of disposing of radioactive PCBs. In addition to the problem of inadequate incinerator capacity, treatment by incineration produces secondary atmospheric emissions and ash that require control and treatment. Now that the Oak Ridge incinerator is scheduled for shut down, perhaps permanently, DOE is again faced with the dilemma of how to dispose of PCB-contaminated radioactive waste. Thus far, no alternative technology to incineration has emerged as the preferred choice for DOE cleanup.

The DOE Integrated Planning, Accountability, and Budgeting Systems (IPABS) database documented a complex-wide inventory of 5,210 cubic meters $\left(\mathrm{m}^{3}\right)$ of radioactive PCB waste in storage at the end of FY2000. This included volumes of 1,164 m3 at the Oak Ridge Reservation, 3,354 $\mathrm{m}^{3}$ at the Paducah Gaseous Diffusion Plant, and $354 \mathrm{~m}^{3}$ at the Ashtabula, Ohio facility. The wastes in storage consist of a variety of solid and liquid matrices. For the period FY2001-FY2010, 70,470 $\mathrm{m}^{3}$ of radioactive PCB waste are expected to be generated throughout the DOE complex. Clearly, the issue of radioactive PCB storage, treatment and disposal will persist throughout the next decade and beyond.

The goals of the project were to investigate two methods of extracting PCBs from solid matrices (using either supercritical carbon dioxide or hot water as the extraction solvent), and to investigate two methods of oxidizing PCBs (using either supercritical water oxidation or a novel electrochemical oxidation method). This research in turn would allow the team to select from among these extraction and oxidation options and to recommend a combined extraction/oxidation process for further development and consideration by DOE.

The ultimate goal of the research is to develop a combined cycle extraction/oxidation technology (see Figure 1) that would reduce the level of PCB contamination in the remaining mixed low-level waste to within EPA clean water standards of 3 parts-per-billion (ppb), thereby removing it from TSCA control. Two key advantages of the process are that it isolates and concentrates the PCBs from the solid matrices, thereby reducing waste volume greatly, and little, if any, secondary solvent or solid wastes are generated.

Decontamination and decommissioning activities in DOE sites routinely generate PCBcontaminated liquid and solid wastes. Frequently these wastes are also contaminated with HTO (tritiated water) or other radioactive species, resulting in a PCB-contaminated mixed low-level radioactive waste (MLLW). The solid waste forms encountered are classified as homogeneous inorganic debris (e.g., scrap metals and concrete), organic debris (e.g., paper, cloth, plastic, rubber), heterogeneous debris, slurries (defined as having Total Suspended Solids (TSS) between $1 \%$ and $30 \%$ by weight) and sludge (defined as having TSS greater than $30 \%$ ). 
This research project originally had intended to focus on the sludge located in the spent fuel rod cooling pond associated with the R Reactor at Savannah River Site. However, when it was determined, after the grant was awarded, that the level of PCB contamination in the reactor pond sludge was not sufficiently high to classify it as a TSCA waste, the team, with the advice of the team member from the SRS Facilities Decommissioning Division, decided to use low-level radioactive PCB-contaminated "Job Control Waste" (JCW) as the primary matrix for our research. The majority of these wastes include materials such as "Toxi-dry," a porous, lipophilic plant-based material that is used to absorb spills, wash solutions, and solvent solutions generated during D\&D activities, and "spill pillows" used to absorb liquid wastes resulting from solvent spills within process facilities.

Changes to the PCB regulations in 1998 provided more disposal options for job control waste. However, most absorbed liquids still must be disposed by incineration. In addition to the problem of inadequate incinerator capacity, disposal by incineration produces secondary atmospheric emissions and ash that require control and treatment. Another significant potential benefit of this research is the development of alternative technologies that do not produce secondary pollution similar to incineration.

The project was conducted by collaborating researchers at the University of South Carolina (USC), Clemson University (CU), and the Savannah River Site (SRS), under the direction of the South Carolina Universities Research and Education Foundation (SCUREF). Four new students (two Ph.D., two M.S.) were trained on this grant. The M.S. students have concluded their work, while the two Ph.D. students will continue.

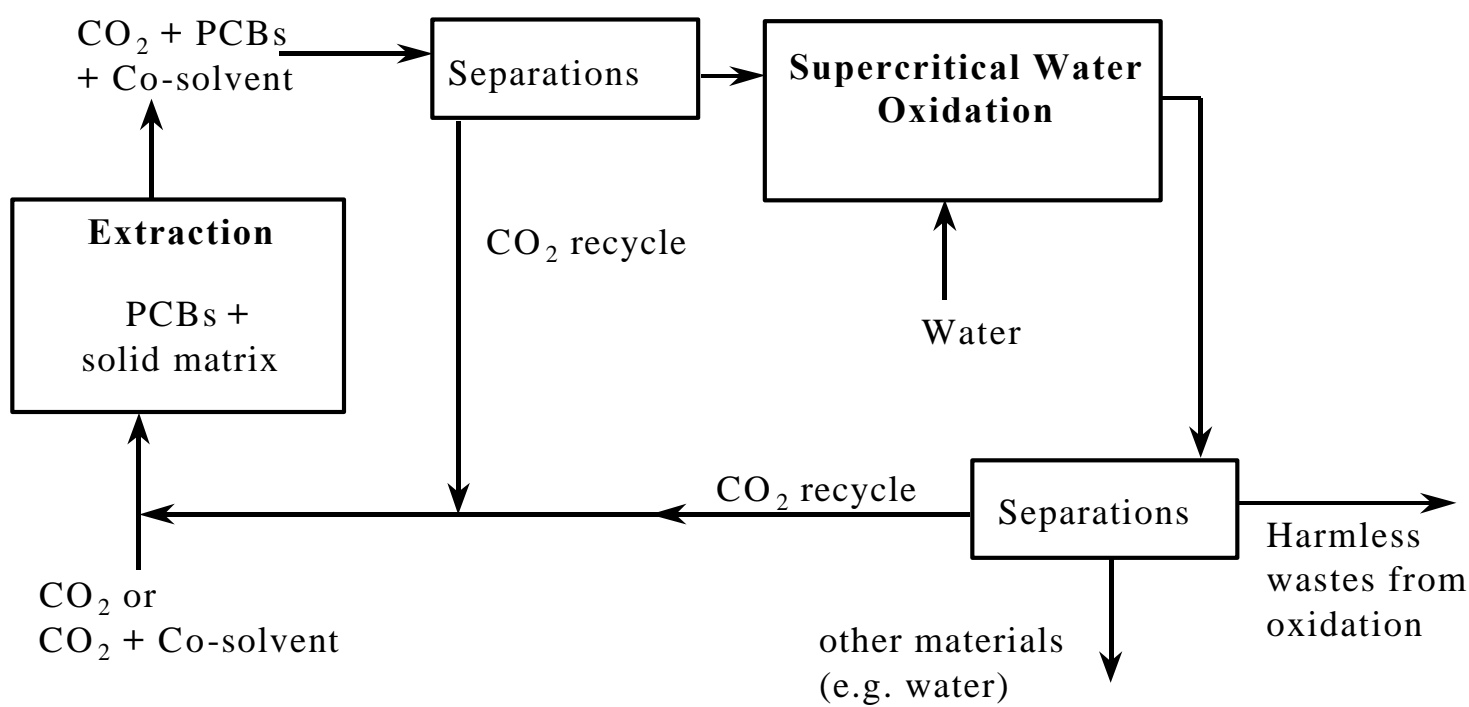

Figure 1. Conceptual process cycle for supercritical fluid extraction and supercritical water oxidation destruction of PCBs.

Figure 1 shows the conceptual process that has been investigated. This diagram assumes that supercritical carbon dioxide-based solvent extraction is being used to remove and concentrate PCBs from the solid matrix. (Should hot water ultimately prove to be the preferred extraction solvent, a similar process diagram would apply.) The extraction research was conducted at the University of South Carolina. Unconsolidated PCB-contaminated waste or debris was placed in a high-pressure extraction vessel. Results to date show that adding small 
amounts of either acetone or ethanol to the $\mathrm{CO}_{2}$ facilitates PCB extraction. SRS collaborators have indicated that ethanol is the preferred cosolvent, because (unlike acetone, methanol, or any other common cosolvents) DOE does not place restrictions on use of ethanol as a process solvent. Therefore, it would be much simpler, faster, and less expensive from a permitting standpoint to use ethanol as a cosolvent.

The effluent from the extractor will contain $\mathrm{CO}_{2}$, cosolvent, and PCBs. Depending on the other components of the waste, additional extract may include water, or additional volatile organics. Downstream of the extractor, a separation unit may be needed to separate the extractable materials from the $\mathrm{CO}_{2}$. The ideal separation would return the bulk of the $\mathrm{CO}_{2}$ to the extractor, leaving ethanol and PCBs in a stream to be fed to the supercritical water oxidation (SCWO) reactor. This separation unit has not been investigated yet, but should funding for continuation of this project be identified, the team would use computer simulations to perform preliminary design and optimization of this unit. Preliminary design of the separation unit requires phase equilibrium data on $\mathrm{PCB} /$ water, $\mathrm{PCB} / \mathrm{CO}_{2}$, and $\mathrm{CO}_{2}$ /ethanol systems for equation of state tuning. $\mathrm{PCB} /$ water data have been collected in the present project; data on the other systems are available in the literature.

Continuing in Figure 1, the PCB and ethanol stream will be fed to the SCWO reactor. The ethanol is needed to provide additional heat of combustion in the SCWO step. The PCB concentration alone is expected to be too small to provide sufficient heat of combustion, and it is common practice in SCWO reactors to add an additional feed to facilitate complete destruction of trace levels of organic waste. Thus in our process, it is advantageous that the ethanol cosolvent need not be separated and recovered; rather it is fed to the SCWO reactor. Ethanol is a commodity chemical and is relatively inexpensive, thus it should be economical to utilize it in our process in this fashion.

Finally in Figure 1, the effluent from the SCWO reactor is directed to additional separations units to recover additional $\mathrm{CO}_{2}$ and/or water (if economical), to neutralize the effluent water, and to direct the waste stream to a discharge system. PCB wastes must be completely oxidized below EPA regulatory limits, so that the separations and treatment downstream of the SCWO reactor are minimal.

It is emphasized that experimental research so far has concentrated on $\mathrm{CO}_{2}$ extraction, solubility of PCBs in hot water, and SCWO. Separations, heat exchange, compressors, and other necessary parts of the process are amenable to preliminary design via computer simulation, once the phase equilibrium data obtained as part of this project are known.

The first eighteen months of the project were dedicated primarily to procuring, assembling, modifying and testing the new experimental equipment. The next twelve months were dedicated to further fine-tuning of the equipment and conducting experimental runs using surrogates for PCBs and obtaining preliminary data. The final nine months, including a threemonth no-cost extension, were dedicated to experiments with PCB-contaminated materials and further fine-tuning of the processes. 


\section{METHODS AND RESULTS}

\subsection{SUPERCRITICAL $\mathrm{CO}_{2}$ FOR EXTRACTION OF PCBS.}

\subsubsection{Objectives:}

1. Find optimal supercritical $\mathrm{CO}_{2}$ extraction conditions for chlorinated aromatics, especially polychlorinated biphenyl (PCBs) samples.

2. Find cosolvents to enhance PCB extraction rate and recovery.

3. Develop new processes for the extraction of PCBs from DOE matrix materials generated during D\&D operations.

\subsubsection{Background:}

Supercritical $\mathrm{CO}_{2}$ solvent extraction of PCBs from solid waste gives a low volume extract that is rich in PCBs. This PCB stream, isolated from the solid matrix that constitutes the majority of the volume of the mixed radioactive low-level solids, should be amenable to destruction with a subsequent oxidation step. Isolating PCBs in this fashion greatly reduces the volume of TSCA-regulated wastes and facilitates destruction of PCBs.

Above the critical temperature $\left(31^{\circ} \mathrm{C}\right)$ and critical pressure (1078 psia), $\mathrm{CO}_{2}$ gas can be compressed to a dense state $\left(0.4-0.9 \mathrm{~g} / \mathrm{cm}^{3}\right)$, which is sufficient density to make it an effective solvent. In the supercritical fluid state, the efficiency of solubilizing and extracting PCBs depends strongly on density, which is a sensitive function of temperature and pressure. Small changes of temperature and pressure may greatly influence the solubility of the solute. In addition, we have shown that small amounts of low-toxicity cosolvents, such as acetone or ethanol, will also improve the PCB extraction efficiency. Moreover, extracts can be easily separated by depressurizing the SCF. Many reviews of the general concepts of supercritical fluid extraction (SFE) are available (McHugh and Krukonis 1993).

Supercritical $\mathrm{CO}_{2}$ is particularly attractive for the extraction of organic-contaminated wastes, including low-volatility compounds such as PCBs, because $\mathrm{CO}_{2}$ is nontoxic, nonflammable, and environmentally acceptable. It is also inexpensive and available in large quantities. $\mathrm{CO}_{2}$ has a low critical temperature $\left(31^{\circ} \mathrm{C}\right)$ and a moderate critical pressure $(1078$ psia), so that equipment development is entirely feasible within the current state of the art. In addition, $\mathrm{CO}_{2}$ can dissolve numerous nonpolar and moderately polar compounds due to its Lewis base characteristics, induced dipole interactions, and quadrupole interactions (Langenfeld 1994). As was discussed above in connection with Figure 1, the proposed process should generate little secondary solvent waste.

There has been considerable research on $\mathrm{CO}_{2}$ extraction of PCBs from environmental samples, almost exclusively soils and sediments. The physical chemistry of PCB adsorption will be markedly different in the types of matrices important to SRS and the rest of the DOE weapons complex (absorbents, fibers, concrete, paint, and metal). Most prior work has been aimed at developing analytical-scale extractions for characterization of PCBs in environmental samples. Analytical-scale research typically does not deal with process dynamics and modeling, which are crucial to process design, or mechanisms of adsorption, which are vital to fundamental understanding and control of processes. 
The factors that influence the mechanism of an SFE process can be grouped into three categories: (1) thermodynamic factors such as the extract adsorption/desorption equilibrium at the matrix surface, and the solubility of the extract, (2) kinetic factors that include the solventsolid contact, extract desorption rate, and the extraction time, and (3) the influence of the solid matrix on diffusion and the interaction of the extract with the solid. Previous work provides a reasonable basis for estimating solubility and modeling mass transfer in a semi-quantitative fashion. However, the effect of the solid matrix on extraction of PCBs is still not understood on a fundamental basis. This question is particularly critical for D\&D operations within DOE because of the wide variety of solid matrices within which PCBs can be found. In this project, our focus has been on a particular matrix identified by Savannah River Site (SRS) collaborators. The matrix is a porous, lipophilic plant-based material ("Toxi-dry") that is used to absorb spills, wash solutions, and solvent solutions generated during D\&D activities

Yak et al. (1999) investigated off-line supercritical fluid extraction (SFE) followed by gamma-radiolysis as an alternative treatment technique for PCB-contaminated soil. The results showed greater than $90 \%$ removal of BZ \#54 from spiked sand and soil using SFE at $150{ }^{\circ} \mathrm{C}$ and 200 atm. Berset et al. (1999) used $\mathrm{CO}_{2}$ for a fast, quantitative and partly selective extraction technique for determining polychlorinated biphenyls (PCBs) in sewage sludge. Trigg et al. (1998) developed automated supercritical fluid extraction for the extraction of organochlorine compounds from sediment and sewage sludge matrices. The extraction method was optimized by varying selected SFE operational parameters, including extraction pressure and temperature and percentage modifier, with all results being compared to those from Soxhlet extraction. Morselli et al. (1998) discussed the effects of a number of parameters (pressure, temperature and modifier) on the SFE of PCBs. Chen et al. (1997) also demonstrated the effectiveness of SFE as a promising technology for the clean up of PCB contaminated soils/sediments. After 30 minutes of extraction at $40{ }^{\circ} \mathrm{C}$ and $100 \mathrm{~atm}$, more than $86 \%$ of PCBs in a Hudson River sediment and $92 \%$ in a St. Lawrence River sediment were removed. Reutergardh et al. (1998) used supercritical $\mathrm{CO}_{2}$ to extract three planar (PCB-77, PCB-169, PCB-126) and three mono-ortho (PCB-105, PCB-156, PCB-189) PCBs from three different tropical soil types. Additional studies involving environmental soils and sediments include those of Dachs et al., (1997), Morselli et al. (1995), Bowadt et al., (1995, 1997,1994), Tong et al. (1995), Van der Velde (1992), Berg et al.(1999), Sweetman et al. (1995), Hetflejs (1994), and Fuoco (1992).

Some generic conclusions can be drawn from these studies. The effect of extraction temperature is a sum of the temperature effects on solute vapor pressure, on the density of the extraction fluid, and on the adsorption of the pollutant in soils. If the pollutant's vapor pressure does not increase significantly with temperature, the extraction efficiency will decrease because of the decreased solvent density (Laitinen et al. 1994). According to Dupeyron et al. (1999), higher temperature enhances the diffusion coefficients and reduces solvent viscosity and superficial tensions. These two effects can contribute to faster mass transfer. Because the temperature effects are complex and usually are PCB congener and matrix dependent, there is no general conclusion as to how temperature affects SFE of PCBs.

Several studies support the use of high (above $100^{\circ} \mathrm{C}$ ) temperatures on PCB extraction. Langenfeld et al. (1993) reported that high extraction temperature can increase PCB recoveries from river sediments. A temperature increase from $50^{\circ} \mathrm{C}$ to $100^{\circ} \mathrm{C}$ increased the recovery of small molecular weight PCBs but not the higher molecular weight species, but further increase of temperature to $200^{\circ} \mathrm{C}$ did increase the PCB recovery greatly. Bowadt et al. (1997) performed 
extractions on two different soils at two different temperatures $\left(80^{\circ} \mathrm{C}\right.$ and $\left.150^{\circ} \mathrm{C}\right)$ at constant pressure (400 atm). The results show that temperature does have a significant effect on the extraction efficiency of PCBs. In aged soil samples, organic pollutants are usually presented in trace amounts in solid materials, and are often bound very strongly to the matrix. For this type of sample, increasing temperature, which facilitates the breaking of strong analyte-matrix interaction, will improve the extraction efficiency, despite the density decrease (Bjorklund et al. 1999).

Extraction of trace amounts of aged organic contaminants like PCBs from environmental samples usually is kinetically controlled (Bjorklund et al. 2000). Dupeyron et al. (1999) pointed out that an increase in pressure can improve penetration of the solvent into matrix pores plugged by water or air bubbles. Reutergardh et al. (1998) found that, at constant temperature of $40^{\circ} \mathrm{C}$, elevating the fluid density from 0.25 to $0.8 \mathrm{~g} / \mathrm{mL}$ resulted in enhancing the extraction efficiency of compounds (three planar and three mono-ortho PCBs) in all three soils. Increasing the density to more than $0.8 \mathrm{~g} / \mathrm{ml}$ has little effect on recoveries of all congeners due to the limitation of the solubility in supercritical $\mathrm{CO}_{2}$.

Because high pressure requires more expensive equipment, considerable effort was focused on enhancing extraction efficiencies by the use of small amounts of co-solvents (e.g. acetone) mixed with supercritical $\mathrm{CO}_{2}$. Co-solvents may increase the solvent power and selectivity of pure dense $\mathrm{CO}_{2}$ at moderate pressures, compared to pure supercritical $\mathrm{CO}_{2}$ (Abaroudi et al. 1999). Popular co-solvents are methanol, ethanol, acetone, water, and light hydrocarbons. At the appropriate concentration, temperature, and density, the co-solvent helps dissolve the solute into a microscopically homogeneous solution (Amador-Hernandez 2000). The presence of a modifier to improve recoveries is thought to work in two ways. First, it increases the effective polarity of the supercritical fluids, equivalent to using a more polar solvent such as dichloromethane for a Soxhlet extraction. The second effect is due to the wetting properties of the cosolvent that disrupt solute/matrix adsorption. Morselli et al. (1998) showed that $\mathrm{CO}_{2}$ modified by acetone yielded high recoveries of PCBs (>95\%). Chen et al. (1997) found that the sample water content and the presence of co-solvent were the most important factors affecting desorption of PCBs. Reutergardh et al. (1998) found that addition of 3 to $5 \%$ methanol could increase the PCB extraction yield up to $28 \%$. The percentage of methanol was varied from 0$10 \%$ to observe the impact of the extraction yield. In contrast, Sweetman (1995) used methanol as a co-solvent at $0 \%, 5 \%$ and $10 \%$ and found that the effect of the modifier appeared to be minimal.

It is recognized that strong adsorption as well as the complex pore structure of certain soils and sediments strongly inhibits complete removal of PCBs from native samples. The SFE methods mentioned above are quite matrix dependent. For different solid matrices, extraction parameters such as pressure, cosolvent, temperature, and flow rate have different effects on PCB extraction, and no general optimal extraction conditions have been identified. For many studies, spiked samples were used, but it was discovered that results obtained from recently spiked samples could not be used to predict the behavior of aged samples (Bjorklund et al. 1999). Aged samples usually need higher extraction temperature or modifiers. According to the kinetic model developed by Pawliszyn (1993), both chromatographic elution (partitioning and bulk transport in the fluid) and desorption (matrix-fluid transport) affect the extraction rate in aged samples, while it is believed that spiked analytes will be affected only by solubility limitations since these have no time to interact with the matrix sufficiently (Bjorklund et al. 2000). 


\subsubsection{Methodology}

As a first step in process design, the feasibility of using SFE to effect a particular separation was tested in an analytical scale apparatus. 1,2,4-trichlorobenzene (TCB) was chosen as the surrogate for PCBs, and supercritical $\mathrm{CO}_{2}$ extractions were conducted in a $10 \mathrm{ml}$ ISCO extractor. TCB was extracted from Toxi-dry using both pure and modified supercritical $\mathrm{CO}_{2}$. The effects of pressure, temperature, and cosolvents were investigated, and the recovery of TCB from Toxi-dry approached $100 \%$ under optimal conditions. The results demonstrated that SFE with $\mathrm{CO}_{2}$ and either ethanol or acetone cosolvent is a promising method for JCW decontamination.

Subsequent to the analytical-scale extraction, a larger vessel that simulated an industrial SFE system was employed in a "process development unit testing". At this stage, 2chlorobiphenyl was spiked onto clean Toxi-dry, and was extracted with pure or ethanol-modified $\mathrm{CO}_{2}$ in a three-liter extractor. Favorable operating conditions and processing modes were established. Experience was also gained in the control of the proposed process. Our results from this bench scale extraction indicated that supercritical $\mathrm{CO}_{2}$ extraction with ethanol could not only quantitatively remove $\mathrm{PCBs}$ from JCW, but also work as an effective decontamination technology for JCW.

Full details of the equipment and procedure are given below, for both analytical and bench scale work.

\section{Sample Preparation}

Small-scale extraction: We spiked 1,2,4-trichlorobenzene into clean Toxi-dry matrix. In the spiking procedure, $0.1 \mathrm{~g}$ of 1,2,4-trichlorobenzene and $500 \mathrm{ml}$ acetone were added to a $1 \mathrm{~L}$ beaker with a magnetic stirrer and mixed vigorously. $42.5 \mathrm{~g}$ of Toxi-dry absorbent was added to the beaker to form a slurry. Stirring was continued for $12 \mathrm{~h}$ to give an even loading. The mixture was placed in a fume hood for two days to evaporate acetone. The spiked Toxi-dry was stored in sealed bottles for at least two weeks before extraction. No water was loaded into the samples during extraction. The properties of Toxi-dry are as indicated in the following table:

\begin{tabular}{|c|c|c|}
\hline \multicolumn{2}{|l|}{ CRUDE FIBER } & $34 \%$ \\
\hline \multicolumn{2}{|c|}{ NITROGEN FREE EXTRACT } & $55 \%$ \\
\hline \multicolumn{2}{|l|}{ MOISTURE } & $8 \%$ \\
\hline \multicolumn{2}{|l|}{ PROTEIN } & $3 \%$ \\
\hline \multicolumn{2}{|l|}{$\mathrm{ASH}$} & $1.5 \%$ \\
\hline \multirow[t]{2}{*}{ SOLUBILITY IN } & ALCOHOL & $5.6 \%$ \\
\hline & WATER & $9.0 \%$ \\
\hline
\end{tabular}

Table 1: Properties of Toxi-dry 


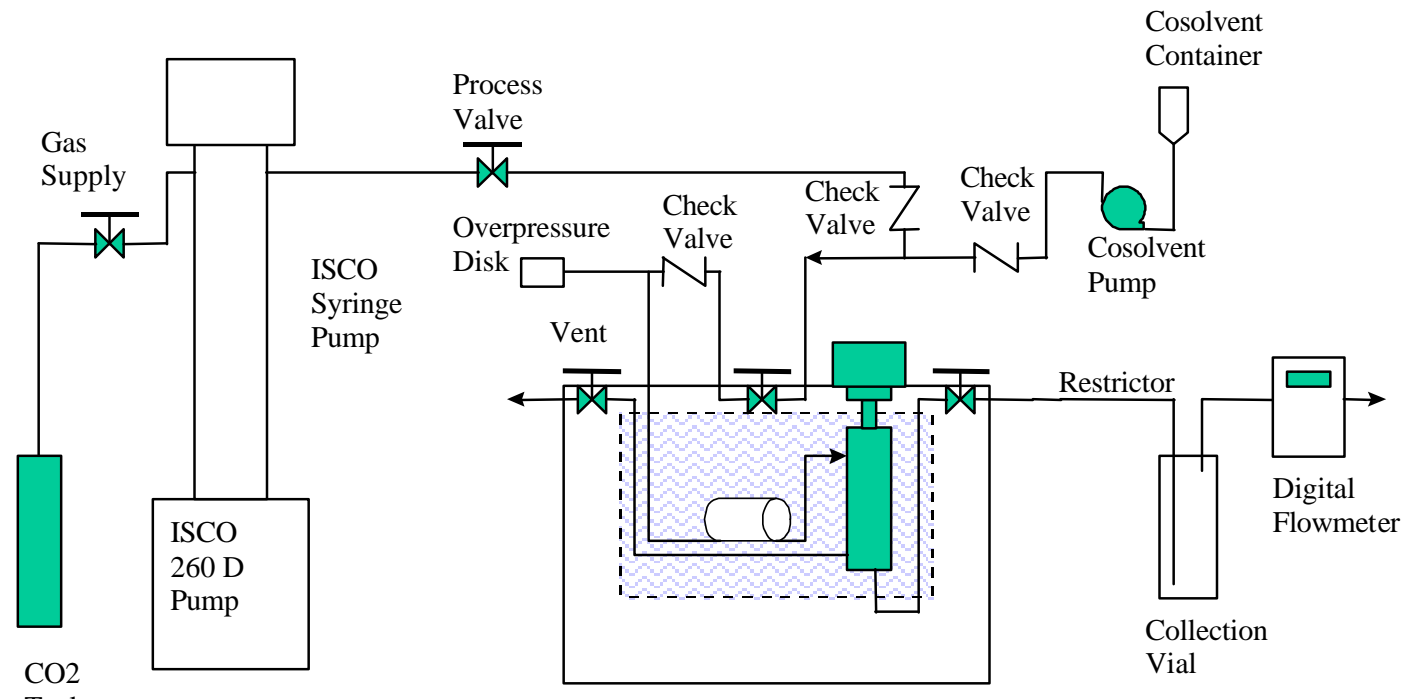

Expanded View of ISCO SFX 2-10

Supercritical Fluid Extractor

Figure 2. Schematic of ISCO extraction apparatus

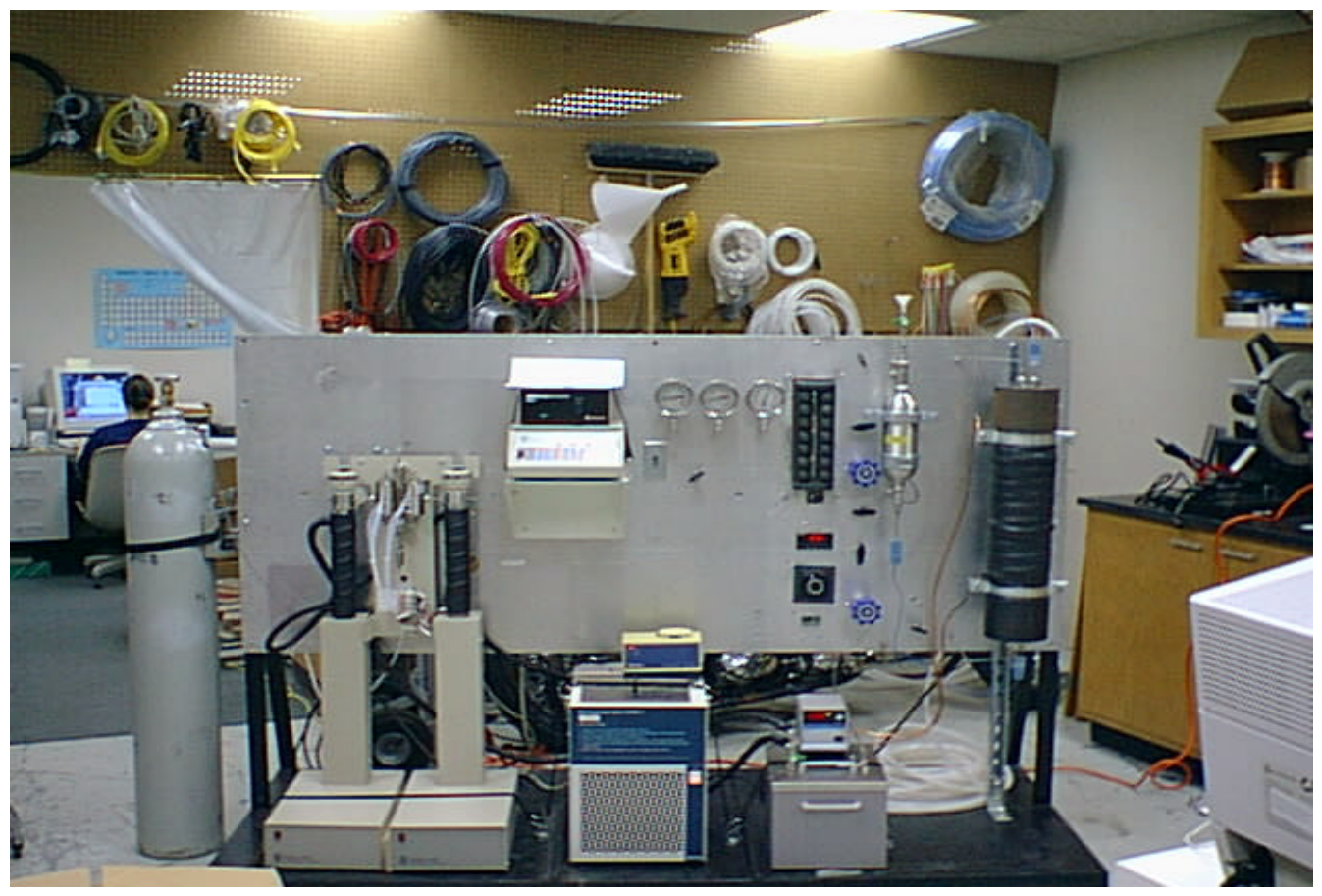

Figure 3. Bench scale extraction apparatus 


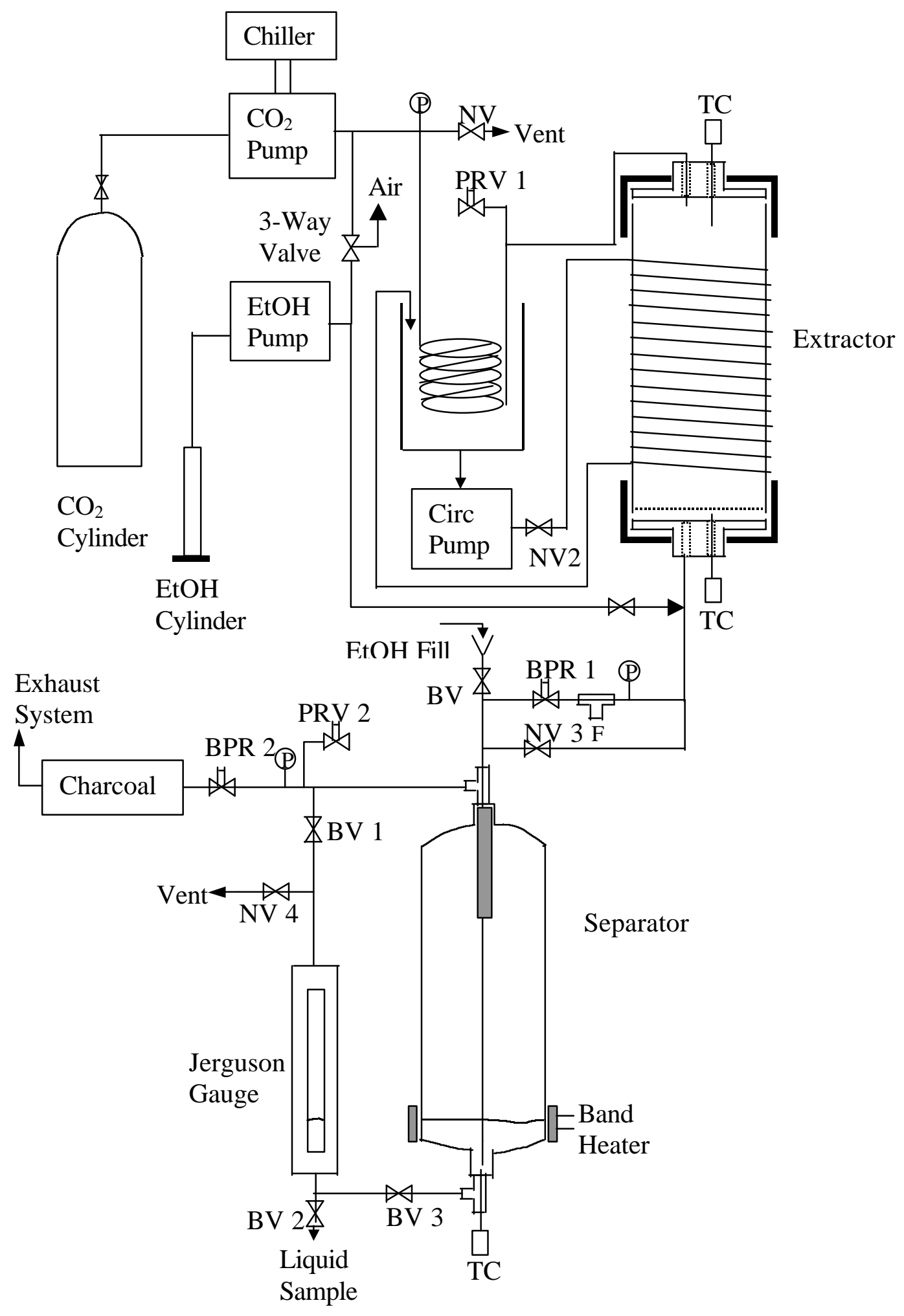

Figure 4. Schematic of Large-scale Extraction Apparatus 
Large-scale Extraction: The spiking procedure used in this study simulates the formation of Toxi-dry JCW. About $0.72 \mathrm{~g} 2$-chloro biphenyl was dissolved into $500 \mathrm{ml}$ ethanol. For each extraction, $50 \mathrm{ml}$ of this PCB-ethanol solution was added to 1,300 $\mathrm{ml}$ of ethanol and was sprayed onto $350 \mathrm{~g}$ of clean Toxi-dry in a tray. This wet Toxi-dry was stirred thoroughly to give an even loading. Then it was placed in a fume hood for two days to evaporate the solvent. The spiked Toxi-dry was stored in a sealed vessel before extraction.

\section{Apparatus Design and Extraction Procedure}

Small-scale extraction: An ISCO SFX 2-10 extractor with two 10-ml extraction cell was employed in this study (Figure 2). An ISCO 260D pump was used as the $\mathrm{CO}_{2}$ pump to provide liquid $\mathrm{CO}_{2}$ and control the system pressure. The extraction temperature was set using the temperature controller of the extractor. To collect the TCB extract, we used solvent trapping with chilled acetone as the solvent. Flow rates were controlled by an ISCO integral restrictor. One gram (1g) sample were packed into a 10-ml extraction cell. Membrane filters (five micron) were placed at each end inside the cell to prevent small particles from reaching the capillary-tube restrictor. After the extraction cell was placed in the extractor, the outlet valve of the syringe pump was then opened. Pure or cosolvent-modified $\mathrm{CO}_{2}$ passed through the preheater, where it was heated up to the extraction temperature before flowing to the extraction cell. Static pressure was maintained for 20 minutes, after which the outlet valve was opened and dynamic extraction was conducted. The TCB-impregnated Toxi-dry samples were extracted for 2 hours. The experimental pressures were $2,000,4,000$ or 6,000 psia, and the temperature was either $40{ }^{0} \mathrm{C}$ or $80{ }^{0} \mathrm{C}$.

Large-scale Extraction: Bench-scale experiments were conducted in a laboratory-scale unit that was designed and fabricated at University of South Carolina. Figure 3 is photo of this apparatus and Figure 4 gives the process schematic. The extraction vessel (HIP Corp.) has a pressure rating of 5,000 psi and has a working volume of 3 liters. Liquid $\mathrm{CO}_{2}$ was supplied via an ISCO 260D pump at high pressure, and cosolvent was supplied at precise flow-rate via an Eldex metering pump. $\mathrm{CO}_{2}$ and cosolvent were mixed and heated up to extraction temperature while flowing through a coil of tubing in a temperature-controlled water bath. The extractor was heated to extraction condition by hot water circulating through a coil of copper tubing wrapped around the extractor, and the extractor temperature was measured with two thermocouples placed at the entrance and exit of the extractor. The pressure in the extractor was controlled with a backpressure regulator (BPR) downstream of the extractor and monitored by pressure gauges placed before and after the extractor.

For SFE, separation and collection of the extracted materials is an important aspect. Stone and Taylor (2000) suggested that elevating the pressure on the collection vial would reduce the loss of volatiles and improve trapping efficiency. Following their recommendation, we designed a two-stage extraction system with the use of two back-pressure regulators: the high pressure (5,000 psi) extraction stage and the low pressure (600 psi) separation stage. In our system, separation of the $\mathrm{CO}_{2}$ from the other components in the extract is accomplished by a reduction in pressure to about 600 psi. The expansion of the supercritical fluid causes a temperature reduction and separation into a gas phase containing predominantly $\mathrm{CO}_{2}$ and a liquid phase containing ethanol, water and PCBs. That mixture is injected below the surface of a pool of ethanol in a 1-liter separation vessel. The gas exits through a mist eliminator at the top of the 
separation vessel and enters a second backpressure regulator through which it expands to atmospheric pressure. A band heater and temperature control loop are employed to keep the separator temperature at $25{ }^{\circ} \mathrm{C}$. A charcoal filter is used to collect residual liquids from the exhaust $\mathrm{CO}_{2}$ stream. A Jerguson gauge situated parallel to the separation vessel is used to collect liquid samples. After the liquid is transferred to the Jerguson gauge, the gauge will be isolated with ball valves, $\mathrm{CO}_{2}$ is vented through a needle valve, and the liquid sample is drained from the gauge. The laboratory scale unit simulates an industrial SFE system and is equipped with various safety devices (two pressure relief valves and two needle vent valves).

The advantage of this separation method is clear: First, when supercritical $\mathrm{CO}_{2}$ passes through the first back-pressure regulator, the pressure drops from 2,000 or 4,000 psi to 600 psi, the density of $\mathrm{CO}_{2}$ drops to $93.5 \mathrm{~kg} / \mathrm{m}^{3}$, so that the volume of $\mathrm{CO}_{2}$ that bubbles through the collection solvent will be about 50 times less that the volume of $\mathrm{CO}_{2}$ under atmospheric pressure. Using this method, an acceptable rate of solvent loss (about 5\%) and high PCB material balances (around 100\%) were obtained. The details are discussed below. In addition, if we consider recompressing $\mathrm{CO}_{2}$, less energy will be consumed in the compressor than if $\mathrm{CO}_{2}$ were compressed from atmospheric pressure. On the other hand, when we combine the SFE process with Supercritical Water Oxidation, no secondary waste will be generated during the decontamination process, while it is usually difficult to deal with contaminated activated carbon after use.

Each extraction was at constant temperature, pressure, and $\mathrm{CO}_{2}$ flow rate. The extraction temperature is $40^{\circ} \mathrm{C}$ or $80^{\circ} \mathrm{C}$; the extraction pressure is 2,000 or $4,000 \mathrm{psi}$; the flow-rate of pure $\mathrm{CO}_{2}$ is $30 \mathrm{ml} / \mathrm{min}$, and the extraction time is 2 or 3 hours. Before each test, a weighed 300-gram sample of PCB-contaminated Toxi-dry was loaded into the extractor, which was subsequently heated to the experimental temperature, and $100 \mathrm{ml} \mathrm{EtOH}$ was poured into the separator. Then the ISCO pump (and sometimes the Eldex pump) was turned on to pressurize the extractor. When the pressure in the extractor reached experimental pressure, the first backpressure regulator was adjusted to keep the extractor pressure at 2,000 or 4,000 psi, and the second BPR was adjusted to keep the separation section of this apparatus at about 600 psi. Then supercritical fluids continuously flowed through the Toxi-dry bed, and the extract was collected in the separator. Every $30 \mathrm{~min}$, a liquid sample of approximately $5 \mathrm{ml}$ was taken via the Jerguson gauge to follow the progress of the extraction.

\section{Analysis}

Small-scale extraction: For analysis of TCB from the analytical-scale apparatus, an HP model 5890 series II GC (Hewlett-Packard, Palto Alto, CA) with FID was used for analyzing the extracted fractions. The GC column was an AT-1 from Alltech (Deerfield IL). A 1- $\mu$ L sample was injected at an oven temperature of $70{ }^{\circ} \mathrm{C}$ (held for $1 \mathrm{~min}$ ) followed by temperature programming to $200{ }^{0} \mathrm{C}$ with a rate of $15{ }^{\circ} \mathrm{C} / \mathrm{min}$. Quantitations were based on an eight-point linear calibration curve from gravimetrically prepared standards. Pure 1,2,4-trichlorobenzene was used for the calibration standards. Identification of analytes was based on comparison of retention times with those obtained from standard solutions.

Large-scale extraction: For each run, two solid samples (contaminated Toxi-dry before and after SFE) and 4 or 6 liquid samples (2-chlorobiphenyl in EtOH) were collected. Analysis of PCB in these samples was conducted by Lionville Laboratory, Inc. The solid samples were 
analyzed by the selected ion monitoring method, and the liquid samples were analyzed by GC/MS.

\subsubsection{Result and Discussion}

\begin{tabular}{llll}
\hline $\mathrm{T}\left({ }^{0} \mathrm{C}\right)$ & $\mathrm{P}(\mathrm{Psi})$ & Cosolvent & TCB Recovery $(\%)$ \\
\hline 40 & 2000 & 0 & 33 \\
40 & 4000 & 0 & 31 \\
40 & 6000 & 0 & 42 \\
80 & 2000 & 0 & 60 \\
80 & 4000 & 0 & 75.6 \\
80 & 6000 & 0 & 96.3 \\
40 & 2000 & $5 \%$ acetone & 56.1 \\
40 & 4000 & $5 \%$ acetone & 58.3 \\
40 & 6000 & $5 \%$ acetone & 61.6 \\
80 & 2000 & $5 \%$ acetone & 96.3 \\
80 & 4000 & $5 \%$ acetone & 100.4 \\
80 & 2000 & $5 \%$ ethanol & 96.7 \\
80 & 4000 & $5 \%$ ethanol & 109.7 \\
\hline
\end{tabular}

Table 2. Extraction Results from Small-scale Extraction of TCB from Toxi-dry

Small-scale extraction: Table 2 gives representative results from extraction with pure $\mathrm{CO}_{2}, \mathrm{CO}_{2}+5$ weight percent acetone, and $\mathrm{CO}_{2}+5$ weight percent ethanol. All extractions lasted two hours. The metric is the percentage recovery of TCB from the Toxi-dry matrix, where $100 \%$ recovery is defined by 24 hour Soxhlet extraction using acetone. Table 2 shows how the TCB extraction efficiency changed with different temperature, pressure and cosolvent conditions. These results will be graphed and discussed in the following sections.

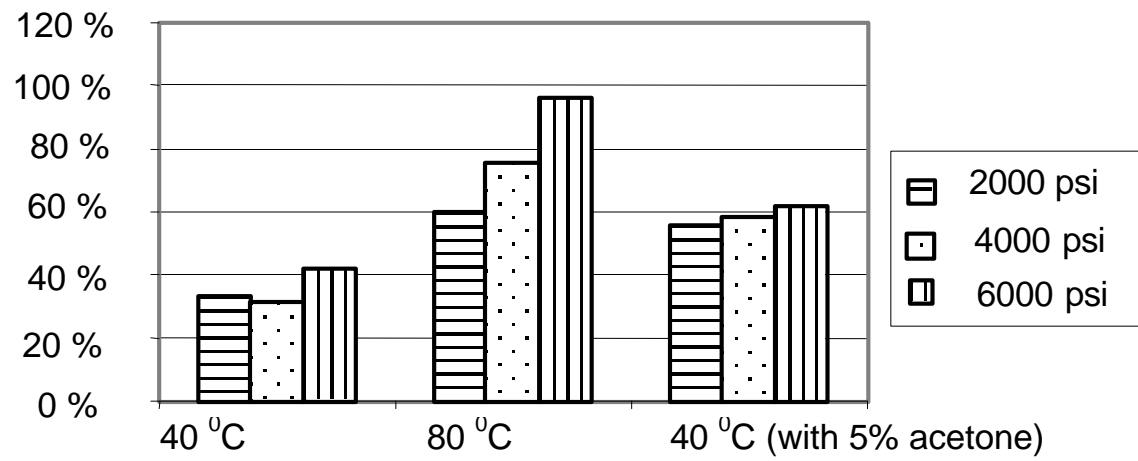

Figure 5. Pressure effect on SFE Efficiency of TCB Extraction from Toxi-dry

Figure 5 illustrates the effect of pressure on TCB recovery at different conditions. Increasing pressure at $40{ }^{\circ} \mathrm{C}$ was found to have little effect on recovery, regardless whether cosolvent was used. At $80{ }^{\circ} \mathrm{C}$, in contrast, the extraction yield increased when extraction pressure was increased. At $40{ }^{\circ} \mathrm{C}$, increasing the pressure from 2,000 psi to 6,000 psi increases the density of pure $\mathrm{CO}_{2}$ from $0.771 \mathrm{~g} / \mathrm{ml}$ to $0.978 \mathrm{~g} / \mathrm{ml}$. At $80{ }^{\circ} \mathrm{C}$, the same pressure change increases the 
density from $0.413 \mathrm{~g} / \mathrm{ml}$ to $0.861 \mathrm{~g} / \mathrm{ml}$. It is a common observation that the logarithm of the solubility is linearly dependent on the density or the log of the density of the supercritical fluid. Increasing solubility helps the partitioning of TCB molecules from the internal sites in the matrix into the bulk supercritical fluid. If the extraction efficiency were only controlled by solubility, one would expect the extraction efficiency to increase proportionally both at $40{ }^{\circ} \mathrm{C}$ and at $80{ }^{0} \mathrm{C}$. This is clearly not the case, as shown in Figure 5. Therefore we conclude that there are other factors besides solubility that can affect the extraction process. A possible explanation for this observation is that after two weeks incubation the majority of TCB molecules diffused into internal sites of the Toxi-dry, and were adsorbed at the internal matrix surface. Therefore some kinetic factors, such as the desorption rate of the TCB molecules from the internal matrix surface and diffusion rate through the porous matrix, could be controlling factors of the extraction process, and enhancing solubility of TCB in the bulk supercritical fluid is not sufficient to yield high extraction efficiencies. It is possible that at $80{ }^{\circ} \mathrm{C}$, the majority of TCB molecules exists as a separate phase within the matrix, and could be removed by simple dissolution, so the desorption control was weak, and pressure/density effect was clear.

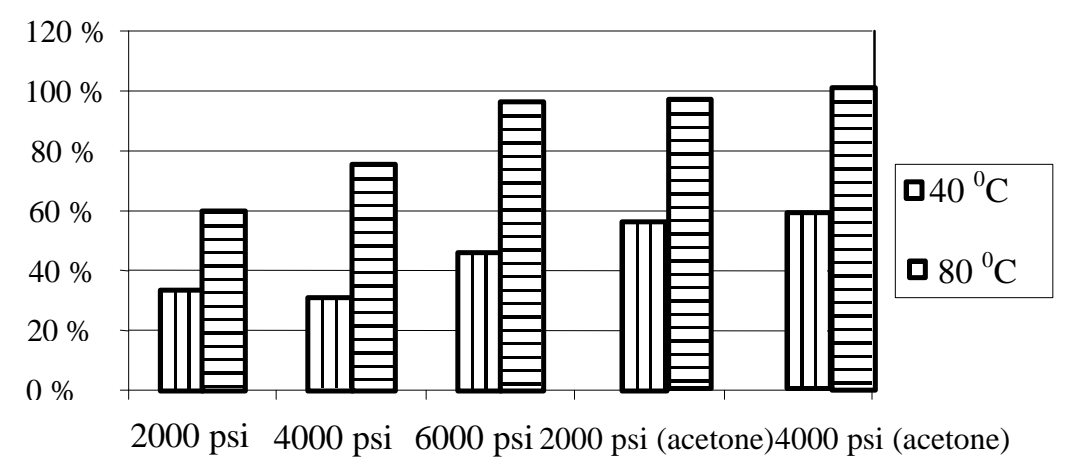

Figure 6. Temperature effect on SFE of TCB

From Figure 6 it is clear that the recoveries of TCB from the Toxi-dry samples are greatly affected by the extraction temperature. Increasing temperature from $40{ }^{\circ} \mathrm{C}$ to $80{ }^{\circ} \mathrm{C}$ at the same pressure increased the extraction efficiency about 30 to 40 percent. As previously noted, the extraction temperature affects the solute vapor pressure, solvent density, and desorption of solute molecules from matrix surface (Langenfeld, 1993). At constant pressure, increasing temperature will increase solute vapor pressure and decrease density of $\mathrm{CO}_{2}$. For example, at $25 \mathrm{MPa}$, for a temperature increase from $40{ }^{0} \mathrm{C}$ to $80{ }^{\circ} \mathrm{C}$, the vapor pressure of 1,2,4-trichlorobenzene changes from 102.4 to $1038 \mathrm{~Pa}$, while the density of $\mathrm{CO}_{2}$ decreases from 0.880 to $0.687 \mathrm{~g} / \mathrm{ml}$. The solubility of TCB in $\mathrm{CO}_{2}$ is dependent on its vapor pressure and density of $\mathrm{CO}_{2}$. The solute vapor pressure increases significantly, and the density decrease of supercritical fluid is relatively small, so the positive effect of temperature is clear. Besides the thermodynamic considerations mentioned above, extraction temperature also affects extraction process kinetically. According to Dupeyron et al. (1999), temperature enhances the diffusion coefficients and reduces solvent viscosity and interfacial tensions. These two effects allow better penetration of the solvent into the matrix, and result in faster mass transfer. 


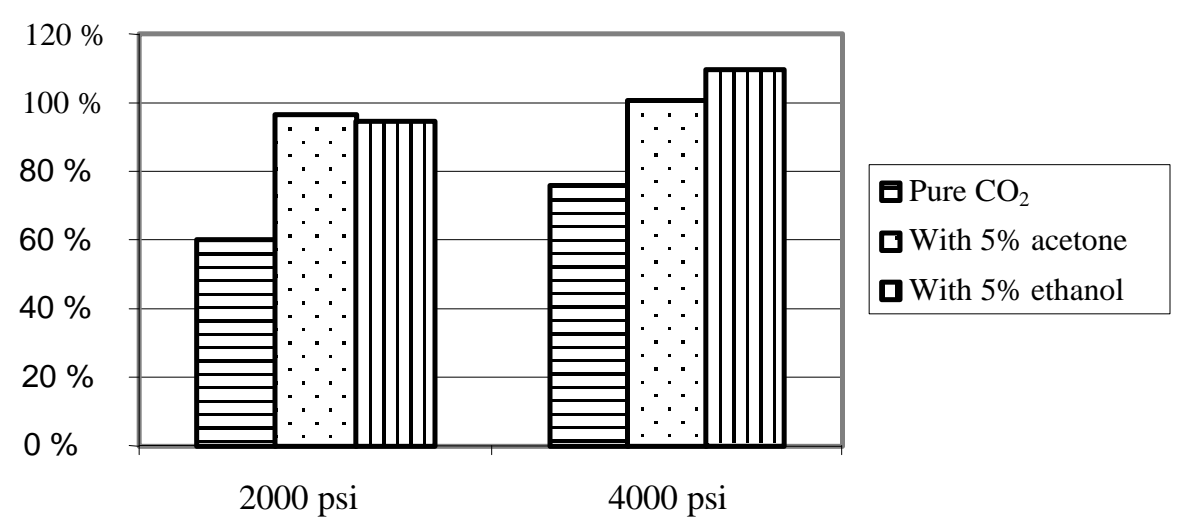

Figure 7. Cosolvent effect on SFE of TCB at $80{ }^{\circ} \mathrm{C}$

Figure 7 illustrates that the efficiency of SC-CO2 extraction of TCB from Toxi-dry absorbent is improved with the addition of a small amount of acetone or ethanol as cosolvent. At $80^{\circ} \mathrm{C}$, TCB recoveries in excess of $90 \%$ and approaching $100 \%$ (within experimental uncertainty) are obtained at pressures as low as 2000 psi. This is a significant benefit because both capital costs and operating costs will be substantially lower if the extraction process can be operated at lower pressures.

Acetone is a polar organic cosolvent and a hydrogen bond acceptor, and ethanol is a selfassociating polar organic cosolvent. Both of them are capable of strong intermolecular interaction with the solute. For this project, ethanol is the DOE preferred cosolvent, because DOE does not place health or safety restrictions on use of ethanol as a process solvent (unlike acetone, methanol, or any other common cosolvents). Jeong and Chesney (1999) also indicated that ethanol, though not as polar as methanol, could be a better choice because of its low toxicity. Therefore, it would be much simpler, faster, and less expensive from a permitting standpoint to use ethanol as cosolvent. In addition, according to the phase equilibrium data provided by Chang et al. (1996), the mixed solvent, acetone $+\mathrm{CO}_{2}$ or ethanol $+\mathrm{CO}_{2}$, will be totally miscible under the extraction conditions.

The mechanism of cosolvent-analyte-matrix interaction is key to understand the effect of pressure, temperature and cosolvent on SFE. Although different potential interactions including dipole interactions, hydrogen-bonding interaction, dispersion interactions and different modifier properties such as polarizablity, acidity/basicity and dipole moment have been considered in previous studies, there is still insufficient information for drawing a general conclusion. In this investigation, the organic matrix, Toxi-dry, has not previously been extracted with supercritical $\mathrm{CO}_{2}$. The large solubility of components of Toxi-dry in solvent, for example 5.6\% in alcohol, makes the situation even more complicated. The color of collection solvents after extraction is pale yellow, which indicated that part of Toxi-dry was dissolved and extracted during SFE. Amador-Hernandez (2000) pointed out that the appropriate cosolvent increases the effective polarity of the supercritical fluids, which increases the bulk solubility of solutes and results in favorable partitioning into the supercritical fluid. The second effect occurs due to the wetting properties of a solvent causing more intimate solvent/solute contact. Moreover, it was believed that cosolvents could interact with the analyte/matrix complex and lower the activation energy barrier of desorption (Langenfeld, 1993). 
Large-Scale extraction: Table 3 gives representative results from extraction of 2chlorobiphenyl (2CBP) with pure or 5\%-ethanol-modified $\mathrm{CO}_{2}$. the results in Table 3 come from the 3-liter apparatus (Figure 4). The 2CBP removed is the amount of PCB removed from Toxidry by extraction. 2CBP removal was calculated based on the concentration of 2CBP in Toxi-dry before and after extraction. The 2CBP recovered in the collection solvent was calculated using measured volumes of the collection solvent and 2CBP concentration in liquid samples.

Extraction temperature is an important operating condition for both analytical and remediation SFEs. For practical considerations, the extraction temperature was set at $40{ }^{\circ} \mathrm{C}$ or 80 ${ }^{0} \mathrm{C}$ to study the temperature effect on extraction efficiency. The results (Figure 8) show that temperature did help to improve the extraction efficiency. When extraction temperature was increased from $40{ }^{\circ} \mathrm{C}$ to $80{ }^{\circ} \mathrm{C}$, the recovery of $2 \mathrm{CBP}$ in the collection solvent increased between $10 \%$ and $15 \%$ during extraction, and the final 2CBP recoveries increased $4 \%$ (Figure 9). Although the temperature effect on 2-PCB recovery is not as significant as its effect on 1,2,4trichlorobenzenze extractions, reducing the final $2 \mathrm{CBP}$ concentration from $15 \mathrm{ppm}$ to $7 \mathrm{ppm}$ (as shown in Table 4) is important for our decontamination study.

\begin{tabular}{lllllllll}
\hline & & & & & \\
SFE & 2CBP [1] & 2CBP [2] & \multicolumn{7}{c}{ 2CBP Recovered in Solvent (\%) [3] } & \\
& (In residue) & Removed(\%) & 30min & 60min & 90min & 120min & 150min & 180min \\
\hline 1 & $14.0 \mathrm{ppm}$ & 91.8 & 15.2 & 48.6 & 75.3 & 91.3 & & \\
2 & $19.0 \mathrm{ppm}$ & 88.1 & 12.6 & 41.0 & 67.6 & 90.0 & & \\
3 & $5.9 \mathrm{ppm}$ & 95.4 & 28.7 & 63.1 & 88.1 & 95.5 & & \\
4 & $7.7 \mathrm{ppm}$ & 94.5 & 24.7 & 55.8 & 80.4 & 94.9 & & \\
5 & $6.1 \mathrm{ppm}$ & 95.1 & 18.3 & 46.8 & 70.1 & 92.0 & 95.1 & 94.6 \\
6 & $7.1 \mathrm{ppm}$ & 94.3 & 11.1 & 40.0 & 69.0 & 88.6 & 93.0 & 94.2 \\
7 & $13.0 \mathrm{ppm}$ & 89.6 & 17.5 & 46.8 & 74.3 & 84.5 & 88.2 & 87.6 \\
8 & $21.0 \mathrm{ppm}$ & 83.8 & 13.9 & 34.9 & 65.8 & 83.0 & 86.7 & 85.4 \\
9 & $74.0 \mathrm{ppm}$ & 53.7 & & & & & & \\
10 & $75.0 \mathrm{ppm}$ & 53.1 & & & & & & \\
\hline
\end{tabular}

[1]. 2CBP concentration in Toxi-dry after extraction

[2]. Percentage of 2CBP removed from Toxi-dry

[3]. 2CBP collected in collection solvent during extraction.

Table 3. Extraction Results from Large-scale Extraction of 2CBP from Toxi-dry

An explanation for the observation that $2 \mathrm{CBP}$ recoveries are lower than $\mathrm{TCB}$ recoveries is as follows. When temperature increases from $40^{\circ} \mathrm{C}$ to $80^{\circ} \mathrm{C}$, the density of $\mathrm{CO}_{2}$ decreases moderately from 0.880 to $0.687 \mathrm{~g} / \mathrm{ml}$ at $25 \mathrm{MPa}$. If the solute vapor pressure increases significantly, the effect of vapor pressure will overwhelm the negative effects of decreased density; if the vapor pressure of a compound does not increase significantly, the temperature will show little effects. When temperature increases from $40^{\circ} \mathrm{C}$ to $80^{\circ} \mathrm{C}$, the vapor pressure of $1,2,4-$ trichlorobenzene increases from 102.4 to $1038 \mathrm{~Pa}$, and the vapor pressure of $2 \mathrm{CBP}$ increases from 3.5 to $63 \mathrm{~Pa}$. (Falconer and Bidleman 1994). Although some analytical extractions achieved high recovery of PCBs at relative high temperatures, like $150{ }^{\circ} \mathrm{C}$ or $200{ }^{\circ} \mathrm{C}$, high temperature is 
not practical for industrial high-pressure equipment. Since with ethanol as a cosolvent, the recovery of 2-chlorobiphenyl could be as high as $95 \%$ after two hours extraction (Table 3), we preferred to maintain this low process temperature.

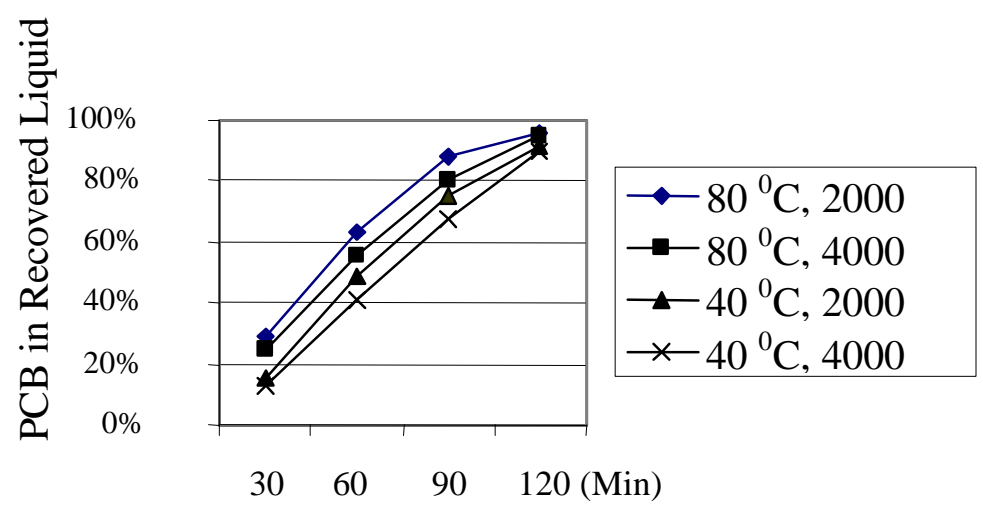

Figure 8. Recoveries with 5\%-EtOH Modified $\mathrm{CO}_{2}$, from the Large-scale Extractor

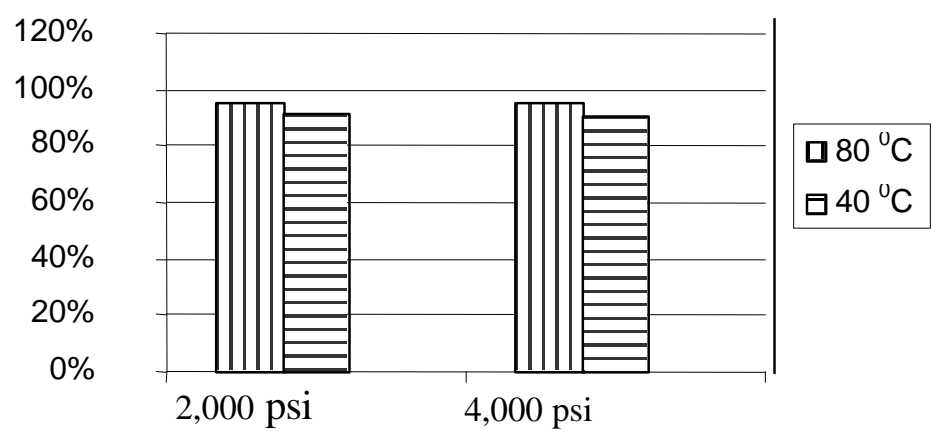

Figure 9. Temperature Effect on Final Extraction Efficiency of 2CBP, from the Large-scale Extractor

Thermodynamics properties such as analyte solubility are useful to understand the SFE process (Hawthorne, 1993). Vapor pressure, polarity, molecular weight, and chemical composition of the solute are the most important factors affecting solubility of compounds in supercritical fluid. At a fixed temperature, the density of $\mathrm{SC}-\mathrm{CO}_{2}$ increases with pressure. When the density of a supercritical fluid is increased, the solubility of a solid solute in this supercritical fluid is also increased (McHugh and Krukonis,1986). If the supercritical fluid extraction is solubility controlled, increasing extraction pressure will result in increasing PCB recovery. On the other hand if the supercritical fluid extraction is kinetic/desorption controlled, the structure of the matrices will have much more effect on recovery, and the density effect may be small.

In these experiments, the temperature was either $40^{\circ} \mathrm{C}$ or $80^{\circ} \mathrm{C}$, and the pressure was either 2,000 or 4,000 psia. Figure 8 shows that increasing pressure from 2,000 to 4,000 psi at $40^{\circ} \mathrm{C}$ or $80^{\circ} \mathrm{C}$ has little effect on recovery. The extraction of trace amounts of $2 \mathrm{CBP}$ from this spiked sample is clearly not solubility controlled, and enhanced solubility of chlorinated species in the supercritical fluid is not sufficient to yield high extraction efficiencies. The extraction conditions must be able to overcome the strong PCB-matrix interaction, and cause the 
partitioning of PCB molecules from the active sites in the matrix into the bulk supercritical fluid. Because high pressure requires more expensive equipment and leads to difficulty in operation, recent studies have focused on the effect of temperature and modifiers, while keeping a moderate extraction pressure.

Results from both the ISCO extractor and the large-scale extractor show that ethanol could be a good cosolvent for extraction of chlorinated species from Toxi-dry. Ethanol is a selfassociating polar organic cosolvent and is capable of strong intermolecular interaction with the solute. When the SFE results for pure $\mathrm{CO}_{2}$ are compared with results for ethanol-modified solvent (Figure 10), it is evident that the efficiency of $\mathrm{SC}_{-} \mathrm{CO}_{2}$ extraction of $2 \mathrm{CBP}$ from Toxi-dry absorbent is improved with the addition of a small amount of ethanol. At $80^{\circ} \mathrm{C}, 2-\mathrm{PCB}$ recoveries in excess of $95 \%$ are obtained at pressures as low as 2000 psia, while the 2CBP recoveries are just 53\% with pure $\mathrm{CO}_{2}$. This is a significant benefit because both capital costs and operating costs will be substantially lower if the extraction process can be operated at lower pressures.

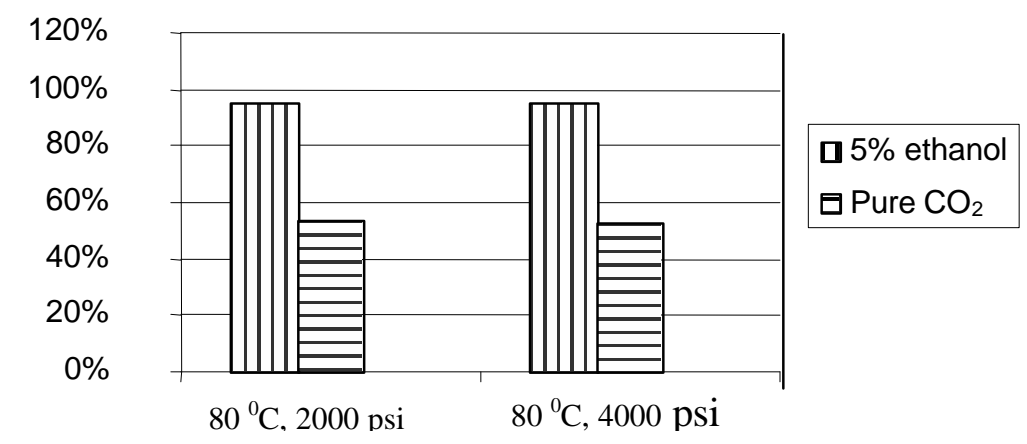

Figure 10. Cosolvent Effect on Final Extraction Efficiencies of 2CBP, Using the Large-scale Extractor

In summary, supercritical $\mathrm{CO}_{2}$ extraction has been shown to be effective for removing $2 \mathrm{CBP}$ from the DOE matrix. The effects of extraction parameters were studied. It was found that increasing temperature over the investigated range (from $40^{\circ} \mathrm{C}$ to $80^{\circ} \mathrm{C}$ ) has a clear effect in improving extraction efficiency. At the same time, increasing pressure from 2,000 to 4,000 psi at $40^{\circ} \mathrm{C}$ or $80^{\circ} \mathrm{C}$ has little effect on recovery. It is believed that the kinetic factors, such as desorption and diffusion, play more important roles than solubility in controlling the extraction rate. The most important parameter investigated is the presence of cosolvent. With 5\% ethanol added as cosolvent, about 95\% 2-chlorobiphenyl was removed from Toxi-dry in two hours at moderate temperature and pressure, while the recoveries with pure $\mathrm{CO}_{2}$ extraction are below $60 \%$ at the same conditions. It would be much simpler, safer, and less expensive from a permitting standpoint to use ethanol as a cosolvent in the future process design. The suggested ranges of extraction conditions are: pressure of $2,000-3,000 \mathrm{psi}$, temperature $40-80^{\circ} \mathrm{C}$, and $5 \%$ ethanol as cosolvent.

The experimental results also demonstrated that the development of the supercritical fluid process is successful. The strong points of this process are obvious. The process reduces solvent loss and recompression energy consumption. Also, when we combine the SFE process with supercritical water oxidation, no secondary waste will be generated during the decontamination process. 


\subsection{ELECTROCHEMICAL SUPEROXIDE CHEMISTRY FOR DESTRUCTION OF PCBS}

\subsubsection{Objectives:}

1. Demonstrate basic superoxide electrochemistry in a high-pressure, CO2-rich environment.

2. Quantify destruction of PCBs and chlorinated aromatics in the presence of $\mathrm{CO} 2$.

3. Design an electrochemical cell for bulk destruction of PCBs.

We developed a low-cost reactor and electrode system for rapid screening of electrochemical reactions under high pressure. Initial high-pressure electrochemical tests were performed in supercritical carbon dioxide $\left(\mathrm{SCCO}_{2}\right)$. We also synthesized a novel $\mathrm{CO}_{2}$-soluble supporting electrolyte tetrakis(decyl)ammonium tetraphenylborate (TDATPhB) and tested it for enhanced conductivity in $\mathrm{CO}_{2}$ at $70^{\circ} \mathrm{C}$ and 3000psi. Unfortunately, sufficient conductivities could not be achieved. Therefore the original concept of generating superoxide ion in a $\mathrm{CO} 2$-rich environment does not appear feasible.

An aprotic solvent acetonitrile with supporting electrolyte tetraethylammonium perchlorate (TEAP, $0.1 \mathrm{M}$ ) was tested. Oxygen pressures of $160 \mathrm{psig}$, with and without $\mathrm{CO}_{2}$ overpressures of $40 \mathrm{psig}$ were added to the high-pressure cell. Superoxide ion $\left(\mathrm{O}_{2}{ }^{\circ}\right)$, the destruction agent, was electrochemically generated under these conditions. This work was presented to the International Society of Electrochemistry.

Although it is possible to generate the superoxide was demonstrated, the use of acetonitrile introduces a secondary waste stream to the PCB destruction process. Therefore, electrochemical oxidation of PCBs in acetonitrile does not appear promising. However, this work led us to investigate alternative, more environmentally benign solvents, namely room temperature ionic liquids (RTILs). The USC investigators received funding from the National Science Foundation to continue to pursue this work. Preliminary results have been published. If successful, electrochemistry in RTILs could be coupled with dense $\mathrm{CO}_{2}$ extraction to produce a process for destroying PCBs.

\subsection{SOLUBiLITy OF PCBS IN Hot WATER}

\subsubsection{Objectives:}

1. Construct a unique, noninvasive in-situ apparatus for measuring the solubility of PCB congeners in hot water.

2. Obtain solubility-temperature relationships for selected PCB congeners.

Although ambient-temperature water is not an effective solvent for PCBs (with solubilities typically on the order of only a few $\mu \mathrm{g} /$ liter), recent research indicates that both compressed hot liquid water and supercritical water have the ability to extract PCBs from solid matrices. Essentially all of the published work has been done with soils, but the results still serve as a useful indication of what may be possible with DOE matrices. Hartonen et al. (1997) extracted sand spiked with PCBs, as well as actual contaminated soil samples. PCB recovery was $85 \%$ in the case of spiked samples, and hot water extraction compared favorably with Soxhlet (organic solvent) extraction. Similarly, Yang et al. (1995) used temperatures from 50 to 
$300{ }^{\circ} \mathrm{C}$ to extract PCBs from certified reference materials, and found that quantitative removal was obtained only at temperatures above $250{ }^{\circ} \mathrm{C}$. Incidentally, the maximum pressure of these experiments was only 50 bar, so some extractions were actually steam stripping of PCBs rather than liquid-phase extraction. Firus and Brunner (1996) showed that hydrocarbon-contaminated soils that are more than 20 years old could not be cleaned effectively with pure $\mathrm{CO}_{2}$. However, these same soils were cleaned to an efficiency of $100 \%$ with near and supercritical water. Both the ability of the water to penetrate the soil matrix (probably because of its polarity) and the high solubility of the PCBs in supercritical water were believed to be responsible for the reported results.

In summary, the limited results available indicate that excellent extraction of PCBs can be obtained with compressed, hot liquid water; operation in the more difficult supercritical water region is probably not necessary. Hot water extraction could be particularly advantageous if it were directly coupled to a downstream supercritical water oxidation process.

Of course, anything other than a completely empirical study of hot water extraction requires that one have available intrinsic solubility data for PCB-water systems, particularly at the conditions of the hot water extraction. Unfortunately, such information was found to be nonexistent; even PCB-water solubilities at ambient conditions are uncommon, and the data that are available are frequently contradictory. Thus, we decided that the design and construction of an apparatus for measuring aqueous solubilities of PCBs in water would be given a high priority, with hot water extraction work to be delayed until additional funding could be obtained.

Additional motivation for knowing such solubility data is related to operation of the SCWO process: the solubilities of PCBs at reaction preheater temperatures determine the limit for PCB concentrations in the feed solutions containing cosolvents in the SCWO process. This requirement derives from the fact that the alcohol cosolvents degrade more readily than the PCB congeners; hence, a homogeneous solution containing high concentrations of PCBs and cosolvent can phase-separate under reaction conditions as the cosolvent is destroyed, preventing the collection of useful kinetic data. Finally, PCB-water solubilities also need to be known for future experiments in which the SCWO of PCBs without a cosolvent is investigated. For such work, the solubility of PCBs in the aqueous feed solution to the reactor, which would have to be a homogeneous solution of hot water in some cases, would need to be known.

At Clemson University, a novel apparatus was constructed for measuring the solubilities of PCBs in hot water. The apparatus had to meet several constraints: (1) Only small (i.e., max of a gram or two) quantities of pure PCB congeners could be used, both from a safety and a cost standpoint; (2) the solubility of PCB congener in the aqueous phase had to be determined in situ, so that no sampling (and no consumption of or exposure to PCBs) would be required; (3) the in situ method of solubility analysis had to be sensitive enough to obtain good accuracies for systems containing as little as a few ppm of PCB congener in water; (4) the apparatus had to operate from ambient to $200-250{ }^{\circ} \mathrm{C}$. A schematic of the apparatus that was designed and constructed is shown in Figure 11. The apparatus, which is of the static recirculating type, consists of a view cell for contacting the PCB liquid (bottom) phase and the aqueous (top) phase, and for establishing equilibrium between these phases. Continuous flow of the aqueous phase through the PCB phase in the cell and through the optical flow cell is accomplished with a magnetic pump that was constructed at Clemson (see Figure 12). A unique feature of the apparatus that, to our knowledge, has not previously been applied to PCB-water systems is the noninvasive sampling technique. A UV light source and detector are used in conjunction with 
the flow cell to determine the concentration of PCB in the aqueous phase in situ. Fiber optic cables are used for providing the incident light and collecting the non-absorbed light signal.

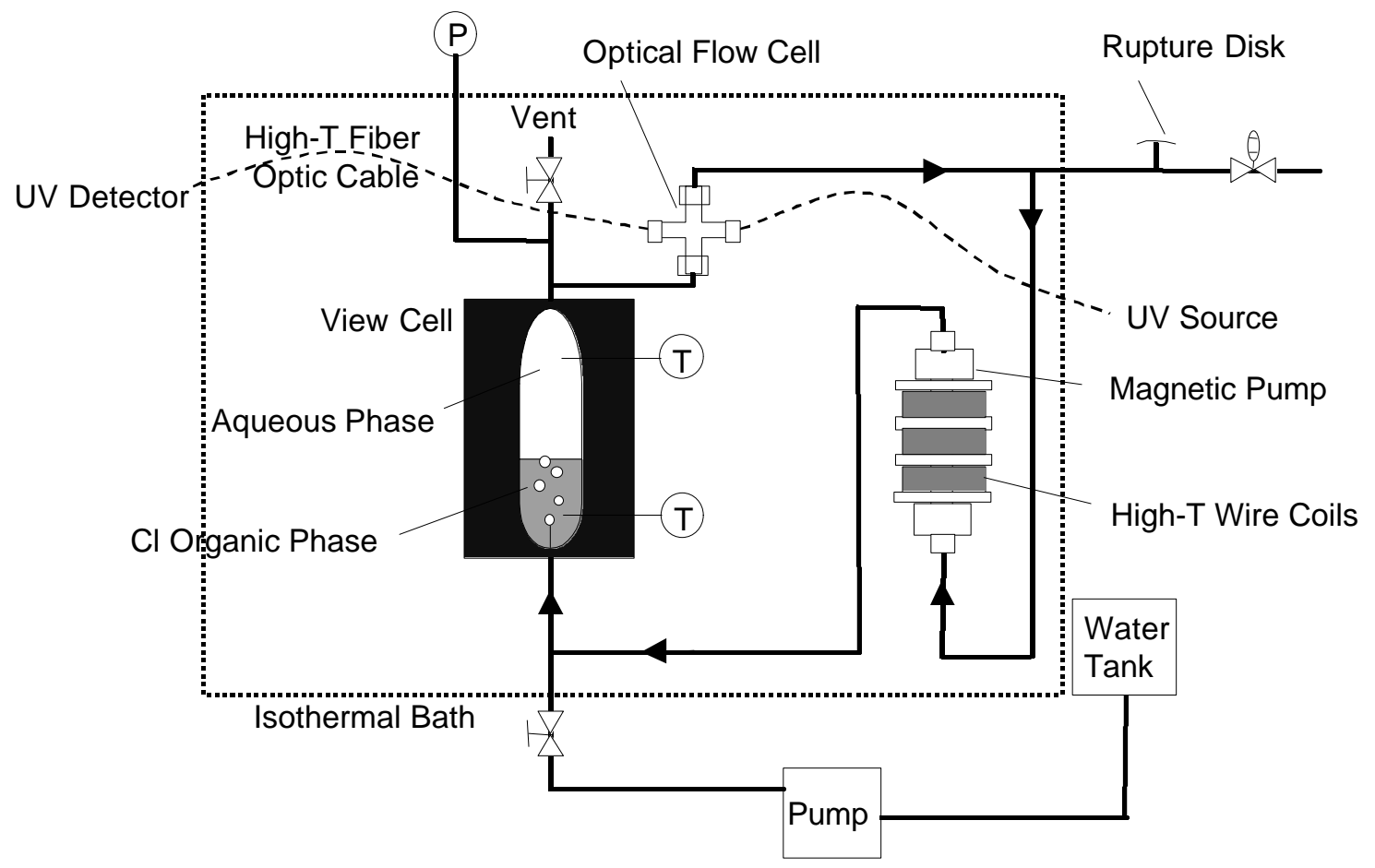

Figure 11. Novel, noninvasive, recirculating apparatus for measuring the solubilities of PCBs in both ambient-temperature and hot water.

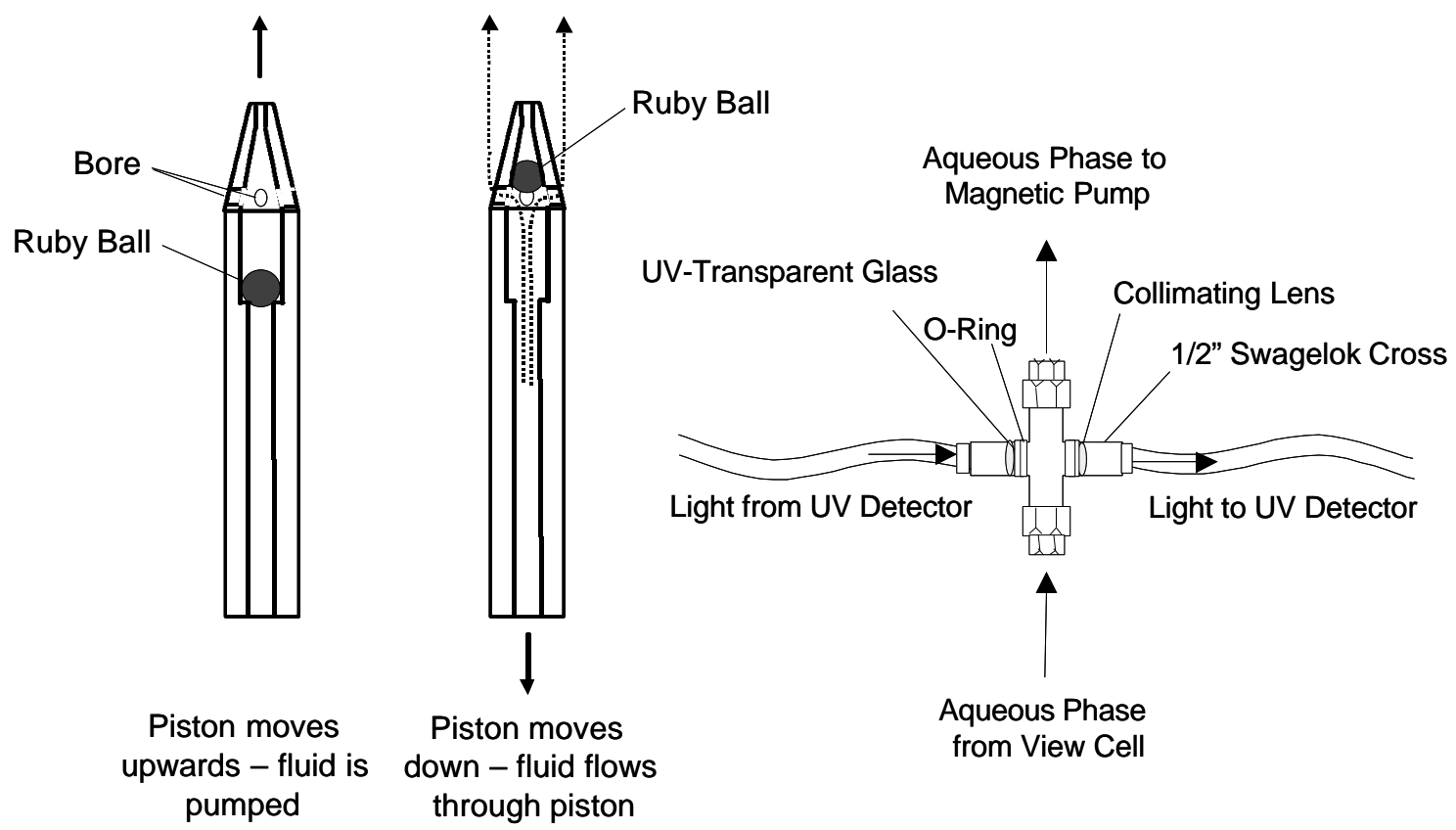

Figure 12. Key features of the apparatus: the magnetic pump and the optical flow cell. 
For a typical experimental run, the view cell is charged with 1-5 g of the PCB congener of interest, such that the PCB liquid phase will be visible through the window. The cell is then charged with water until full, with excess water being vented out the top of the cell. The pressure is typically maintained about 2 bar above the vapor pressure of water so that no vapor phase is present. The effect of pressure on the reported compositions is negligible, as the water is essentially an incompressible fluid at the conditions of interest. No specific degassing measures are employed, as the presence of dissolved air in the phases has a negligible impact on the liquid-liquid equilibrium (LLE) of interest. The isothermal bath is then set to the desired temperature, usually starting near ambient conditions. Next, the magnetic pump is activated, and water is bubbled up through the PCB liquid phase, out the top of the view cell, through the optical flow cell, and back to the magnetic pump. As this recirculation process is performed, the UV absorbance of the aqueous phase in the flow cell is continuously monitored; after several hours, the absorbance reaches a steady-state value when the aqueous phase becomes saturated with PCB. Both primary and secondary absorbance bands were monitored; consistent results were obtained regardless of which bands were used for calculations. (As an example, the UV absorbance spectra for 2-chlorobiphenyl is shown in Figure 13.) Beer's law is assumed to be valid (this assumption was validated by reproducing literature data for chlorobenzene), and the concentration of PCB in water is calculated. To determine the solubility at a higher temperature, the isothermal bath temperature is increased to the new, desired setpoint, the apparatus is allowed to reach equilibrium, and the above process is repeated. Temperatures were measured by means of a difference thermocouple setup, with the thermocouples being placed directly in the fluid phases. The reference thermocouples were placed in an aluminum block whose temperature was measured to an accuracy of $\pm 0.05^{\circ} \mathrm{C}$ with a secondary standard RTD. The reported temperatures are believed to be accurate to $\pm 0.20{ }^{\circ} \mathrm{C}$.

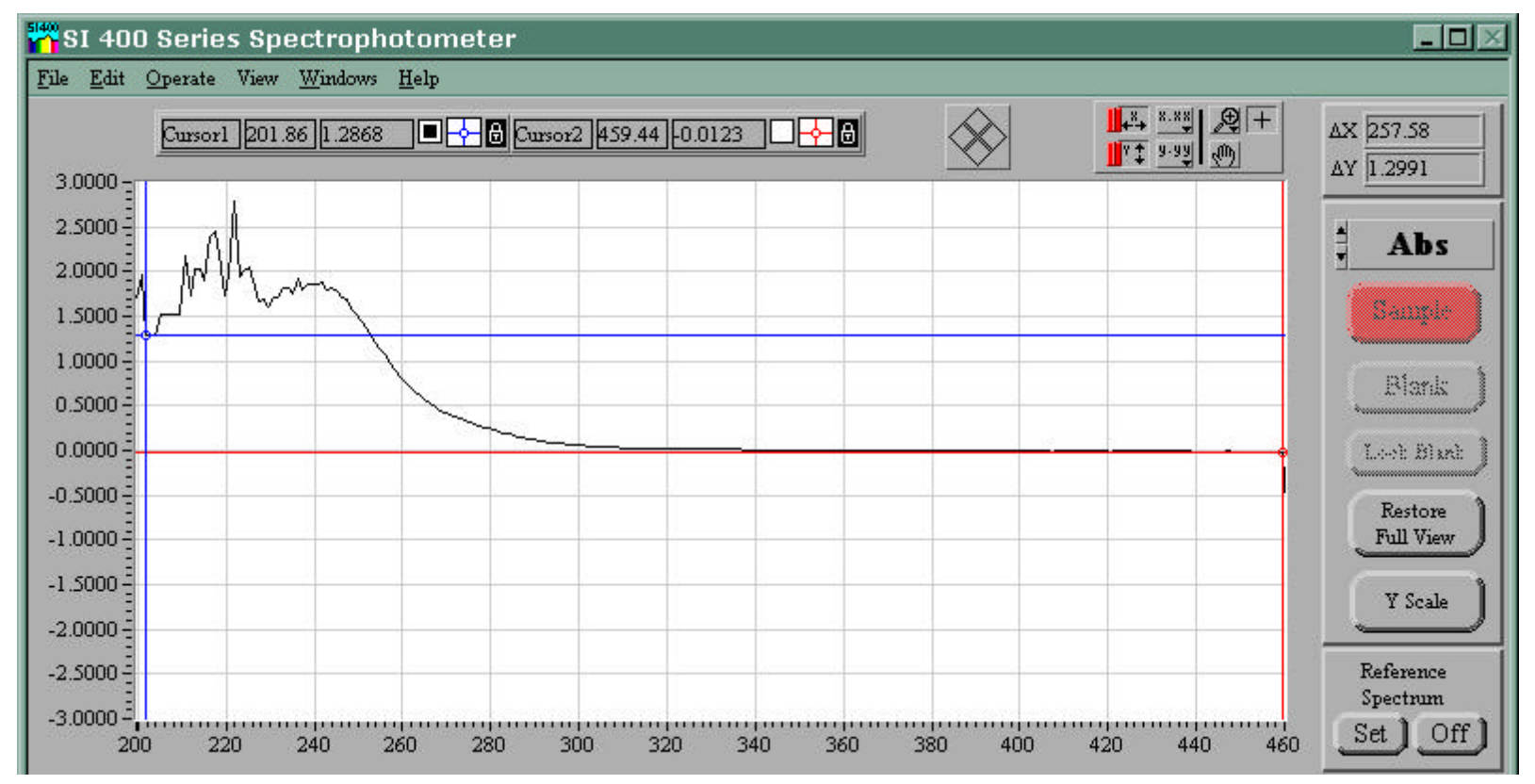

Figure 13. UV absorbance of 2-chlorobiphenyl in water. For maximum accuracy, multiple bands were monitored. 
Aqueous solubility measurements were performed for two systems, chlorobenzene and 2chlorobiphenyl. The chlorobenzene-water was selected for measurement in order to test the reliability of our new apparatus, as literature data was available for this system. As shown in Figure 14, good agreement was obtained with the results of two previous workers. It is of interest to note that the measurements of several other workers (not shown), including Othmer, were grossly in error. To ensure that our results contained no systematic error (due, for example, to offset in the UV instrument), the apparatus was taken apart, cleaned, and reassembled. The UV spectrometer was turned off, turned on and recalibrated. The measurements for chlorobenzene in water were then repeated. Results from both of these runs are given in Figure 10; no bias was seen between the two runs, and compositions were reproducible to within $3 \%$.

As can be seen in Figure 14, good reproducibility was also obtained for the 2chlorobiphenyl/water system, even though solubilities well under $100 \mathrm{ppm}$ were measured. 2chlorobiphenyl (2-CBP) is a solid at room temperature, so measurements were carried out only at temperatures where it is a liquid (the data point a $25^{\circ} \mathrm{C}$ from the literature is for solid 2-CBP).

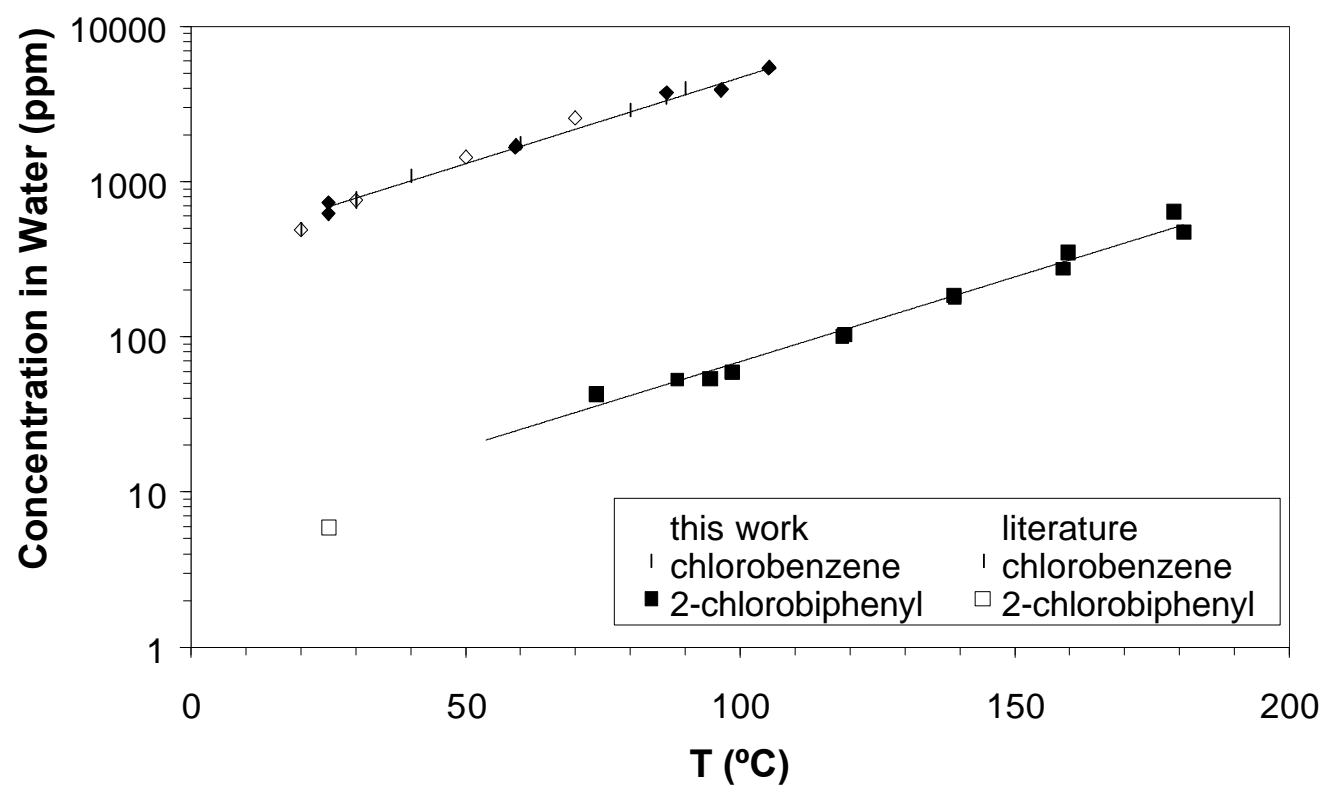

Figure 14. Solubility of chlorobenzene and 2-chlorobiphenyl in water.

In summary, a novel apparatus has been designed and constructed that can be used for the accurate, safe measurement of aqueous PCB solubilities. With such an apparatus, we now have the capability to fill the significant gaps in the literature that exist for aqueous PCB solubilities, and to determine the validity of the literature data that are currently being used.

\subsection{SUPERCRITICAL WATER OXIDATION OF PCBS}

\subsubsection{Objectives:}


1. Demonstrate effectiveness of apparatus on actual DOE mixed low level waste.

2. Understand and model the effects of process variables (i.e., temperature, pressure, flow rates, etc.) on PCB conversion.

3. Determine destruction efficiencies and kinetics of destruction of PCB congeners.

In a supercritical water oxidation (SCWO) reactor, aqueous waste streams containing organic pollutants, oxygen, and water are subjected to temperatures and pressures above the critical point of water $\left(\mathrm{T}_{\mathrm{c}}=374^{\circ} \mathrm{C}, \mathrm{P}_{\mathrm{c}}=218 \mathrm{~atm}\right)$, where these materials form a single homogeneous phase. In the supercritical state, mass transfer limitations for the oxidation reactions are essentially eliminated, and both reaction rates and destruction efficiencies are dramatically increased, resulting in the complete oxidation of organics to innocuous compounds. SCWO can be used to convert $\mathrm{PCBs}$ to $\mathrm{CO}_{2}$, water, and $\mathrm{HCl}$ with high efficiencies. In fact, the limited results that are available indicate that $99.99 \%$ destruction of PCB-contaminated sludge is possible, even though reactor design has yet to be optimized (Crain et al., 2000). The HCl byproduct from the reaction can then be easily neutralized with the addition of $\mathrm{NaOH}$ or $\mathrm{Na}_{2} \mathrm{CO}_{3}$ so that only nonhazardous materials remain (Caruana, 1995).

In order to meet EPA requirements, PCB-contaminated liquid wastes must be treated such that the effluent stream contains less than $3 \mathrm{ppb}$ of PCBs, favoring the use of larger reactor volumes. On the other hand, the treatment of MLLW will render the reactor tube radioactive, so reactor volumes need to be as small as is feasible. Thus, the efficient design and optimization of SCWO reactors is particularly important for DOE complex operations. Unfortunately, the information needed for efficient reactor design, that is, knowledge of the governing reaction kinetics, is essentially nonexistent. To our knowledge, only two fundamental kinetic studies of PCB destruction in supercritical water have been made, and both of these, although useful, are incomplete. Hatakeda et al. (1999) measured the destruction of a model PCB congener, 3chlorobiphenyl, with hydrogen peroxide in supercritical water and obtained conversions of up to 99.99\%. However, the range of conversions measured was limited; thus, the kinetic rate constants necessary for reactor design could not be obtained. In the second study, Anitescu and Tavlarides (2000) determined the global reaction rate constants for the destruction of an actual Aroclor mixture (i.e., no. 1248, a mixture of 76 PCB congeners) by SCWO.

Given the diversity of PCB congeners and congener mixtures (Aroclors), neither of these studies provides sufficient information to design and model a SCWO reactor capable of destroying the broad range of PCBs found in the DOE complex. This lack of data is particularly significant considering that PCBs are some of the most stable organic compounds known and are thus particularly resistant to oxidation by any means. For example, in a study reported by Dietrich et al. (1985), only $63 \%$ of Aroclor 1254 was destroyed by wet air oxidation at $320{ }^{\circ} \mathrm{C}$ and a residence time of 2 hours. (For phenol, on the other hand, the comparable numbers were $99.8 \%, 275^{\circ} \mathrm{C}$, and 1 hour.) Using SCWO, 99.99\% of the same Aroclor was destroyed, but even here 3.7 minutes were required at $510^{\circ} \mathrm{C}$ and $250 \mathrm{~atm}$ (Modell, 1989). Additionally, research by Anitescu and Tavlarides (2000) has shown that the global conversion of Aroclor 1248 in a SCWO reactor operated at $250 \mathrm{~atm}$ varied from $36 \%$ at $450{ }^{\circ} \mathrm{C}$ (with a residence time of $6 \mathrm{sec}$ ) to $99.95 \%$ at $550{ }^{\circ} \mathrm{C}$ (where the residence time was $54 \mathrm{sec}$ ). Kinetic data are thus particularly important for the proper design of reactors suitable for destroying these compounds.

Considering the importance of PCB destruction, one may wonder why there have been so few detailed kinetic studies of their oxidation in supercritical water. Probably the most important reason is the difficulty of the experiments. PCBs are only slightly soluble in water at ambient 
conditions (i.e., 1 ppm and less); thus, techniques must be developed such that they can be delivered at an accurately known flow rate to the reactor, preferably as part of a homogeneous phase. Up to now, almost all research on the SCWO of organic compounds has focused on compounds that have a high enough solubility in water for the feed solution to be prepared at ambient conditions. For example, chlorophenol has been studied (Li et al., 1993) instead of chlorobenzene. A second problem with studying oxidation of PCBs is that their use is strictly regulated, with EPA approval being required even for research in a university setting. Third, most of the pure components required for kinetic analysis are solids at room temperature, further complicating both the method for feeding the solution and the sample collection technique. Fourth, the high-purity congeners needed for kinetic experiments are expensive.

Another important aspect of the design of a SCWO reactor has to do with the economics of operating the process. The operational costs for a SCWO reactor mandate that the design contain some level of heat integration between the reactor effluent and the aqueous feed stream. Additionally, the efficient operation of a large-scale SCWO reactor requires that the feed solution contain at least 5 weight percent organics because the exothermic oxidation of these organic wastes is used to generate the energy needed to heat the SCWO reactor. These energy considerations have both been incorporated into designs currently being tested for military applications. For example, the U.S. Army's Pine Bluff Arsenal is collaborating with Sandia on the destruction of obsolete munitions by SCWO (operation began in 1998), and General Atomics has developed a SCWO reactor for the U.S. Air Force that is capable of destroying chemical warfare agents and solid rocket propellants.

The success of these two pilot-scale units demonstrates the feasibility of the SCWO process for the destruction of hazardous organic materials, but the reagents examined in both of these studies were much more easily oxidized than PCBs. Clearly, high-quality kinetic data for the destruction of pure PCB congeners and PCB mixtures via SCWO had to be acquired before a reactor appropriate for DOE needs could be designed and constructed.

Several advances in the kinetic analysis of PCB destruction via SCWO have been made as a result of this project at Clemson. These efforts have yielded information about the optimum design of SCWO reactors, especially the importance of mixing the oxygen- rich feed stream with the organic waste stream. These studies have also shown that an alcohol, or similar polar solvent, will be required to increase the solubility of PCBs in the low-temperature aqueous feed to the reactor. Economic considerations have also suggested that the exothermic oxidation of added solvent would be an excellent energy source for maintaining the reaction temperature above the supercritical temperature of water. This latter concern is particularly significant for the design of large-scale SCWO reactors that would otherwise require the continuous use of external heating devices that are prone to failure and require high operational costs. Thus far, two alcohol cosolvents, methanol and ethanol, have been used in the SCWO of PCB congeners. Both alcohols are readily degraded under the conditions required to oxidize PCBs. Ethanol is a particularly attractive co-solvent because it can be generated from renewable resources, is not heavily regulated, and is nontoxic. These current studies, however, fall well short of supplying sufficient reaction rate data to predict the degradation behavior of all PCB congeners, which is essential for any scale-up process that is going to ensure 99.99+\% destruction of PCBs.

A state-of-the-art flow reactor was developed for the kinetic laboratory studies. This flow reactor, shown as a schematic in Figure 15, was used to study the oxidation rates of chlorobenzene, 2-chlorobiphenyl, and alcohol cosolvents. There are several reasons for using 
this reactor configuration. First, scale-up from the laboratory to the pilot scale at a DOE facility, such as SRS, will be simplified if the same reactor configuration is used for both cases. Second, flow reactors are ideal for studying reactions that can occur over short residence times, especially when intermediates need to be identified. Third, because steady-state conditions are achieved, multiple samples are readily obtained under the same reactor conditions, allowing one to check the reproducibility of both the reactor operation and the analytical results. The flow reactor design used at Clemson, shown in Figures 16 and 17, incorporates many of the advanced design concepts developed for the destruction of water soluble organic compounds (Savage et al., 1995); however, as discussed below, several significant modifications were made to the conventional apparatus design in order to study PCBs.

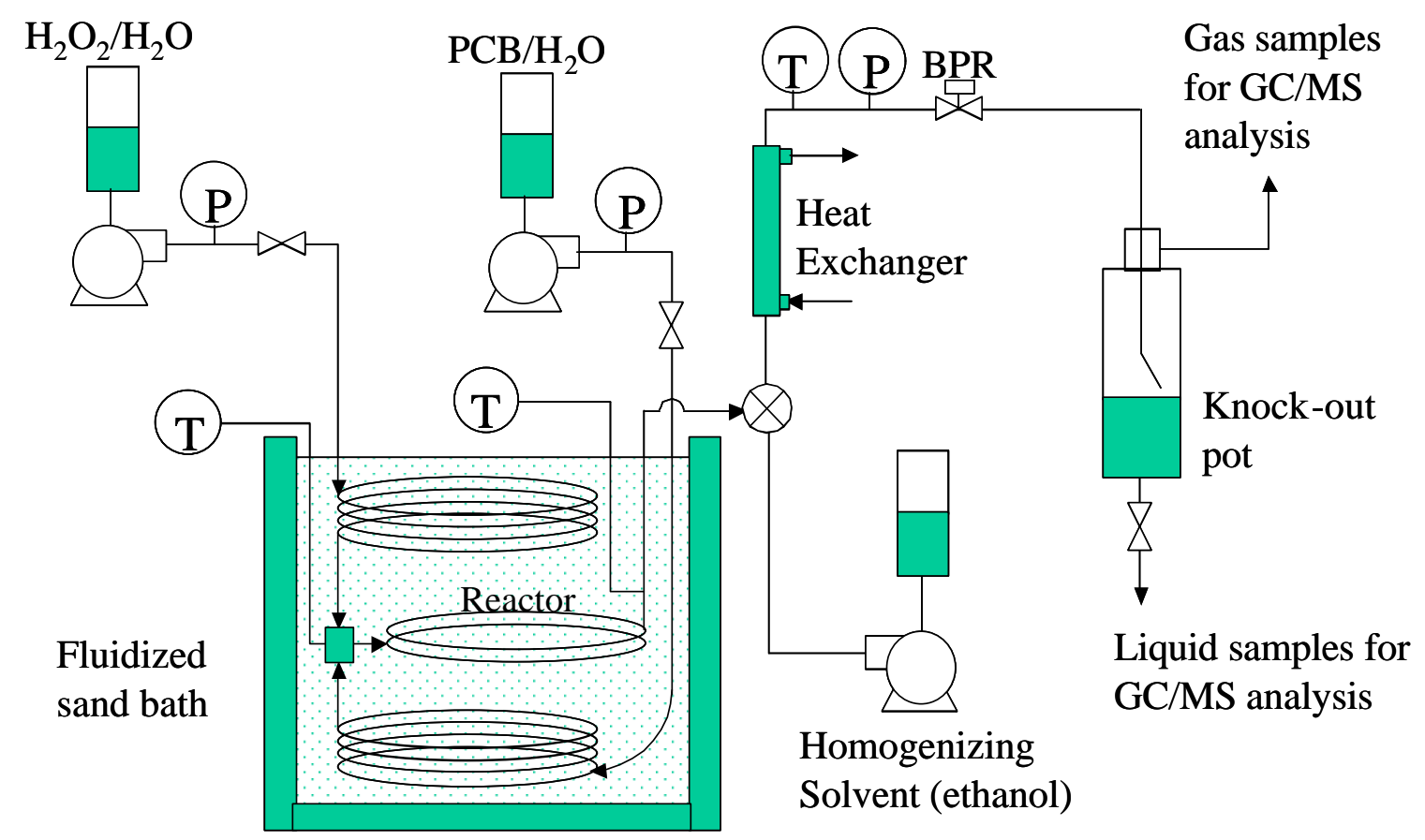

Figure 15. Experimental supercritical water oxidation (hydrothermal oxidation) apparatus at Clemson University 


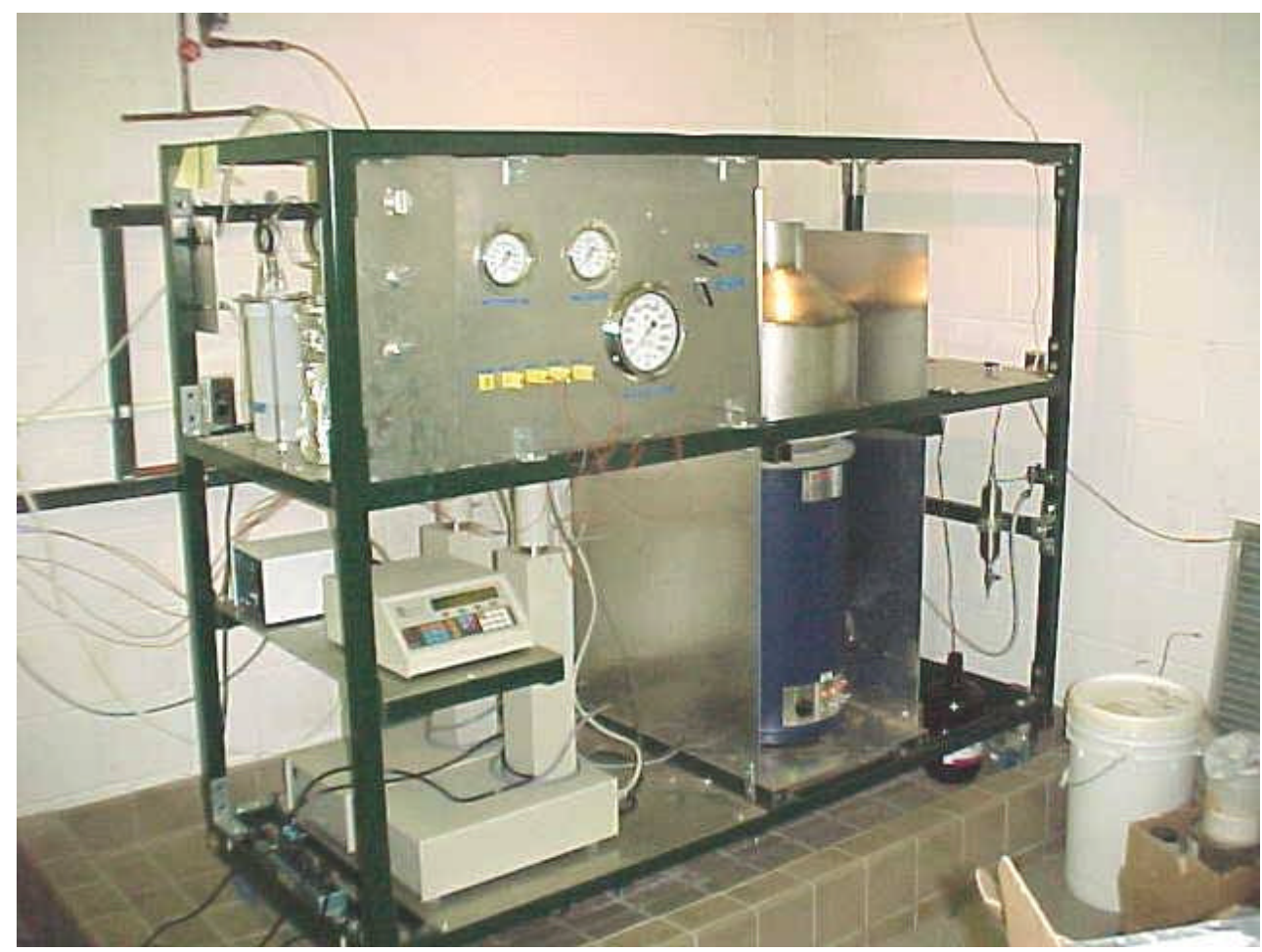

Figure 16. Supercritical Water Oxidation apparatus at Clemson University

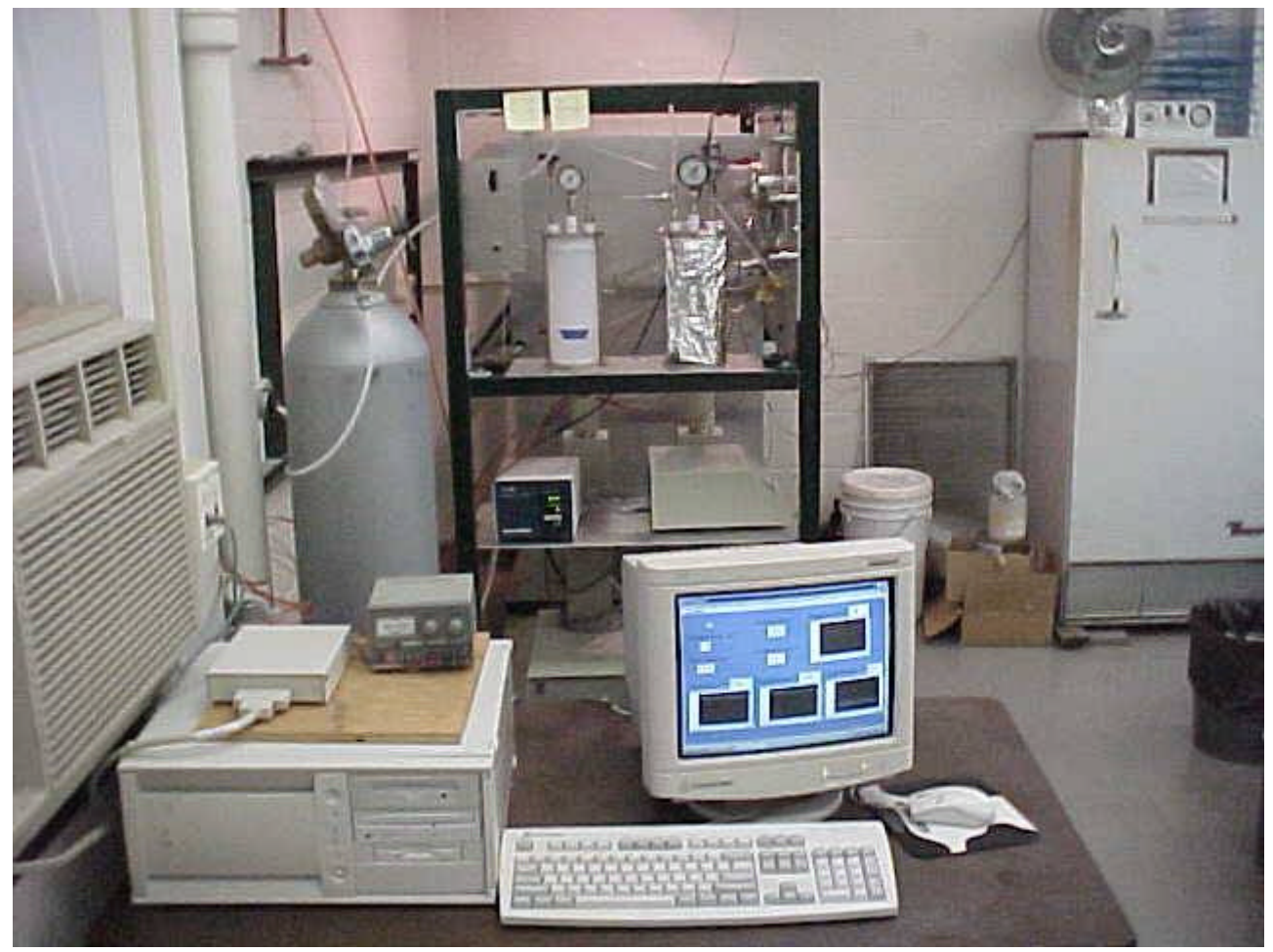

Figure 17. PC equipped with LabVIEW for real-time monitoring of temperature (via five thermocouples) and pressure (via transducer) 
For an experimental run, homogeneous solutions of PCB and water and of hydrogen peroxide and water are pumped at the desired operating pressure into separate preheating tubes heated by a fluidized sand bath. Inside the bath, the solutions are heated to the desired operating temperature. Following preheating, the two solutions are mixed together in a specially designed impingement tee (see Stevenson et al., 1994) at the entrance to a tubular reactor. After flowing through the reactor, the liquid products exiting the sand bath are first cooled by a small heat exchanger and then the pressure is reduced to atmospheric pressure by a high-precision back pressure regulator. Liquid phase samples containing unreacted PCBs and solvent are collected from the bottom port of a knock-out pot located downstream of the backpressure regulator. Gaseous products, including $\mathrm{CO}_{2}$ and $\mathrm{HCl}$, are collected from the gas sampling port atop the knock-out pot and analyzed using GC-MS. For some reaction studies a homogenizing solvent was added after the reactor to prevent the formation of an inhomogeneous condensed phase in the heat exchanger and knock-out pot.

Liquid samples containing the concentrated PCBs extracted from the extraction apparatus at USC were sent to Clemson and were run through the SCWO. Three samples were collected from the SCWO and were sent to Lionville Labs. We found that the feed from USC was very insoluble in water because of the PCBs and corn oil present from the Toxi-dry. In order to ensure a single phase in the pump, significant amounts of organic material had to be decomposed. Thus, large quantities of ethanol were added. The organic:oxidant flow rate ratio was varied over the course of three runs. By the final run, all of the organics in the feed were able to be decomposed. No PCBs were detected in any of the SCWO runs by GC-MSD analysis. Lionville Labs confirmed the absence of PCBs in the samples, although the lab claims detection limits on the order of $100 \mathrm{ppb}$, which exceeds the DOE requisite of $3 \mathrm{ppb}$ for "PCB free". However, the GC-MSD has a sensitivity of $<10 \mathrm{ppb}$ for identification purposes; thus, we are fairly certain that the SCWO reactor meets that requirement. In the final sample, the only organic present was small quantities $(\sim 10 \mathrm{ppb})$ of a compound created by the reaction of the corn oil with the PCB, creating a large molecule. This molecule is likely a benzene ring structure with two long ester-linked carbon chains. Additional residence time would be required to decompose it. The reaction conditions for the third, most successful, run were: $\mathrm{T}=565^{\circ} \mathrm{C}, \mathrm{P}$ $=3700$ psig, and Residence Time $=29$ seconds (Volumetric flow rates: Organic stream -20 $\mathrm{ml} / \mathrm{hr}$, Oxidant stream - $500 \mathrm{ml} / \mathrm{hr}$ ).

Experiments on the SCWO of o-PCB (pure, not the USC samples) are confirming the ability of the reactor to decompose PCBs. Conversions of $98+\%$ are obtained at temperatures as low as $450{ }^{\circ} \mathrm{C}$ at a residence time of 15 seconds. Essentially complete conversion is obtained at higher temperatures and/or longer residence times. 


\section{RELEVANCE, IMPACT AND TECHNOLOGY TRANSFER}

This research project focuses on a critical DOE environmental management problem, i.e., the existence of large quantities of PCB-contaminated waste at DOE sites across the country, and more PCB-contaminated waste will continue to be generated during decontamination and decommissioning (D\&D) operations. Conventional methods of remediating these wastes, such as thermal incineration and bioremediation, are costly, time-consuming, and generate large amounts of secondary waste.

The new scientific knowledge generated by this project has the potential to significantly reduce the costs and risks of remediating PCB-contaminated waste. First, by extracting the PCBs from the TSCA-regulated MLLW, the wastes are removed from the TSCA regime and are moved under RCRA control. Second, destroying the remaining PCB extract through supercritical water oxidation avoids the costs and risks of incineration, including the need to dispose the secondary waste generated by incineration. This process produces little if any secondary waste to be disposed.

As a result of the research conducted through this project, we have gained a much better understanding of the thermodynamic and kinetic factors involved in extracting and oxidizing PCBs from solid matrices such as the Toxi-dry absorbent. Thus, this knowledge has bridged the gap between theory and the application of this knowledge to a real problem within the DOE weapons complex, that is, the disposal of large quantities of PCB-contaminated mixed low-level waste. However, to realize its potential, this research must be taken beyond its current state. Further work must involve: (1) performing additional lab-scale tests comparing hot water and $\mathrm{CO}_{2}$ as the extraction solvent, and extracting PCBs from additional solid matrices of interest to SRS and DOE; (2) performing additional experiments and kinetic analysis of the SCWO process; (3) obtaining additional phase equilibrium data for PCBs in support of extraction and oxidation modeling; and (4) modeling and consolidating all technical data.

With regard to the use of hot water $\left(150-300^{\circ} \mathrm{C}\right)$ to extract $\mathrm{PCBs}$, we want to investigate the possibility that hot water with ethanol may extract just as well as near critical water or supercritical $\mathrm{CO}_{2}$ with ethanol cosolvent. If a hot water plus alcohol extraction process can be developed that operates at pressures lower than 2000 psia (supercritical $\mathrm{CO}_{2}$ minimum pressure), then the extractor effluent could pass directly to a SCWO reactor. Further, as described above, the sole matrix that we have investigated to date is Toxi-dry, a plant-based absorbent. SRTC collaborators have recommended additional work on iron and aluminum oxides (simulating reactor basin sludge), cotton fibers, and neoprene rubber. These materials represent a variety of waste forms commonly encountered. They are very difficult to characterize in terms of physical properties such as surface area and porosity. Therefore, experiments with these materials must be interpreted on a case-by-case basis, and scale-up models developed accordingly.

With regard to objective 4 above, it is vital that extraction, solubility, and oxidation kinetics results be combined into models that will allow design and evaluation of a larger scale process for DOE consideration. Further research will provide new data on the extraction behavior of PCBs from different DOE matrices. Engineering models showing the effects of different matrix surface compositions and process conditions on extraction dynamics and PCB removal efficiencies must be developed. Extraction data must be correlated with a transportbased model that can be used for extraction process scale-up (e.g., Fu and Matthews, 1998). The 
models to be developed will answer the following key questions that DOE must consider in deciding whether to adopt the proposed process for extracting and destroying PCBs:

- Which extraction process is best in terms of removing PCBs from solid waste down to the EPA-prescribed limits?

- What process conditions remove PCBs while minimizing capital and operating costs?

- Are secondary solvent or water wastes and discharges truly minimized or eliminated?

- Which extraction process is most easily coupled to the SCWO process?

Depending on the results of the above research and development, DOE would be in a position to conduct large-scale field trials of the combined extraction/oxidation process as a final step prior to moving to industrial application. 


\section{PROJECT PRODUCTIVITY}

The goals of the project were to investigate two methods of extracting PCBs from solid matrices (using either supercritical carbon dioxide or hot water as the extraction solvent), and to investigate two methods of oxidizing PCBs (using either supercritical water oxidation or a novel electrochemical oxidation method). This research in turn would allow the team to select from among these extraction and oxidation options and to recommend a combined extraction/oxidation process for further development and consideration by DOE. The ultimate goal of the research is to develop a combined cycle extraction/oxidation technology that would reduce the level of PCB contamination in the remaining mixed low-level waste to within EPA clean water standards of 3 parts-per-billion ( $\mathrm{ppb}$ ), thereby removing it from TSCA control.

With regard to research on supercritical $\mathrm{CO}_{2}$ extraction of $\mathrm{PCBs}$, the project has determined the optimal conditions and the effective cosolvents and $\mathrm{CO}_{2}$-soluble surfactants for extracting PCBs from Toxi-dry, a commonly used adsorbent in D\&D operations. However, we were able to perform experiments on only this one matrix material of interest to DOE. SRTC collaborators have recommended additional work on iron and aluminum oxides (simulating reactor basin sludge), cotton fibers, and neoprene rubber. These materials represent a variety of waste forms commonly encountered. They are very difficult to characterize in terms of physical properties such as surface area and porosity. Therefore, experiments with these materials must be interpreted on a case-by-case basis, and scale-up models developed accordingly.

As discussed above, research on electrochemical oxidation of PCBs was suspended because sufficient conductivities in the reactor could not be achieved without the use of acetonitrile, which introduces a secondary waste stream. Therefore, electrochemical oxidation of PCBs in $\mathrm{CO}_{2}$ does not appear promising at this stage of development. However, this work led us to investigate alternative, more environmentally benign solvents, namely room temperature ionic liquids (RTILs). The USC investigators received funding from the National Science Foundation to continue to pursue this work. Preliminary results have been published. If successful, electrochemistry in RTILs could be coupled with dense $\mathrm{CO} 2$ extraction to produce a process for destroying PCBs.

Also as mentioned above, research on hot water extraction of PCBs was suspended in order to concentrate the resources of the Clemson component of the team on supercritical water oxidation. However, the USC component of the team has installed a 1-liter, stirred, stainless steel autoclave (PPI Industries, Inc.) rated to 6,000 psia and $340^{\circ} \mathrm{C}$ that will be used for extraction studies using hot water. It has two feed pumps capable of providing a continuous flow of water and a secondary solvent, such as ethanol, if desired. This apparatus has been assembled and pressure-tested, and will be utilized to study hot water extraction should the team receive future funding.

Finally, the project team proved the effectiveness of their supercritical water oxidation reactor design in decomposing PCBs. Essentially complete destruction was achieved at temperatures greater than $450{ }^{\circ} \mathrm{C}$ and residence times greater than 15 seconds. 


\section{PERSONNEL SUPPORTED}

Supported at USC

Thomas A. Davis, Research Professor

Michael A. Matthews, Professor

John W. Weidner, Associate Professor

Jun Li, Ph.D student

Matthew Leonard, M.S. student

Supported at Clemson

Mark Thies, Professor

David Bruce, Associate Professor

Chris O'Brien, Ph.D student

Bryan Majkrzak, M.S. student

$\underline{\text { SRTC Collaborators }}$

Lawrence Oji

John Pickett

Nancy Lowry 


\section{PUBLICATIONS}

1. Li, J.; Davis, T.A.; Matthews, M.A. Supercritical fluid extraction of 1,2,4-trichlorobenzene from DOE Job-Control-Wastes, accepted by Separation Science and Technology.

2. Majkrzak, B.; Bruce, D. A.; Thies, M. C. A noninvasive apparatus for measuring the solubility of PCB congeners in hot water. Environ. Sci. Tech., submitted for publication, 2002.

3. McWilliams, H.; Li, J.; Matthews, M.A. Economic analysis of supercritical technology for extraction and destruction of PCBs from DOE Job-Control-Waste. (In preparation) 


\section{INTERACTIONS}

"Decontamination \& Decommissioning of PCB Sites at SRS." J. Pickett, L. Oji, M. Matthews, R. White, J. Weidner, D. Bruce, M. Thies. Poster paper given at the Workshop on Integration of End User Needs with Research Projects for the Environmental Management Science Program, Savannah River Site, November 17-18, 1998.

"Mass transfer in $\mathrm{CO}_{2}$ /surfactant systems." Presented at the 1998 AIChE Annual Meeting, Miami Beach, FL November 15-20, 1998.

"Basic Engineering Research for D\&D of PCB Wastes at DOE Sites." EMSP National Conference, Atlanta GA, April 24-27, 2000. Poster presentation and oral presentation in the MWFA Working Group.

"Supercritical Carbon Dioxide Extraction of Chlorinated Aromatics from Job Control Waste." Presented at the 2000 Annual Meeting of the American Chemical Society, Washington, DC.

"Electrochemical Reactions in Supercritical Carbon Dioxide." Presented at a conference of the International Society of Electrochemistry, Warsaw, Poland, Sep. 5, 2000.

"Extraction and Oxidation of PCBs from Mixed Low-Level Solid Waste at DOE Sites" Presented at the 222 ACS National Meeting, August 2001 in Chicago, IL.

"Supercritical Fluid Extraction of 1,2,4-Trichlorobenzene from DOE Job Control Wastes". Presented at the 222 ACS National Meeting, August 2001 in Chicago, IL.

"A Noninvasive Apparatus for Measuring the Solubility of PCB Congeners in Hot Water", AIChE Annual Meeting, Reno, NV, Nov. 2001.

"Electrochemically Generated Superoxide Ion in Ionic Liquids: Applications to Green Chemistry." Accepted for 223 ACS National Meeting, April 2002 in Orlando, FL

"Development of an Ultraviolet Fiber Optic Spectrometer Detection System for Monitoring Supercritical Carbon Dioxide Extraction Process". Accepted for 223 ACS National Meeting, April 2002 in Orlando, FL

"A Novel Process for Treatment of PCB Contaminated Mixed Low Level Waste." Accepted for 223 ACS National Meeting, April 2002 in Orlando, FL

"Supercritical Carbon Dioxide Extraction of Polychlorinated Biphenyls from DOE Waste." Accepted for 223 ACS National Meeting, April 2002 in Orlando, FL

The project team included professional personnel from the Westinghouse Savannah River Company, including the Savannah River Technology Center and the Facilities Decommissioning Division. These personnel, listed above, were invaluable in guiding the university researchers, responding to and advising on proposed research designs, and in assisting the university researchers in complying with EPA and South Carolina Department of Health and Environmental Control regulations. 


\section{PATENTS}

"Process and Composition for Selective Oxidation in Novel Solvents." Invention disclosure submitted to Office of Technology Transfer, University of South Carolina, October. 2000. Disclosure No. IDF 20279 


\section{FUTURE WORK}

\subsection{EXTRACTION OF PCBs USING SUPERCRITICAL $\mathrm{CO}_{2}$ OR HOT WATER}

Based on our experience with this project, as well as on practical technical guidance provided by SRTC collaborators, the most promising route to a feasible extraction and oxidation process depends on the utility of ethanol as a cosolvent. The extraction results to date show that the required pressure for the supercritical $\mathrm{CO}_{2}$ extraction step can be greatly reduced by the use of ethanol as a cosolvent, compared to using pure $\mathrm{CO}_{2}$. Research on SCWO shows that PCB solubility in water is greatly improved by adding ethanol, and that the SCWO oxidation reactor will require an inexpensive organic feed to improve performance. Therefore, the possibility that hot water with ethanol may extract just as well as near critical water or supercritical $\mathrm{CO}_{2}$ with ethanol as a cosolvent should be investigated. If a hot water plus alcohol extraction process can be developed that operates at pressures lower than 2000 psia (supercritical $\mathrm{CO}_{2}$ minimum pressure), then the extractor effluent could pass directly to a SCWO reactor.

If the results of experimental work with hot water plus ethanol extraction indicate that the process has real promise, a careful comparison of its benefits and limitations should be made with those of supercritical $\mathrm{CO}_{2}$ extraction. If hot water extraction can be shown to be superior, then process design efforts should be directed away from $\mathrm{CO}_{2}$ and toward hot water. On the other hand, if hot water extraction is found to have serious limitations, then efforts on that study would be curtailed so that maximum resources can be directed toward extraction with supercritical $\mathrm{CO}_{2}$.

To compare the two solvent systems, we would propose to conduct extraction experiments over the following range of conditions:

\begin{tabular}{l|ll} 
& $\mathbf{C O}_{2}+$ ethanol & Water + ethanol \\
\hline Temperature & $40-80{ }^{\circ} \mathrm{C}$ & $150-300{ }^{\circ} \mathrm{C}$ \\
Pressure & $2,000-6,000$ psia & $500-1500$ psia
\end{tabular}

For future work, better understanding of the nature of the ethanol cosolvent effect needs to be obtained through experimentation with additional solid matrices. As described above, the sole matrix that we have investigated to date is Toxi-dry, a plant-based absorbent. SRTC collaborators have recommended additional work on iron and aluminum oxides (simulating reactor basin sludge), cotton fibers, and neoprene rubber. These materials represent a variety of waste forms commonly encountered. They are very difficult to characterize in terms of physical properties such as surface area and porosity. Therefore, experiments with these materials must be interpreted on a case-by-case basis, and scale-up models developed accordingly.

Finally, some modifications to the extraction equipment are required. Real-time extraction data must be available so that we can optimize the required extraction time. The supercritical $\mathrm{CO}_{2}$ apparatus described above allows one to obtain only initial and final PCB concentrations. Therefore, we would add on-line UV detection of the extracted analyte, using the same technique developed at Clemson University, so that real-time extraction data can be obtained. 


\subsection{SOLUBILITY OF PCBS IN NEAR-CRITICAL WATER}

As described above, it will be necessary to modify the existing phase equilibrium cell to accommodate higher temperature measurements. The UV absorbance of the samples is measured using a cross-flow cell equipped with UV transparent windows and Viton seals. This cross-flow cell was obtained commercially, but has been proven to be somewhat unreliable, as it has to be rebuilt every month or so, and cannot even meet its stated temperature limit of $200{ }^{\circ} \mathrm{C}$. Therefore, future experiments will use a UV-Vis fiber optic flow cell designed in-house by Clemson researchers and rated for temperatures and pressures of $300{ }^{\circ} \mathrm{C}$ and $200 \mathrm{bar}$. Thies and co-workers (1990) have previously designed cells of a similar type for $400{ }^{\circ} \mathrm{C}$ and 350 bar.

\subsection{KINETIC ANALYSIS OF SUPERCRITICAL WATER OXIDATION}

For future work, the global reaction kinetics involved the SCWO reactor should be determined using experimental design techniques, which have successfully been used by Clemson researchers (e.g., Dauche et al., 1998). These experiments would measure variations in the reaction rate with systematic changes in the concentration of reactive species and reaction conditions. Approximate feed concentrations of PCB from 5 to about 1000 ppm would be used, and hydrogen peroxide concentrations would be varied so as to maintain an excess of oxygen in the reactor at all times. Residence times would be varied with two objectives in mind: (1) to examine the formation of reaction intermediates and (2) to optimize the conversion within the reactor. Different reactor lengths and flow rates would be used to obtain the desired variations in residence time.

A nonlinear least squares regression technique can be used to calculate both the reaction order and the pseudo rate constants for the general oxidation process described by the rate equation shown below (Mezaki et al., 1968; Froment and Bischoff, 1979):

reaction rate $=\frac{-\mathrm{dC}_{\mathrm{PCB}}}{\mathrm{dt}}=\mathrm{k}_{\mathrm{TST}} \mathrm{C}_{\mathrm{PCB}}^{\alpha} \mathrm{C}_{\mathrm{O}_{2}}^{\beta}$

Because the range of concentrations of the PCB congeners is limited to low values by solubility considerations, it is unlikely that the reaction order will shift for these species; however, the concentration of oxygen can vary considerably. Thus, the presence of shiftingorder kinetics for the oxidant will need to be examined. From these initial studies we would be able to determine the global reaction order and pseudo rate constant for the oxidation process.

For SCWO, the effects of variable solvent density on the reaction rate must be understood and controlled. Therefore, additional experiments should examine these effects by varying the system pressure from 150 to 350 atm and the temperature from 350 to $500{ }^{\circ} \mathrm{C}$. A thermodynamic formulation of transition state theory (TST) can be used to model these effects (Glasstone et al., 1941; Steinfeld et al., 1989). The theory assumes that there is an activated intermediate or transition state $\left(\mathrm{X}^{*}\right)$ that is formed on the pathway from reactants to products (note: the double dagger represents an intermediate species):

$$
\mathrm{A}+\mathrm{B} \rightarrow \mathrm{X}^{\ddagger} \rightarrow \mathrm{P}
$$

With this model, the effects of pressure and temperature can be accounted for within the reaction rate constant. Using the thermodynamic formulation of TST, the rate constant $\mathrm{k}_{\mathrm{TST}}$ is 
defined by the equation shown below, where $k_{\mathrm{B}}$ is the Boltzmann constant and $h$ is Planck's constant:

$\mathrm{k}_{\mathrm{TST}}=\frac{k_{\mathrm{B}} \mathrm{T}}{h} \mathrm{e}^{-\mathrm{E}_{\mathrm{a}, \mathrm{TST}} / \mathrm{RT}}$

The activation energy term $\left(\mathrm{E}_{\mathrm{a}, \mathrm{TST}}\right)$ in the TST model accounts for both the standard enthalpy of the reaction process $\left(\Delta \mathrm{H}_{0}^{\ddagger}\right)$ and the standard volume of activation $\left(\Delta \mathrm{V}_{0}^{\ddagger}\right)$ as shown below:

$\mathrm{E}_{\mathrm{a}, \mathrm{TST}}=\Delta \mathrm{H}_{0}^{\ddagger}+\mathrm{RT}-\mathrm{P}\left(\Delta \mathrm{V}_{0}^{\ddagger}\right)$

It is the volume of activation term that models variations in the reaction rate with changes in reactor pressure. Although alternative formalisms can be used to model the effects of pressure, previous work with polar and ionic systems in water has demonstrated that the thermodynamic formulation of TST has significant advantages over the other modeling techniques (Wilkins, 1974; Savage, 1994). 


\section{LITERATURE CITED}

Abaroudi, K.; Trabelsi, F.; and Recasens, F. Mass transport enhancement in modified supercritical fluid, Ind. Eng. Chem. Res., 38, 35051999

Amador-Hernandez, J; Luque, De Castro M.D. On-line detection for supercritical fluid extraction. J. Biochem. Biophys. Methods 43, 329-343 2000

Anitescu, G.; Tavlarides, L.L., Oxidation of Aroclor 1248 in Supercritical Water: A Global Kinetic Study, Ind. Eng. Chem., 39, 583-591, 2000.

Berg, B.E.; Lund, H.S.; Kringstad, A.; Kvernheim, A.L. Routine analysis of hydrocarbons, $\mathrm{PCB}$ andPAH in marine sediments using supercritical $\mathrm{CO} 2$ extraction Chemosphere 38 (3) 587-599 1999

Berset, J.D.; Holzer, R. Quantitative determination of polycyclic aromatic hydrocarbons, polychlorinated biphenyls and organochlorine pesticides in sewage sludges using supercritical fluid extraction and mass spectrometric detection J. Chromatography A 852: (2) 545-558 Aug 131999

Bjorklund, E.; Nilsson, T.; Bowadt, S.; Pilorz, K.; Mathiasson, L.; Hawthorne, S.B. Introducing selective supercritical fluid extraction as a new tool for determining sorption/desorption behavior and bioavailability of persistent organic pollutants in sediments J Biochem. Biophys. Methods 43, 295-311, 2000

Bjorklund, E.; Bowadt, S.; Mathiasson, L.; Hawthorne, S.B. Determining PCB sorption desorption behavior on sediments using selective supercritical fluid ertraction. 1. Desorption from historically contaminated samples ENVIRON SCI TECHNOL 33: (13) 2193-2203 JUL 11999

Bowadt, S.; Mazeas, L.; Miller, D.J.; Hawthorne, S.B. Field-portable determination of polychlorinated biphenyls and polynuclear aromatic hydrocarbons in soil using supercritical fluid extraction J Chromatography A 785: (1-2) 205-217 OCT 171997

Bowadt, S.; Johansson, B.; Wunderli, S.; Zennegg, M.; Dealencastro, L.F.; Grandjean, D. Independent comparison of Soxhlet and supercritical fluid extraction for the determination of PCBs in an industrial soil Anal. Chem. 67: (14) 2424-2430 JUL 151995

Bowadt, S.; Johansson, B. Analysis of PCBs in sulfur-containing sediments by off-line supercritical-fluid extraction and HRGC-ECD Anal. Chem 66: (5) 667-673 MAR 1994

Caruana, C.M. Supercritical water oxidation aims for waste-water clean-up, CHEM. ENG. PROG. 91 (4): 10-\& APR 1995

Chang, C.J.; Day, C. Y.; Chen, C. Y. Vapor-liquid Equilibria and Correlation of Ethanol + CO2 and Acetone + CO2 at Elevated Pressure, J. The Chin. I. Ch. E., 27, 243-249 1996 
Chen, P.; Zhou, W.; Tavlarides, L.L. Remediation of polychlorinated biphenyl contaminated soils/sediments by supercritical fluid extraction Environ. Prog. 16: (3) 227-236 FALL 1997

Crain, N.; Shanableh, A.; Gloyna, E. Supercritical water oxidation of sludges contaminated with toxic organic chemicals, WATER SCIENCE AND TECHNOLOGY, 42, 363-368, 2000

Dachs, J.; Fernandez, I.; Bayona, J.M. Combined experimental design and information theory for the optimization of supercritical fluid extraction of organic priority pollutants from sediment ANAL CHIM ACTA 351: (1-3) 377-385 SEP 301997

Dietrich, M.J.; Randall, T.L.; Canney, P.J. Wet air oxidation of hazardous organics in waste water, Environmental Progress, 4, 171-177, 1985

Dupeyron, S.; Dudermei, P.; Couturier, D.; Guarini, P.; Delatter, J. Extraction of polycyclic aromatic hydrocarbons from soils: A comparison between focused microwave assisted extraction, supercritical fluid extraction, subcritical fluid extraction, sonication and Soxhlet techniques. Intern. J Environ Anal. Chem. 73(3), 191-210, 1999

Falconer, R.L.; and Bidleman T.F. Vapor Pressure and Predicted Particle/Gas Distribution of Polychlorinated Biphenyl Congeners as Function of Temperature and Ortho-chlorine Substitution, Atmospheric Environment, 28, 547-554, 1994

Firus, A.; Brunner, G. Continuous extraction of contaminated soil with supercritical water, Presented at the $3^{\text {rd }}$ Int. Symposium on High Pressure Chemical Engineering, Zurich, Switzerland, October, 1996

Fuoco. R.; Griffiths. P.R. Analysis of polychlorinated-biphenyls in contaminated soil samples by supercritical fluid extraction supercritical fluid chromatography coupled with FTIR spectrometry ANN CHIM-ROME 82: (5-6) 235-245 1992

Hatakeda, K.; Ikushima, Y.; Ito, S.; Saito, N.; Sato, O., Supercritical water oxidation of a PCB of 3-chlorobiphenyl using hydrogen peroxide, Chem. Lett. 245-246, 1997.

Hawthorne. S.B.; Miller, D.J.; Burford, M.D.; Langenfeld, J.J.; Eckert-Tilotta, S.; Louie, P.K. Factors Controlling Quantitative Supercritical Fluid Extraction of Environmental Samples, J. Chromatography 642, pp.301-317 1993

Hartone, K,; Inkala, K.; Kangas, M.; Riekkola, M.L. Extraction of polychlorinated biphenyls with water under subcritical conditions. J. Chromatography A, 785, 219-226,1997

Hetflejs; J. Detoxification of solid-waste containing PCBs CHEM LISTY 88: (9) 545-556 SEP 1994

Jeong, M.L.; Chesney, D.J. Investigation of Modifier Effects in Supercritical CO2 Extraction from Various Solid Matrices, J. Supercritical Fluids, 16, 33-42. 1999 
Laitinen, A.; Michaux, A.; Aaltonen, O. Soil cleaning by carbon dioxide extraction: A review Environ. Tech. 15, 715-727, 1994

Langenfeld, J.J.; Hawthorne, S.B.; Miller, D. J.; Pawlisz, N. J. Role of Modifiers for Analytical-scale Supercritical Fluid Extraction of Environmental Samples, Anal. Chem., 66 (4), 909-916 1994

Langenfeld, J.J.; Hawthorne, S.B. Miller, D.J.; Pawlisz, N.J. Effects of temperature and pressure on supercritical fluid extraction efficiencies of polycyclic aromatic-hydrocarbons and polychlorinated-biphenyls ANAL CHEM 65: (4) 338-344 FEB 151993

McHugh, M.; Krukonis, V. Supercritical Fluid Extraction, Butterworth Publishers, Stoneham, MA 1986

Morselli, L.; Setti, L.; Iannuccilli, A.; Spinozzi, G.; Dinelli, G.; Quattroni, G. PCBs and hydrocarbons in soil matrix controlled by supercritical fluid extraction (SFE). Preliminary studies. ANN CHIM-ROME 88: (7-8) 545-553 JUL-AUG 1998

Morselli, L; Sabbioni, M.; Zappoli, S.; Quattroni, G. Comparison between SFE and Soxhlet extraction in the determination of PCB in soil samples FRESEN ENVIRON BULL 4: (8) 463-468 AUG 1995

Pawliszyn, J. Kinetic model of supercritical fluid extraction. J Chromatogr. Sci. 31, 31-37, 1993

Reutergardh, L.B.; Parkpian, P.; Chaiyaraksa, C. Supercritical fluid extraction of planar and mono-ortho PCB in selected tropical soils CHEMOSPHERE 36: (7) 1565-1573 MAR 1998

Savage, P.E. Gopalan, S.; Mizan, T.I.; Martino, C.J.; Brock, E.E. Reactions at supercritical conditions: applications and fundamentals, AICHE J., 41, 1723-1778, 1995

Stone, M.A.; Taylor, L.T. Improved solvent trapping of volatiles in supercritical fluid extraction by pressurizing the collection vial Analytical Chemistry 72(6), 1268-1274, 2000

Sweetman, A.J.; Watts, C.D. Development of a supercritical-fluid extraction method for PCBs and chlorobenzenes from soils and sludge-amended soils ENVIRON TECHNOL 16: (1) 73-80 JAN 1995

Tong, P.; Imagawa, T. Optimization of supercritical fluid extraction for polychlorinatedbiphenyls from sediments ANAL CHIM ACTA 310: (1) 93-100 JUN 251995

Trigg, R.J.; Keenan, G.A.; McMullan, D.; Conner, A.I. Automated SFE combined with GCMS for the determination of organochlorine compounds in sludge and sediment INT $\mathbf{J}$

ENVIRON AN CH 70: (1-4) 47-57 1998 
Van der Velde, E.G.; Dehaan, W.; Liem, A.K.D. Supercritical fluid extraction of polychlorinated-biphenyls and pesticides from soil-Comparison with other extaction methods J CHROMATOGR 626: (1) 135-143 DEC 161992

Yak, H.K.; Mincher, B.J.; Chiu, K.H.; Wai, C.M. Supercritical fluid extraction/gammaradiolysis of PCBs from contaminated soil J HAZARD MATER 69: (2) 209-216 OCT 29 1999

Yang, Y.; Bowadt, S.; Hawthorne, S.B.; Miller, D.J. Subcirtical water extraction of polychlorinated biphenyls from soil and sediment, Anyl. Chem., 67, 4571-4576, 1995 


\section{FEEDBACK}

This project was funded for three years. The original project was submitted in response to DOE Notice 98-04. We submitted a renewal under EM Science Program Notice 01-19 (the renewal proposal number was 82753). We find inconsistencies and lack of continuity in the grant process.

1). Notice 98-04, and the EMSP meeting we attended, emphasized connection with DOE stakeholder problems, practical reference, and speedy transition to the user. Our renewal proposal stressed these aspects, however, one reviewer of the renewal complained that " the project ... seems like a direct extension of past work. It does not appear to offer any groundbreaking attempts." We contend that, to transition lab research to the DOE user, direct extension of the original project is a necessity. The reviewer's comment is inconsistent with the goal of transitioning.

2). The original project was assigned to D\&D. Then it was changed to mixed waste. It is not clear that EMSP ever assigned this project to a single entity for project ownership.

3). The call for renewal proposal required that we submit the renewal only two years into a three year project. Thus, the opportunity to substantially complete the first project was not afforded us. 


\section{APPENDICES}

1. Supercritical fluid extraction of 1,2,4-trichlorobenzene from DOE Job-Control-Wastes, accepted by Separation Science and Technology.

2. Economic analysis of supercritical technology for extraction and destruction of PCBs from DOE Job-Control-Waste. (Draft in preparation, to be submitted) 
Appendix 1. Paper submitted to Separation Science and Technology, acceptance pending

\title{
SUPERCRITICAL FLUID EXTRACTION OF 1,2,4-TRICHLOROBENZENE FROM DOE JOB CONTROL WASTES
}

\author{
Jun Li, Thomas A. Davis, Michael A. Matthews* \\ Department of Chemical Engineering \\ The University of South Carolina \\ Columbia, South Carolina, 29208
}

* Author to whom correspondence should be addressed

\begin{abstract}
At DOE sites, significant amounts of Job Control Waste (JCW) need to be disposed. This JCW is generated and contaminated with polychlorinated biphenyls (PCBs) during clean-up operations. A commercial, plant-based absorbent material, "Toxi-dry", is used extensively for decontamination and decommissioning of DOE waste sites and is classified a hazardous JCW after use. In this investigation, 1,2,4trichlorobenzene (TCB) was chosen as the surrogate for PCBs. As a promising separation technology, supercritical fluid extraction (SFE) was investigated for removing and recovering PCBs from contaminated of JCW. TCB was extracted from Toxi-dry using both pure and modified supercritical carbon dioxide. It was found that at constant pressure, increasing temperature from $40{ }^{\circ} \mathrm{C}$ to $80{ }^{\circ} \mathrm{C}$ greatly improved the recoveries, while the pressure effect of SFE was not as clear as the temperature effect. With $5 \mathrm{wt} \%$ acetone or ethanol added as cosolvent, the efficiency of SFE of TCB was also significantly improved.
\end{abstract}




\section{INTRODUCTION}

Due to their high chemical and biological stability and high lipophilicity, persistent organic pollutants like polycyclic aromatic hydrocarbons (PAH), polychlorinated biphenyls (PCB), chlorobenzenes, and pesticides cause serious environmental problems (1-5). These pollutants leach into soil, sediment and groundwater and finally contaminate the food chain. At DOE sites across the country, large quantities of PCB contaminated wastes exist and will continue to be generated during decontamination and decommissioning (D\&D) operations. DOE sites, including the Savannah River Site (SRS), need a promising technology to isolate and then destroy PCBs that contaminate certain solid waste forms. Conventional methods of remediating these wastes are costly, time-consuming, and generate large amounts of secondary waste. No proposed process for the recovery and/or destruction of these persistent pollutants has emerged as the preferred choice for DOE cleanup.

In this work, supercritical fluid extraction (SFE) using carbon dioxide $\left(\mathrm{CO}_{2}\right)$ has been investigated for the decontamination of PCBs from DOE wastes. During this first stage of process research, the feasibility of using $\mathrm{SFE}$ with $\mathrm{CO}_{2}$ to remove and recover PCBs was tested in an analytical scale apparatus on a representative DOE matrix. This paper focuses on our analytical scale extraction results. The objectives of this paper are to find the optimal supercritical $\mathrm{CO}_{2}$ extraction conditions, reveal the mechanisms of extraction from porous DOE wastes, and provide reliable bench-marks for further decontamination investigations. 


\title{
BACKGROUND
}

\author{
Job Control Waste at DOE Sites
}

From 1929 to 1979, approximately 1.4 million pounds of PCBs were produced worldwide and caused serious contamination problems (6). At DOE sites across the country, PCBs are found in many solid matrices, as well as in trace levels in contaminated water. D\&D activities generate PCB-contaminated job control waste, tank/basin sediments, paint chips, etc. Frequently these wastes are also contaminated with HTO (tritiated water) or other species, resulting in a PCB-contaminated low-level radioactive waste (LLW). Such wastes contain constituents regulated under the Toxic Substances and Control Act (TSCA) regulations, and thus are also mixed low-level wastes (MLLW). Incineration is the only approved disposal path for certain PCB wastes. The TSCA incinerator at Oak Ridge is the only incinerator in the nation that is permitted to burn radioactive $\mathrm{PCB}$ waste. In addition to the problem of inadequate incinerator capacity, disposal by incineration produces secondary atmospheric emissions and ash that require control and treatment. A significant potential benefit of this research is the development of alternative technologies that do not produce secondary pollution similar to incineration.

The solid waste forms encountered are classified as homogeneous inorganic debris (e.g., scrap metals and concrete), organic debris (e.g., paper, cloth, plastic, rubber), heterogeneous debris, slurries (defined as having Total Suspended Solids (TSS) between $1 \%$ and $30 \%$ by weight) and sludges (defined as having TSS greater than $30 \%$ ). A specific example of PCB-contaminated radioactive waste in storage at SRS is waste generated by clean-up activities, named "Job Control Waste" (JCW). The majority of these wastes include materials such as "Toxi-dry" and "spill pillows" used to absorb liquid wastes resulting from PCB spills within process facilities. Toxi-dry, a plant-based absorbent, was the solid matrix used during this investigation.

\section{Supercritical Fluid Extraction of Job Control Waste}

As an analytical-scale extraction method, supercritical $\mathrm{CO}_{2}$ extraction is more efficient than conventional techniques, giving higher recoveries than liquid extraction and with no need for the clean-up steps required in Soxhlet extraction $(1,7)$. Furthermore, SFE is faster and requires less sample handling. In commercial-scale SFE, the solvent power of the fluid can be manipulated by changing pressure, and temperature, or by adding small amount of a co solvent, such as alcohol or water. Compared to liquid solvents, $\mathrm{SCF} \mathrm{CO}_{2}$ has lower viscosity and surface tension and has higher solute diffusivities; therefore, it can penetrate into porous solid materials more effectively and give superior mass transfer rates. Moreover, extracts can be easily separated by depressurizing the SCF (8). These advantages have prompted research on supercritical $\mathrm{CO}_{2}$ as a basis for large-scale decontamination of contaminated soils, sediments, and other solids. 
Supercritical carbon dioxide $\left(\mathrm{SC}-\mathrm{CO}_{2}\right)$ is particularly attractive for the extraction of organic-contaminated wastes, because $\mathrm{CO}_{2}$ is nontoxic, non-flammable, and environmentally acceptable. It is also cheap and available in large quantities. $\mathrm{CO}_{2}$ has a low critical temperature $\left(31{ }^{\circ} \mathrm{C}\right)$ and a moderate critical pressure $(1078 \mathrm{psia})$, so that equipment development is entirely feasible within the current state of the art. In addition, $\mathrm{CO}_{2}$ can dissolve numerous nonpolar and moderately polar compounds due to its Lewis base characteristics, induced dipole interactions, and quadrupole interactions (9).

There are several possible factors that influence the mechanism of a particular SFE: (1) thermodynamic factors such as the solubility of the extract in the SCF, (2) kinetic factors such as slow desorption of the analyte from the surface, diffusion of the analyte through the organic matrix of the sample, matrix swelling, and the extraction time, and (3) physical factors such as the influence of the solid matrix on diffusion and the complex solvent-solute-matrix interaction $(9,10,11)$.

Thermodynamics properties such as analyte solubility are useful to understand the SFE process (12). Vapor pressure, polarity, molecular weight, and chemical composition of the solute are the most important factors affecting solubility of compounds in supercritical fluid. At fixed temperature, the density of $\mathrm{SC}-\mathrm{CO}_{2}$ increases with pressure. When the density of a supercritical fluid is increased, the solubility of a solid solute in this supercritical fluid is also increased (8). If the supercritical fluid extraction is solubility controlled, increasing extraction pressure will result in increasing extraction recovery. On the other hand, if the supercritical fluid extraction is kinetically or desorption controlled, the structure of the matrices will have much more effect on recovery, and the density effect will be small. Extraction of trace amounts of aged organic contaminates like PCBs from environmental samples usually is kinetically controlled (5).

The effect of extraction temperature is complex, and is a combination of the effects on thermodynamic properties (solute vapor pressure, fluid density, and desorption isotherm) as well as dynamic properties (viscosity, desorption kinetics, mass transfer coefficients).

Usually the extraction is more efficient at higher temperature if the solute is volatile. But if the solute vapor pressure does not increase significantly with temperature, a decrease of extraction efficiency will result from increasing temperature due to the decreased density (13). For SFE of PCBs, some studies found insignificant temperature effects $(1,14)$, while others claim a beneficial effect of temperature (15).

Previous studies have indicated that the solvent power of pure dense $\mathrm{CO}_{2}$ is not strong enough to extract persistent pollutants from environmental samples. When the pressures for extraction are much above the critical pressure of $\mathrm{CO}_{2}$, or the polarity of the fluid is not suitable for the targeted solute, the use of cosolvents is necessary to enhance recoveries in SFE (16). Although numerous modifiers with different chemical characteristics have been employed in SFE, choice of a modifier for an application has 
been highly empirical. The choice of modifier is highly matrix dependent, and the characteristics of the analyte have a pronounced effect on the efficiency of modifiers.

In this study, 1,2,4-trichlorobenzene (TCB) was spiked onto the Toxi-dry. It is believed that results obtained from recently spiked samples cannot be used to predict the behavior of aged samples, especially not for heterogeneous environmental samples (5). Adsorption and desorption of contaminants from a specific matrix can give insight in verifying validation of the spiking method. Cornelissen et al. determined desorption kinetics for 1,2,4-trichlorobenzenze in sediment at various concentrations (17). They also studied how a large amount of freshly added 1,2,4-trichlorobenzene affects the desorption behavior of field-aged chemicals (PCBs and HCB), and found that the freshly added compounds were able to compete with aged ones for active adsorption sites in matrix. The authors stated that several weeks of incubation are sufficient for solutes to reach slow sorption sites. They demonstrated that the longer a spiked organic chemical was allowed to interact with the matrix, the stronger the absorption became (18).

The effect of the solid matrix on extraction of PCBs is still not understood on a fundamental basis. While organic content of the matrix has been frequently implicated as a major factor affecting desorption of organic pollutants, other matrix characteristics, such as type of organic matter and particle size, also need to be considered (12). This question is particularly critical for D\&D operations within DOE, because the physical chemistry of PCB absorption will be markedly different in the types of matrices important to SRS and the rest of the DOE weapons complex (absorbents, fibers, concrete, paint, and metal). In the current investigation, our focus has been on a particular matrix, Toxi-dry, identified by Savannah River Site (SRS) collaborators. The matrix is a porous, lipophilic, plant-based material that is used to absorb spills, wash solutions, and solvent solutions generated during D\&D activities. There have been no studies on PCB extraction from this commonly used absorbent, and clearly the characteristics of this lipophilic organic matrix are quite different from soils and sediments that have been widely studied. Because the effects of solid matrix, cosolvent, temperature, and pressure are still not understood in a fundamental level, and phase equilibrium and mass transfer rate are usually not available in SFE process, experimental SFE data are indispensable for process design. 


\section{METHODOLOGY}

Materials

For these preliminary laboratory studies, 1,2,4-trichlorobenzene (TCB) is the chosen surrogate for PCBs. Chlorobenzenes are found on many lists of priority pollutants, and are present in significant amounts in the environment.

Toxi-dry absorbent was obtained from Mt. Pulaski Products, and was used without further treatment. The product specifications are: Crude fiber (34\%), NitrogenFree-Extraction (55\%), moisture (8\%), and protein (3\%). Its solubility in water is $9 \%$, and in alcohol is 5.6\%. The 1,2,4-trichlorobenzene (purity $>99 \%$ ) and acetone (purity $>99.8 \%$ ) were obtained from Fluka. Ethanol (purity $>99.6 \%$ ) was obtained from Sigma. SFE grade $\mathrm{CO}_{2}$ (purity $>99.99 \%$ ) was obtained from Air Products.

\section{Spiked Samples}

A spiked sample can be useful in developing a preliminary SFE method for complex environmental samples. Because of the difficulty in working with radioactive PCB-contaminated waste, and because of strict EPA regulations in handling MLLW, we spiked 1,2,4-trichlorobenzene into clean Toxi-dry matrix, and extracted these samples. In the spiking procedure, $0.1 \mathrm{~g}$ of 1,2,4-trichlorobenzene and $500 \mathrm{ml}$ acetone were added to a $1 \mathrm{~L}$ beaker with a magnetic stirrer and mixed vigorously. $42.5 \mathrm{~g}$ of Toxi-dry absorbent was added to the beaker to form a slurry. Stirring was continued for $12 \mathrm{~h}$ to give an even loading. The mixture was placed in a fume hood for two days to evaporate acetone. The spiked Toxi-dry was stored in sealed bottles for at least two weeks before extraction. No water was loaded into the samples during extraction.

\section{Supercritical Fluid Extraction}

Figure 1 gives a schematic of the ISCO supercritical $\mathrm{CO}_{2}$ extraction system. An ISCO 260D pump was used as the $\mathrm{CO}_{2}$ pump to provide liquid $\mathrm{CO}_{2}$ and control the system pressure. One gram $(1 \mathrm{~g})$ sample were packed into a $10-\mathrm{ml}$ extraction cell. Membrane filters (five micron) were placed at each end inside the cell to prevent small particles from reaching the capillary-tube restrictor. After the extraction cell was placed in the extractor, the temperature was set using the temperature controller of the extractor. The outlet valve of the syringe pump was then opened. Pure or cosolvent-modified $\mathrm{CO}_{2}$ passed through the preheater, where it was heated up to the extraction temperature before flowing to the extraction cell. Static pressure was maintained for 20 minutes, after which the outlet valve was opened and dynamic extraction was conducted. To collect the TCB extract, we used solvent trapping with chilled acetone as the solvent. The TCBimpregnated Toxi-dry samples were extracted for 2 hours. Flow rates were controlled by an ISCO integral restrictor. The experimental pressures were 2,000, 4,000 or 6,000 psia, and the temperature was either $40{ }^{\circ} \mathrm{C}$ or $80{ }^{\circ} \mathrm{C}$. 


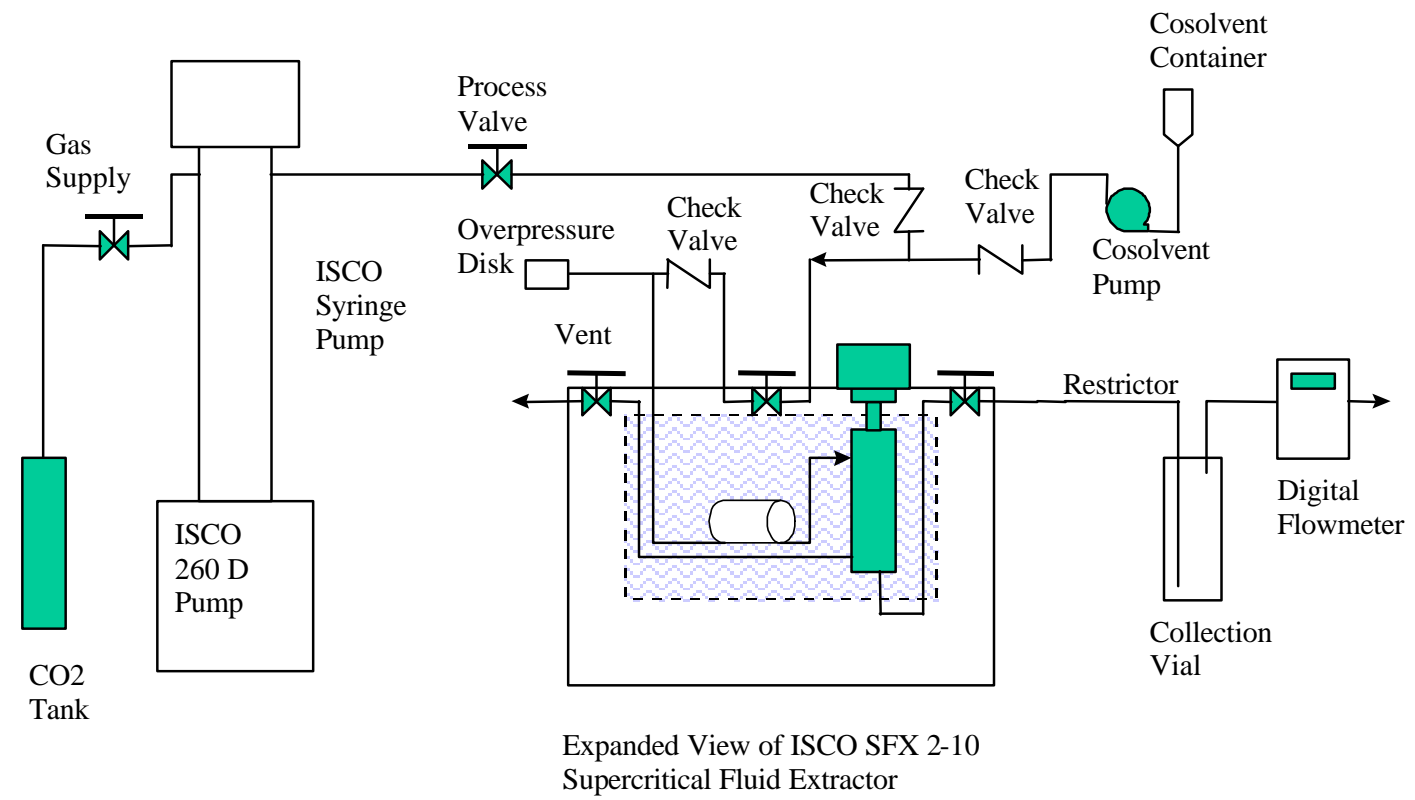

Figure 1. Schematic of extraction apparatus

Since $1 \mathrm{ml} / \mathrm{min}$ of supercritical $\mathrm{CO}_{2}$ extractant at extraction conditions can expand to $500 \mathrm{ml} / \mathrm{min}$ of gaseous $\mathrm{CO}_{2}$ during sample collection, volatile and semi-volatile organics extracted can easily be lost during the collection step while the depressurized fluids pass through collection solvent at high flow-rate. It is clear the more volatile the chlorinated benzene is, the more likely it was lost during collection. For example, Sweetman et al. (1) indicated that chlorobenzenes were partially lost during transfer from the vaporizing carbon dioxide as it bubbled through the hexane. We cooled the collection vial to $3^{0} \mathrm{C}$, and extracted the TCB samples for 2 hours under a low flowrate of $\mathrm{CO}_{2}(0.2-$ $0.3 \mathrm{ml}$ liquid $\mathrm{CO}_{2}$ per minute.) to reduce the loss of TCB from the collection solvent during extraction.

In this work, both acetone and ethanol were used as the cosolvents at approximately 5 weight percent. There are three common ways to introduce the cosolvents: using a cosolvent pump; using pre-mixed fluids from a cylinder; and directly spiking cosolvent on the matrix before extraction. In this study cosolvent was introduced with an Eldex Metering pump (Model A-30 -VS) and was mixed with $\mathrm{CO}_{2}$ before the preheater. Thus the sample was continuously extracted by the cosolvent-modified $\mathrm{CO}_{2}$ of constant composition. The extraction results with modified solvent are compared with SFE results using pure $\mathrm{CO}_{2}$.

\section{Soxhlet Extraction and Sonication}

Soxhlet extraction was used to quantify the amount of TCB on Toxi-dry both before and after $\mathrm{CO}_{2}$ extraction. For the purpose of defining an "extraction efficiency," it is assumed that Soxhlet extraction removes $100 \%$ of the impregnated 1,2,4 TCB. The 
amount of TCB extracted by supercritical $\mathrm{CO}_{2}$, or $\mathrm{CO}_{2}+$ co-solvent, was then compared to the amount removed by Soxhlet extraction. For all Soxhlet extractions, about $5 \mathrm{~g}$ of sample were weighed into a cellulose extraction thimble, and the sample was extracted with $150 \mathrm{ml}$ of acetone for $24 \mathrm{~h}$. After the extraction was completed, the solvent was evaporated to a volume of $10 \mathrm{ml}$ for gas chromatographic analysis. Sonication is another traditional analytical technique in environmental sample analysis. In addition to Soxhlet extraction, some samples of TCB spiked Toxi-dry were extracted using sonication in acetone. This gave a second method to verify SFE recoveries. For sonication, the SFE residues were mixed with $15 \mathrm{ml}$ acetone in a 30-ml vial, and sonicated for $12 \mathrm{~h}$.

\section{Gas Chromatographic Analysis}

Gas chromatography coupled with flame ionization (FID), electron capture (ECD), or multiple ion detection-mass spectrometer (MID-MS) has been used to analyze trace TCB in environmental samples (14). For this work, an HP model 5890 series II GC (Hewlett-Packard, Palto Alto, CA) with FID was used for analyzing the extracted fractions. The GC column was an AT-1 from Alltech (Deerfield IL). A 1- $\mu \mathrm{L}$ sample was injected at an oven temperature of $70^{\circ} \mathrm{C}$ (held for $1 \mathrm{~min}$ ) followed by temperature programming to $200{ }^{\circ} \mathrm{C}$ with a rate of $15{ }^{\circ} \mathrm{C} / \mathrm{min}$. Quantitations were based on an eightpoint linear calibration curve from gravimetrically prepared standards. Pure 1,2,4trichlorobenzene was used for the calibration standards. Identification of analytes was based on comparison of retention times with those obtained from standard solutions. 


\section{RESULTS AND DISCUSSION}

Table 1 gives representative results for extraction of spiked Toxi-dry with pure $\mathrm{CO}_{2}, \mathrm{CO}_{2}+5$ weight percent acetone, and $\mathrm{CO}_{2}+5$ weight percent ethanol. All extractions lasted two hours. The metric is the percentage recovery of TCB from the Toxi-dry matrix, where $100 \%$ recovery is defined by 24 hour Soxhlet extraction using acetone. Table 1 shows how the TCB extraction efficiency changes with temperature, pressure and cosolvent. These results will be graphed and discussed in the following sections.

\begin{tabular}{|c|c|c|c|}
\hline P (psia) & Cosolvent & Extraction Time (min) & \% TCB Recovered \\
\hline 2000 & 0 & 120 & 33 \\
\hline 4000 & 0 & 120 & 31 \\
\hline 6000 & 0 & 120 & 42 \\
\hline 2000 & 0 & 120 & 60 \\
\hline 4000 & 0 & 120 & 75.6 \\
\hline 6000 & 0 & 120 & 96.3 \\
\hline 2000 & $5 \%$ acetone & 120 & 56.1 \\
\hline 4000 & $5 \%$ acetone & 120 & 58.3 \\
\hline 6000 & $5 \%$ acetone & 120 & 61.6 \\
\hline 2000 & $5 \%$ acetone & 120 & 96.3 \\
\hline 4000 & $5 \%$ acetone & 120 & 100.4 \\
\hline 2000 & $5 \%$ ethanol & 120 & 94.7 \\
\hline 4000 & $5 \%$ ethanol & 120 & 109.7 \\
\hline
\end{tabular}

Table 1 Representative Results for Extraction of TCB

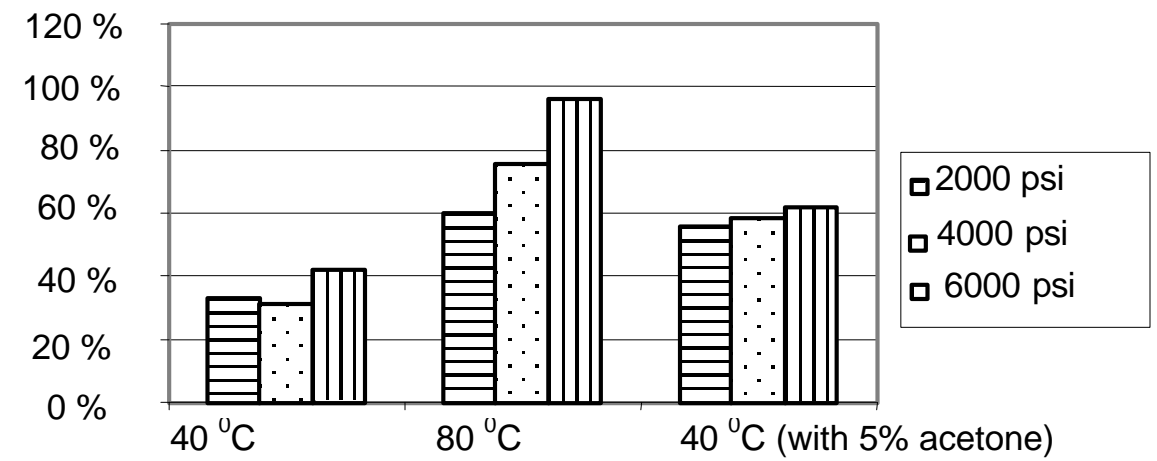

Figure 2. Pressure effect on SFE Efficiency of TCB from Toxi-dry

Figure 2 highlights the effect of pressure on TCB recovery at different conditions. Increasing pressure at $40{ }^{\circ} \mathrm{C}$ was found to have only a small effect on recovery, regardless of whether cosolvent was used. For pure $\mathrm{CO}_{2}$ extraction at $80{ }^{\circ} \mathrm{C}$, in contrast, the extraction yield increased significantly when extraction pressure was increased. At $40{ }^{\circ} \mathrm{C}$, 
increasing the pressure from 2,000 psi to 6,000 psi increases the density of pure $\mathrm{CO}_{2}$ from $0.771 \mathrm{~g} / \mathrm{ml}$ to $0.978 \mathrm{~g} / \mathrm{ml}$. At $80{ }^{0} \mathrm{C}$, the same pressure change increases the density from $0.413 \mathrm{~g} / \mathrm{ml}$ to $0.861 \mathrm{~g} / \mathrm{ml}$ (19). It is a common observation that the logarithm of the solubility is linearly dependent on the density or the log of the density of the supercritical fluid. Increasing solubility favors the partitioning of TCB molecules from the internal sites in the matrix into the bulk supercritical fluid. If the extraction efficiency were only controlled by solubility, one would expect the extraction efficiency increase noticeably both at $40{ }^{\circ} \mathrm{C}$ and at $80{ }^{\circ} \mathrm{C}$. This is clearly not the case, as shown in Figure 2 . Therefore we conclude that there are other factors besides solubility of TCB that control the extraction process. A possible explanation for this observation is that after two weeks storage of spiked samples, the majority of TCB molecules diffuse into the interior of the Toxi-dry, and were adsorbed at the internal matrix surface. Therefore, kinetic factors, such as the desorption rate of the TCB molecules from the internal matrix surface and diffusion rate through the porous matrix, could control factors of the extraction process, In this scenario enhancing the solubility of TCB in the bulk supercritical fluid is not sufficient to yield high extraction efficiencies. It is possible that at $80{ }^{\circ} \mathrm{C}$, the majority of TCB molecules exists as a separate phase within the matrix, and could be removed by simple dissolution, so the desorption control was weak, and pressure/density effect was clear. Figure 2 also illustrates that acetone improves the TCB recovery at $40{ }^{\circ} \mathrm{C}$ compared to using pure $\mathrm{CO}_{2}$ solvent. Again, though, the effect of pressure on the recovery using the mixed solvent is small. The cosolvent effect will be discussed in more detail subsequently.

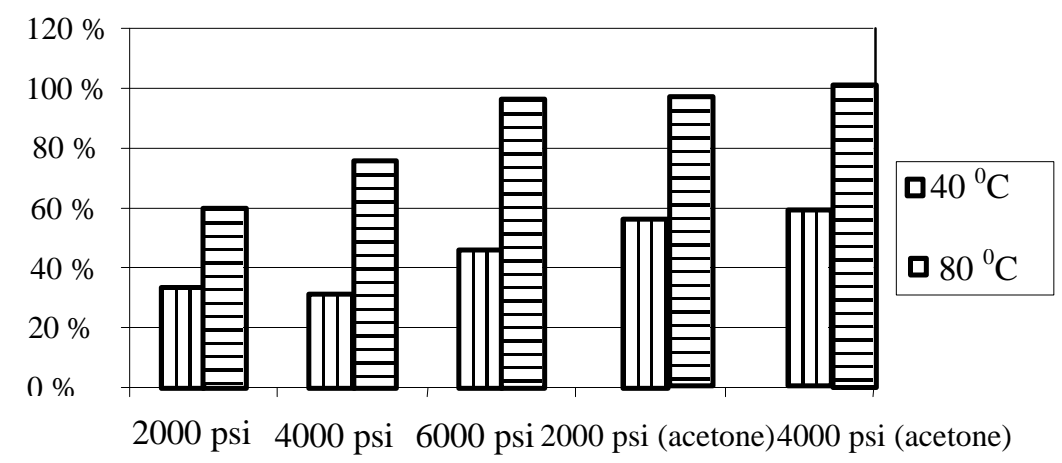

Figure 3. Temperature effect on SFE of TCB

From Figure 3 it is clear that the recoveries of TCB from the Toxi-dry samples are greatly affected by the extraction temperature. Increasing temperature from $40{ }^{\circ} \mathrm{C}$ to 80 ${ }^{0} \mathrm{C}$ at the same pressure increased the extraction efficiency about 30 to 40 percent. As previously noted, the extraction temperature affects the solute vapor pressure, solvent density, and desorption of solute molecules from matrix surface (20). At constant pressure, increasing temperature will increase solute vapor pressure and decrease density of $\mathrm{CO}_{2}$. For example, at $25 \mathrm{MPa}$, for a temperature increase from $40{ }^{\circ} \mathrm{C}$ to $80{ }^{\circ} \mathrm{C}$, the vapor pressure of 1,2,4-trichlorobenzene changes from 102.4 to $1038 \mathrm{~Pa}$, while the density of $\mathrm{CO}_{2}$ decreases from 0.880 to $0.687 \mathrm{~g} / \mathrm{ml}$. The solubility of TCB in $\mathrm{CO}_{2}$ is 
dependent on its vapor pressure and density of $\mathrm{CO}_{2}$. The solute vapor pressure increases significantly, and the density decrease of supercritical fluid is relatively small, so the positive effect of temperature is clear. Besides the thermodynamic considerations mentioned above, extraction temperature also affects extraction process kinetically. According to Dupeyron et al. (21), temperature enhances the diffusion coefficients and reduces solvent viscosity and interfacial tensions. These two effects allow better penetration of the solvent into the matrix, and result in faster mass transfer. Sweetman et al. also found that increasing temperature appeared to increase the recoveries of chlorinated benzenes in some cases (1).

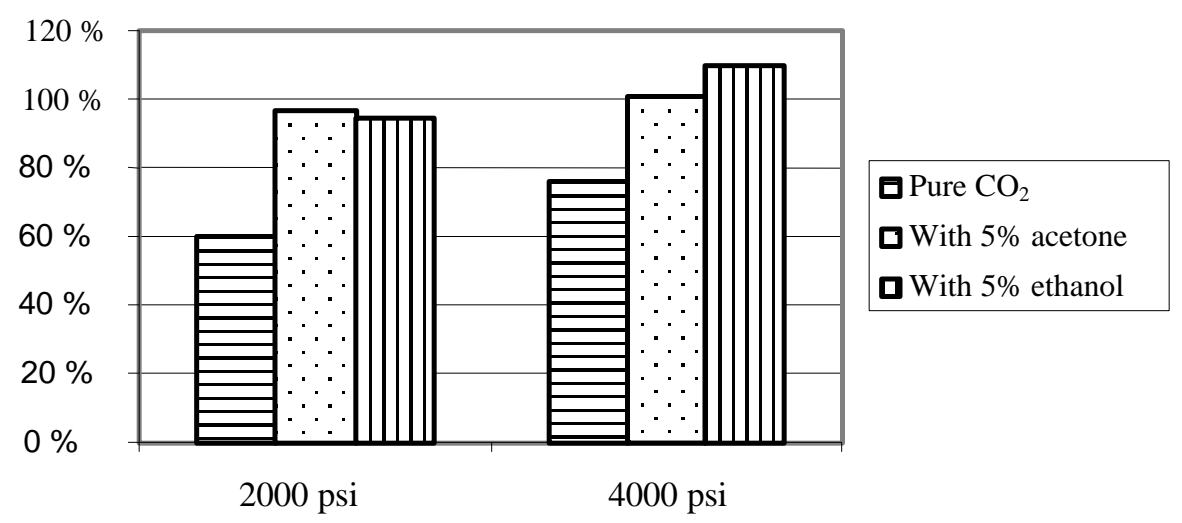

Figure 4. Cosolvent effect on SFE of TCB at $80{ }^{\circ} \mathrm{C}$

Figure 4 illustrates that the efficiency of TCB extraction from Toxi-dry absorbent is improved with the addition of a small amount of acetone or ethanol as cosolvent. At $80^{\circ} \mathrm{C}$, TCB recoveries in excess of $90 \%$ and approaching $100 \%$ (within experimental uncertainty) are obtained at pressures as low as 2000 psi. This is a significant benefit because both capital costs and operating costs will be substantially lower if the extraction process can be operated at lower pressures. Based on these results, the most favorable extraction condition should is $80{ }^{\circ} \mathrm{C}, 2,000$ psi and $5 \%$ ethanol as cosolvent.

Acetone is a polar organic cosolvent and a hydrogen bond acceptor, and ethanol is a self-associating polar organic cosolvent. Both of them are capable of strong intermolecular interaction with the solute. Of the two cosolvent investigated, ethanol is the DOE preferred cosolvent, because DOE does not place health or safety restrictions on use of ethanol as a process solvent (unlike acetone, methanol, or other common cosolvents). Jeong and Chesney also indicated that ethanol, though not as polar as methanol, could be a better choice because of its low toxicity (22). Therefore, it would be much simpler, faster, and less expensive from a permitting standpoint to use ethanol as cosolvent. In addition, according to the phase equilibrium data provided by Chang et al. (23), the mixed solvent, acetone $+\mathrm{CO}_{2}$ or ethanol $+\mathrm{CO}_{2}$, will be totally miscible under the extraction conditions.

The mechanism of cosolvent-analyte-matrix interaction is a key point to understand the effect of pressure, temperature and cosolvent on SFE. Although different potential interactions including dipole interactions, hydrogen-bonding interaction, dispersion interactions and different modifier properties such as polarizablity, acidity/basicity and 
dipole moment have been considered in previous studies, there is still insufficient information for drawing a general conclusion. In this investigation, the organic matrix, Toxi-dry, has not previously been extracted with supercritical $\mathrm{CO}_{2}$. The large solubility of Toxi-dry in solvent (Toxi-dry is 5.6\% soluble in alcohol) makes the situation even more complicated. The color of the collection solvent after extraction is pale yellow, which indicates that components of Toxi-dry are dissolved and extracted during SFE. Amador-Hernandez pointed out that the appropriate cosolvent increases the effective polarity of the supercritical fluids, which increases the bulk solubility of solutes and results in favorable partitioning into the supercritical fluid (24). The second effect occurs due to the wetting properties of a solvent causing more intimate solvent/solute contact. Moreover, it was believed that cosolvents could interact with the analyte/matrix complex and lower the activation energy barrier of desorption (15). 


\section{CONCLUSION}

This work explores the optimal conditions for supercritical fluid extraction of chlorinated aromatics from DOE Job Control Wastes. In this preliminary study, 1,2,4trichlorobenzene (TCB) was used as a surrogate for PCBs in spiked Toxi-dry samples. Spiked Toxi-dry samples were extracted with pure supercritical carbon dioxide and modified supercritical carbon dioxide (with 5 wt \% acetone or ethanol), and the efficiency of SFE was compared with Soxhlet extraction and sonication. The extraction results indicate that the supercritical fluid extraction of TCB from Toxi-dry is controlled primarily by kinetic factors. The effects of temperature, pressure and cosolvent on extraction efficiency were studied. It was found that increasing temperature from $40{ }^{0} \mathrm{C}$ to $80{ }^{\circ} \mathrm{C}$ greatly improved the recoveries of TCB. Increasing pressure at $80{ }^{\circ} \mathrm{C}$ increased TCB recoveries, while increasing pressure did not have clear effect on TCB recoveries at $40{ }^{0} \mathrm{C}$. Addition of $5 \mathrm{wt} \%$ cosolvent also substantially improved the efficiency of SFE of TCB. Based on these results as well as safety and environmental regulations at DOE sites, ethanol is the preferred cosolvent for extraction of chlorinated organics from solid job control wastes. 


\section{ACKNOWLEDGEMENT}

This study was supported by the U.S. DOE (EMSP Project \#64979-SC). The authors thank Mark C. Thies and David A. Bruce (Clemson University) for providing the reference material Toxi-dry and constructive comments during the research. 


\section{REFERENCES:}

1. Sweetman, A.J.; Watts, C.D. Development of a Supercritical Fluid Extraction Method for PCBs and Chlorobenzenes from Soils and Sludge-Amended Soils. Environ. Technol. 1995, 16 (1), 73-80.

2. Madras, G.; Erkey C.; Akgerman, A. Supercritical Extraction of Organic Contaminants from Soil Combined Adsorptiom onto Activated Carbon. Environmental Progress 1994, 13, 45-48.

3. Vandervelde, E.G.; Dehaan, W.; Liem, A.K.D. Supercritical Fluid Extraction of Polychlorinated-biphenyls and Pesticides from Soil-Comparison with other Extraction Methods. J. Chromatogr. 1992, 626 (1), 135-143.

4. Berg, B.E.; Lund, H.S.; Kringstad, A.; Kvernheim, A.L. Routine Analysis of Hydrocarbons, PCB and PAH in Marine Sediments Using Supercritical $\mathrm{CO}_{2}$ Extraction. Chemosphere 1999, 38 (3), 587-599.

5. Bjorklund, E.; Nilsson, T.; Bowadt, S.; Pilorz, K.; Mathiasson, L.; Hawthorne, S.B. Introducing Selective Supercritical Fluid Extraction as a New Tool for Determining Sorption/desorption Behavior and Bioavailability of Persistent Organic Pollutants in Sediments. J Biochem. Biophys. Methods 2000, 43, 295311.

6. Abrha, Y.; Raghavan, D. Polychlorinated Biphenyl (PCB) Recovery from Spiked Organic Matrix Using Accelerated Solvent Extraction and Soxhlet Extraction. J. Hazardous Materials 2000, B80, 147-157.

7. Bowadt, S.; Johansson, B.; Wunderli, S.; Zennegg, M.; Dealencastro, L.F.; Grandjean, D. Independent Comparison of Soxhlet and Supercritical Fluid Extraction for the Determination of PCBs in an Industrial Soil. Anal. Chem. 1995, 67 (14), 2424-2430.

8. McHugh, M.; Krukonis, V. Supercritical Fluid Extraction. Butterworth Publishers, Stoneham, MA 1986

9. Langenfeld, J.J.; Hawthorne, S.B.; Miller, D.J.; Pawlisz, N.J. Role of Modifiers for Analytical-scale Supercritical Fluid Extraction of Environmental Samples. Anal. Chem. 1994, 66 (4), 909-916 .

10. Sahle-Demessis, E.; Richardson, T. Cleaning-up Pesticide Contaminated Soils: Comparing Effectiveness of Supercritical Fluid Extraction with Solvent Extraction and Low Temperature Thermal Desorption. Environmental Tech. 2000, 21, 447-456.

11. Hawthorne, S.B.; Miller, D.J.; Burford, M.D.; Langenfeld, J.J.; Eckert-Tilotta, S.; Louie, P.K. Factors Controlling Quantitative Supercritical Fluid Extraction of Environmental Samples. J. Chromatography 1993, 642, 301-317.

12. Bjorklund, E.; Bowadt, S.; Mathiasson, L.; Hawthorne, S.B. Determining PCB Sorption Desorption Behavior on Sediments Using Selective Supercritical Fluid Extraction. 1. Desorption from Historically Contaminated Samples. Environ. Sci. Technol. 1999, 33 (13), 2193-2203.

13. Laitinen, A.; Michaux, A.; Aaltonen, O. Soil Cleaning by Carbon Dioxide Extraction: A Review. Environ. Tech. 1994, 15, 715-727. 
14. Reutergardh, L.B.; Parkpian, P.; Chaiyaraksa, C. Supercritical Fluid Extraction of Planar and Mono-ortho PCB in Selected Tropical Soils. Chemosphere 1998, 36 (7), 1565-1573.

15. Langenfeld, J.J.; Hawthorne, S.B.; Miller, D.J.; Pawlisz, N.J. Effects of Temperature and Pressure on Supercritical Fluid Extraction Efficiencies of Polycyclic Aromatic-hydrocarbons and Polychlorinated-biphenyls Anal. Chem. 1993, 65 (4) 338-344.

16. Abaroudi, K.; Trabelsi, F.; Recasens, F. Mass Transport Enhancement in Modified Supercritical Fluid. Ind. Eng. Chem. Res., 1999, 38, 3505

17. Cornelissen, G.; van der Pal, M.; van Noort, P.; Govers, H.A.J. Competitive Effects on the Slow Desorption of Organic Compounds from Sediments. Chemosphere 1999, 39, 1971-1981.

18. Cornelissen, G.; Rigterink, H.; van Norrt, P.C.M.; Govers, H.A.J. Slowly and Very Slowly Desorbing Organic Compounds in Sediments Exhibit Langmuir Sorption , Environmental Toxicology and Chemistry 2000, 19, 1532

19. Span, R.; Wagner, W. A New Equation of State for Carbon Dioxide Covering the Fluid Region from the Triple-Point Temperature to $1100 \mathrm{~K}$ at Pressure up to 800 Mpa J. Phys. Chem. Ref. Data, 1996, 25, 1509-1596

20. Langenfeld, J.J.; Hawthorne, S.B.; Miller, D.J.; Pawlisz, N.J. Effects of Temperature and Pressure on Supercritical Fluid Extraction Efficiencies of Polycyclic Aromatic-hydrocarbons and Polychlorinated-biphenyls Anal. Chem. 1993, 65 (4) 338-344.

21. Dupeyron, S.; Dudermei, P.; Couturier, D.; Guarini, P.; Delatter, J. Extraction of Polycyclic Aromatic Hydrocarbons from Soils: A Comparison Between Focused Microwave Assisted Extraction, Supercritical Fluid Extraction, Subcritical Fluid Extraction, Sonication and Soxhlet Techniques. Intern. J. Environ Anal. Chem. 1999, 73(3), 191-210.

22. Jeong, M.L.; Chesney, D.J. Investigation of Modifier Effects in Supercritical $\mathrm{CO}_{2}$ Extraction from Various Solid Matrices. J. Supercritical Fluids 1999, 16, 33-42.

23. Chang, C.J.; Day, C.Y.; Chen, C.Y. Vapor-liquid Equilibria and Correlation of Ethanol $+\mathrm{CO}_{2}$ and Acetone $+\mathrm{CO}_{2}$ at Elevated Pressure, J. The Chin. I. Ch. E., 1996, 27, 243-249.

24. Amador-Hernandez, J.; Luque De Castro, M.D. On-line Detection for Supercritical Fluid Extraction. J. Biochem. Biophys. Methods 2000, 43, 329-343. 
Appendix 2.

\title{
ECONOMIC ANALYSIS OF SUPERCRITICAL TECHNOLOGY FOR EXTRACTION AND DESTRUCTION OF PCBS FROM DOE JOB-CONTROL- WASTES
}

\author{
Halle McWilliams, Jun Li, Michael A. Matthews
}

\begin{abstract}
An economic analysis of PCB remediation options was undertaken in the spring semester, 2001 in ENGR 540: Environmentally Conscious Manufacturing taught by Dr. Michael Matthews at the University of South Carolina.1 The focus of this economic analysis was to compare, on an environmental and economic basis, several methods of PCB disposal. A life cycle assessment (LCA) was performed on six different technical options that have been proposed for management and disposal of PCB wastes: (1) on-site long-term storage, (2) permanent storage at the Waste Isolation Pilot Plant, (3) incineration of entire waste at the TSCA incinerator, supercritical carbon dioxide (SC-CO2) extraction followed by either:
\end{abstract}

(4) incineration of small volume of PCB extract at TSCA incinerator, or

(5) chlorine removal by metallic sodium (Safety Kleen method), or

(6) supercritical water oxidation (SCWO) of PCB extract.

The first step in performing a LCA is setting the boundaries of the processes to be studied. The boundaries were set to begin with the drums of PCB wastes contained at the DOE sites and end with the options stated above for managing and/or disposing of the PCB wastes. Refer to Figures 13.1, 13.2, and 13.3, and 13.4 at the end of this chapter for the process diagrams and boundaries of Options \#3, \#4, \#5, and \#6. The second step of a LCA is a life cycle inventory (LCI), which is a quantitative account of the inputs and outputs of the process within the set boundaries. In this case, the LCI is the quantity of PCB waste contained at the DOE complexes.

The authors of this analysis were Paul Rogerson, a senior engineering student, Chapel Leadingham and Halle McWilliams, both graduate students in the School of the Environment. At the time of this analysis, the volume of waste was obtained from a 1998 report entitled "Decontamination and Decommissioning of PCB Sites at DOE: Extraction, Electrokinetics, and Hydrothermal Oxidation." The report stated that there are approximately $19,000 \mathrm{~m}^{3}$ of PCB waste stored at the DOE sites across the country. Life Cycle Impact Assessment (LCIA) is the third step of a LCA. In this step, the effects of the inputs and outputs on human health, health of ecosystems, and the overall environment must be determined. The effects of PCBs on human health, ecosystems, and the environment have been studied for quite some time. PCBs range from medium to high toxicity, depending on the congener. Furthermore, they are probable human carcinogens. Exposure to PCBs causes skin and eye irritation, adverse reproductive and developmental effects, neurobehavioral impairment, and liver damage. Federal laws require that PCBs be destroyed, therefore eliminating the need for further environmental impact assessment.

Because the first three steps are well defined, the focus of this analysis was on the last step of LCA, which is improvement analysis. An improvement analysis helps determine which of the six options is the most economically and environmentally sound for managing and/or disposing of the PCB wastes at the DOE facilities. 
Due to regulatory restrictions, on-site long-term storage (Option \#1) is neither neither a viable nor a legal option for dealing with the PCB wastes. The Toxic Substance Control Act (TSCA) prohibits indefinite storage of PCB wastes that are greater than 50 parts per million. TSCA requires that the PCB wastes must be disposed of within one year from the date that the PCBs first became a waste. DOE facilities have continually circumvented this requirement by applying for and receiving storage extensions. They have received these extensions mainly due to the lack of any permanent disposal methods for the waste (Lowry, 1999; USDOE, 1999). Option \#2 is permanent storage of the PCB waste at the Waste Isolation Pilot Plant (WIPP) in New Mexico. After researching the charter for WIPP, it was determined that it is not a legal option for permanent storage of the PCB waste. This is because WIPP is currently only accepting transuranic waste (WIPP Information Center, 2000).

Option \#3 is incineration of the entire 19,000m3 of the PCB waste at the DOE facilities. Refer to Figure 6.1 for the process diagram of Option \#3. This option gives rise to several economic and regulatory ramifications. The economics of incineration are based on data obtained from the U.S. Army Corps of Engineers' (USACE) "Report on Treatment, Storage, and Disposal Facilities for Hazardous, Toxic, and Radioactive Waste" (1998). There are two major costs: transport of waste to TSCA incinerator and cost of actual incineration process. Several broad assumptions were made for the calculations. It was assumed for transportation cost purposes that half of the waste $(9,500 \mathrm{~m} 3)$ is contained at the Savannah River Site in Aiken, South Carolina and the other half of the waste $(9,500 \mathrm{~m} 3)$ is evenly distributed among the other DOE facilities across the United States. It was also assumed that the data provided by the Army Corps of Engineers is applicable to the PCB wastes at DOE sites.

As mentioned above, there are approximately $19,000 \mathrm{~m}^{3}$ of PCB wastes within the DOE complex, which relates to about 91,250 55-gallon drums of waste. It is approximately 290 miles from SRS in Aiken, SC to the TSCA Oakridge Incinerator K-25 in Oakridge, TN. The mileage from four other DOE sites (Pacific Northwest in Richland, WA; Naval Petroleum Reserves in Bakersfield, CA; Niagara Falls Storage Site in Niagara Falls, NY; and Pinella Area Production Facility in Clearwater, FL) was averaged to obtain the approximate distance that the other half of the waste would have to be transported. The average distance from these sites to the TSCA Oakridge Incinerator is 1,400 miles. The average cost of loading and unloading waste is $\$ 60$ per hour and the average cost of transport is $\$ 2.38$ per mile. Assuming it would take approximately 8 hours total to load and unload the waste from the transport truck, it would cost $\$ 480$ per trip for loading/unloading. The assumption was made that 80 drums of waste could be transported in one trip, and thus, 1,140 trips would be required to transport all waste. Therefore, the load/unload costs are approximately $\$ 547,200$ and the transport cost from SRS and the other DOE facilities to the Oakridge Incinerator is $\$ 2.3$ million. The total transport cost for all waste is $\$ 2.8$ million. However, this calculation does not include the costs of manifesting the waste in accordance with the transportation regulations.

The cost of total waste incineration was also calculated using the data provided by the Army Corps of Engineers. The costs of waste incineration are on average \$173 per 55-gallon drum of solid waste, and $\$ 106$ per 55-gallon drum of hazardous liquid waste. Therefore, by averaging these costs and multiplying by the number of drums of waste, the total incineration cost would be $\$ 12.8$ million. However, it is recognized that this value may be an underestimate for incineration due to the fact that PCBs must be incinerated at very high temperatures (USACE, 1998). Thus, the total cost of transport and incineration of the entire PCB waste 
volume contained in the DOE complex would be at least $\$ 15.6$ million. A potential drawback in relying on incineration is the pending closure in 2003 of the K-25 TSCA Incinerator at the Oak Ridge Reservation in Oak Ridge, Tennessee.

The regulations governing both the transport and incineration of PCB waste, whether solid or liquid, are contained in the Hazardous Materials Transportation Act (HMTA), the Toxic Substances Control Act (TSCA), the Resource Conservation and Recovery Act (RCRA), and the Atomic Energy Act (AEA). The main regulation in South Carolina that addresses the transportation of radioactive wastes is SC Regulation 61-83 "Transportation of Radioactive Waste Into or Within South Carolina." This regulation applies to any shipper, carrier, or other person who transports radioactive waste, to any persons involved in the generation of radioactive waste, and to any shipper whose waste is delivered, stored, or disposed of within S.C. In addition, this regulation requires compliance with SC Regulation 61-63, 49 CFR parts 171-179, 48 CFR part 970, 49 CFR parts 386-399, and 10 CFR part 71. These regulations specifically address the license requirements for the packaging, transportation, disposal, storage and delivery of radioactive materials. It is assumed that since the hazardous waste that contains PCBs was generated at DOE sites, at least a portion of the waste is radioactive. SC Regulation 61-83 contains the following forms that must be filled out when waste is transported:

Form RHA-200P “Application for Radioactive Waste Transport Permit”;

Form RHA-PNC “Radioactive Waste Shipment Prior Notification and Manifest Form”; and

\section{Form RHA-CT "Radioactive Waste Shipment Certification Form."}

Along with the permit, a fee must be paid to the Bureau of Radiological Health of DHEC. In addition, the transporter must provide proof of liability insurance coverage of $\$ 500,000$ per occurrence and $\$ 1,000,000$ aggregate. The liability insurance must be specific to the packaging, transportation, disposal, storage, and delivery of the waste. Any person who commits a radiological violation will, on the first occurrence, be fined not less than $\$ 1,000$ nor more than $\$ 5,000$ and will have his permit suspended for a period of not less than thirty days. Provisions are enumerated in this regulation for additional violations.

The Department of Transportation regulations that address packaging and container criteria are contained in 49 CFR parts 171-179. This federal regulation deals with hazardous waste and the provisions in the event of a hazardous materials incident. Included is the transportation of hazardous materials in interstate, intrastate, and foreign commerce by rail car, aircraft, motor vehicle, and vessel. "DOE Management and Operating Contracts," 48 CFR part 970, addresses those transport companies with which DOE can contract for transport of the hazardous waste. Furthermore, 49 CFR part 385, "Safety Fitness Procedures," prohibits any carrier of hazardous waste who has received an "unsatisfactory" rating from the Federal Motor Carrier Safety Administration (Department of Transportation) from being eligible to apply for federal contracts.

The above regulations, which are part of the Hazardous Materials Transportation Act (HMTA), "are rationally related to policy of developing acceptable levels of public safety for each mode of transportation [and] provide[s] adequate protection against the risks to life and property inherent in the transportation of hazardous material in commerce by improving the regulatory and enforcement authority of the Secretary of Transportation" (49 CFR part 5101). 
The Toxic Substances Control Act (40 CFR part 761.61) states, "Bulk PCB remediation waste may be sent off-site for decontamination or disposal...provided the waste is either dewatered on site or transported off-site in containers meeting the requirements of the DOT Hazardous Materials Regulations." Consequently, this regulation allows for the shipment of PCB wastes off-site for disposal. The Atomic Energy Act (AEA) was enacted to address the financial consequences in the event there is an accident in the realm of the development of nuclear energy. This covers any public liability claims due to damage of property or risk to human health. In accordance with this act the limit of liability is $\$ 500,000,000$ and excludes the costs of investigating, settling claims, and defending lawsuits for damage. Theoretically, if there is a problem with the transportation of the PCB wastes that are considered radioactive, a person may be able to file suit against DOE under the Atomic Energy Act.

The Toxic Substance Control Act (TSCA) and the Resource Conservation and Recovery Act (RCRA) are the two primary regulations that regulate the incineration of PCB wastes. The following are the TSCA requirements for incineration of liquid and non-liquid PCBs:

PCB liquids introduced to incinerator must be maintained at a 2-second dwell time at $1200 \mathrm{oC}$ and $3 \%$ oxygen in the stack gas or a 1.5 -second dwell time at $1600 \mathrm{oC}$ and $2 \%$ oxygen;

Combustion efficiency must be at least $99.9999 \%$;

The rate and quantity of PCBs that are fed into incinerator must be measured and recorded at least every 15 minutes;

The temperature of the incinerator must be continually measured and recorded;

Stack emissions must be tested and monitored for oxygen, $\mathrm{CO}, \mathrm{NOx}, \mathrm{HCl}, \mathrm{PCBs}$, and PM;

The flow of PCBs to incinerator must stop automatically when temperature drops below the specified $1200 \mathrm{oC}$ or $1600 \mathrm{oC}$, when there is a failure of monitoring operations, or excess oxygen falls below the specified $3 \%$ or $2 \%$; and

Scrubbers must be used during incineration for $\mathrm{HCl}$ control.

There are also two requirements of RCRA for the incineration of liquid and non-liquid PCB wastes. They are as follows:

Incinerator must achieve a destruction and removal efficiency rate of $99.99 \%$ and

Hazardous waste incinerators must not emit more than 180mg / m3 air of PM (USDOE, 1999; 40 CFR 761.7).

Remediation option \#4 is supercritical carbon dioxide (SC-CO2) extraction of the PCBs from the solid waste, followed by incinerating the PCBs and disposing of the non-hazardous solid waste in a landfill. Refer to Figure 6.2 for the process diagram for Option \#4. As with Option \#3, several assumptions were made concerning SC-CO2 extraction of the PCBs from the solid waste. There is some uncertainty regarding the amount of PCBs that can be effectively extracted using carbon dioxide. However, for cost calculations, it was assumed that $100 \%$ could be extracted. Assumptions were also made regarding the concentration of PCBs in the wastes under consideration. It is known that the wastes contain greater than $50 \mathrm{ppm}$ PCB, however exact concentrations are not known. 0.1 volume percent (100,000 ppm with similar densities and 
molecular weights) was assumed. Extraction costs were calculated using data obtained from a study performed by Matthews et al. (1998). The capital cost to build the extractor would be between $\$ 2$ and $\$ 10$ million. The extraction cost is approximately $\$ 0.20$ per pound of waste. There is about 5 million pounds of waste. Therefore, extraction of all PCB waste would cost $\$ 1$ million. The total cost of extraction, including capital cost, is between $\$ 3$ and $\$ 11$ million. The cost of transport and incineration is approximately $\$ 1.6$ million (1/10 of \$15.6 million).

The assumptions used for calculating the landfill costs of the solid waste after extraction are as follows: the PCB wastes consist of PCBs and material similar to ToxiDry, with an average density of $0.12 \mathrm{~g} / \mathrm{cm} 3$, and the same volume of ToxiDry is present after extraction (19,000 m3). Landfill costs of non-hazardous solid waste with organics are approximately $\$ 0.13$ / pound (Mulholland and Dyer, 1999). Therefore, the calculated landfill cost of the extracted waste is $\$ 652,000$ plus transportation cost. Transportation of the nonhazardous solid waste is not expected to be very costly because it is not regulated. The total calculated cost of extraction plus incineration is between $\$ 5.2$ and $\$ 13.3$ million (depending on capital cost of the SC-CO2 extractor). The extraction process reduces the volume of PCBs by a factor of ten and reduces the $\mathrm{PCB}$ disposal cost by the same factor. Therefore, extracting the waste prior to incineration is a definite advantage. However, as stated in the Option \#3 above, relying on incineration for the long-term is not a wise choice due to the pending closure in 2003 of the K-25 TSCA Incinerator at the Oak Ridge facility. The regulatory requirements for this remediation option are the same as stated above for Option \#3.

Option \#5 is dechlorination of PCBs using a method provided by Safety Kleen. Refer to Figure 6.3 for the process drawing of this option. Dechlorination requires carbon dioxide extraction of the PCBs from the hazardous solid waste. The dechlorination process can be used to dispose of concentrated liquid PCBs in transformers, capacitors, and oils. In the case of electrical equipment, the PCBs are drained from the equipment before they are dechlorinated. Dechlorination of PCBs at Safety Kleen involves stripping the PCB molecules of chlorine using metallic sodium. This process forms a sodium salt and a polyphenol, neither of which are toxic. The Safety Kleen dechlorination process can be transported to the DOE facilities, therefore eliminating costly transportation of PCB waste. Extraction of PCBs from the solid waste greatly reduces the volume of PCBs to be treated, and thus reduces the cost of dechlorination (UNEP, 2000). Again, $100 \%$ efficiency of PCB removal in the CO2 extractor was assumed. The concentration PCBs in the waste, as stated above, was assumed to be 0.1 volume percent $(100,000 \mathrm{ppm})$. SC-CO2 extraction costs for Option \#5 are the same as stated above for Option $\# 4$ - between \$3 and \$11 million. The cost of dechlorination of PCBs is \$100 per 55-gallon drum (UNEP, 2000). After extraction of the PCBs, there would be approximately 9125 drums (1/10 of total volume) to be dechlorinated. Using these assumptions and costs, the cost of the dechlorination of the PCB extract is $\$ 912,500$. The landfill cost of the cleaned solid waste is $\$ 652,000$ (the same as calculated in remediation Option \#4). Therefore, the total cost for SC$\mathrm{CO} 2$ extraction followed by dechlorination of the PCB extract is between $\$ 4.6$ and $\$ 12.6$ million (depending on capital cost of extractor).

The last option considered, Option \#6, SC-CO2 extraction of the 19,000m3 of PCB contaminated solid waste followed by supercritical water oxidation (SCWO) of the PCB wastes. See Figure 6.4 for the process diagram of this option. SC-CO2 extraction costs for Option \#6 are the same as stated above for Option \#4 - between $\$ 3$ and \$11 million. Again, it was assumed that $\mathrm{SC}-\mathrm{CO} 2$ extraction would reduce the $\mathrm{PCB}$ volume to $1 / 10$ of original volume of hazardous 
waste. SCWO has proven to be an effective method in treating aqueous waste streams. The theory behind SCWO is that it uses an oxidizing agent, such as oxygen or hydrogen peroxide, in the presence of water above its critical point to oxidize the organic compounds. The estimated capital cost for SCWO is about $\$ 5.9$ million. This cost includes the cost of the heat exchangers, compressor, high pressure pumps, reaction vessel, and the separator (Abraham et al., 1998). The same assumptions regarding the volume of waste and PCB levels in the waste are used: approximately 9,125 - 55 gallon drums and 100,000 ppm waste concentration. The operating cost was estimated by Abraham et al. (1998) to be approximately $\$ 0.37$ per gallon to treat aqueous waste. Therefore, the total operating cost to treat the PCB waste is about $\$ 185,693$ (501,875 gallons of waste $\mathrm{x} \$ 0.37$ per gallon). Thus, the total cost of extraction followed by SCWO of PCB wastes ranges between $\$ 9.1$ million and $\$ 17.1$ million, depending on the capital costs of the SC-CO2 extraction system. Thus, Option \#6 is economically competitive with Option \#5 (extraction followed by dechlorination). SCWO is advantageous over Options \#3 and \#4 that involve incineration, because SCWO does not produce hazardous emissions and is less energy intensive.

Extraction followed by incineration (Option \#4) and extraction followed by dechlorination (Option \#5) were compared against total incineration of all wastes (Option \#3) to determine the savings associated with carbon dioxide extraction. The costs for total incineration were divided evenly over the life of the project to determine the savings that result from the extraction process. The labor costs associated with operating the extractor were based on the hiring of two operators and one clerical worker, including all permitting costs that may be incurred. The other costs associated with each of the processes have already been discussed. In order to compare the options, the net present value (NPV), internal rate of return (IRR), and payback period were calculated. An example calculation for extraction and incineration (Option \#4) is shown in the following table.

\begin{tabular}{|c|c|c|c|c|c|c|}
\hline & \multicolumn{6}{|l|}{ Year } \\
\hline & & 1 & 2 & 3 & 4 & 5 \\
\hline Capital Expenses & $\$ 5,000,000$ & & & & & \\
\hline Operators/Clerical & & $-\$ 200,000$ & $-\$ 200,000$ & $-\$ 200,000$ & $-\$ 200,000$ & $-\$ 200,000$ \\
\hline Extraction & & $-\$ 200,000$ & $-\$ 200,000$ & $-\$ 200,000$ & $-\$ 200,000$ & $-\$ 200,000$ \\
\hline Incineration & & $-\$ 320,000$ & $-\$ 320,000$ & $-\$ 320,000$ & $-\$ 320,000$ & $-\$ 320,000$ \\
\hline Landfill Costs & & $-\$ 130,000$ & $-\$ 130,000$ & $-\$ 130,000$ & $-\$ 130,000$ & $-\$ 130,000$ \\
\hline Savings & & $\$ 3,120,000$ & $\$ 3,120,000$ & $\$ 3,120,000$ & $\$ 3,120,000$ & $\$ 3,120,000$ \\
\hline Cash Flow & $-\$ 5,000,000$ & $\$ 2,270,000$ & $\$ 2,270,000$ & $\$ 2,270,000$ & $\$ 2,270,000$ & $\$ 2,270,000$ \\
\hline PV & $-\$ 5,000,000$ & $\$ 2,063,000$ & $\$ 1,876,000$ & $\$ 1,705,000$ & $\$ 1,550,000$ & $\$ 1,409,000$ \\
\hline NPV & $\$ 3,604,000$ & & & & & \\
\hline NPV for IRR & $\$ 0$ & & & & & \\
\hline Payback Period & 2.6 years & & & & & \\
\hline
\end{tabular}


\begin{tabular}{|l|l|}
\hline IRR & $35.43 \%$ \\
\hline
\end{tabular}

Table 13.1. Cash Flow Table Example

Table 13.1 shows the cash flow for each year during the proposed 5-year lifespan of the project. The present value of each cash flow was calculated using an interest rate of $10 \%$ compounded annually. The NPV of the project is the summation of all the present values, and the payback period is the time it takes to recover the initial capital expense. The IRR is the interest rate at which the capital investment would have to be made to make the return in 5 years that is saved by this project.

A cash flow diagram was constructed for options 4 and 5 available at different initial capital investments, and varying project lifetimes. The results from these calculations are shown below in Table 13.2.

\begin{tabular}{|c|c|c|c|c|c|c|}
\hline \multicolumn{7}{|c|}{ Assumption: All Waste is to be Extracted } \\
\hline \multirow[b]{2}{*}{ Description } & \multicolumn{3}{|c|}{ Option 4 - Extraction + Incineration } & \multicolumn{3}{|c|}{ Option 5 - Extraction + Dechlorination } \\
\hline & NPV & IRR & Payback Time & NPV & IRR & Payback Time \\
\hline 3 year, $\$ 5 \mathrm{~m}$ Investment & $\$ 4,987,000$ & $61.11 \%$ & 1.4 years & $\$ 5,557,000$ & $66.51 \%$ & 1.33 years \\
\hline 5 year, $\$ 5 \mathrm{~m}$ Investment & $\$ 3,604,000$ & $35.43 \%$ & 2.6 years & $\$ 4,125,000$ & $38.80 \%$ & 2.45 years \\
\hline $\begin{array}{l}3 \text { year, } \$ 10 \mathrm{~m} \\
\text { Investment }\end{array}$ & $-\$ 13,000$ & N/A & N/A & $\$ 557,000$ & $13.14 \%$ & 2.83 years \\
\hline $\begin{array}{l}5 \text { year, } \$ 10 \mathrm{~m} \\
\text { Investment }\end{array}$ & $-\$ 1,396,000$ & N/A & N/A & $-\$ 875,000$ & N/A & N/A \\
\hline $\begin{array}{l}10 \text { year, } \$ 5 \mathrm{~m} \\
\text { Investment }\end{array}$ & $\$ 1,358,000$ & $16.01 \%$ & 7.92 years & $\$ 1,781,000$ & $17.77 \%$ & 6.34 years \\
\hline \multicolumn{7}{|c|}{ Assumption: Only $60 \%$ is to be Extracted, the Remainder is Incinerated } \\
\hline 3 year, $\$ 5 \mathrm{~m}$ Investment & $\$ 793,000$ & $18.81 \%$ & 2.54 years & $\$ 1,135,000$ & $22.50 \%$ & 2.4 years \\
\hline $\begin{array}{l}3 \text { year, } \$ 10 \mathrm{~m} \\
\text { Investment }\end{array}$ & $-\$ 4,027,000$ & N/A & N/A & $\$ 3,685,000$ & N/A & N/A \\
\hline
\end{tabular}

Table 13.2. Economic Comparison of Incineration and Dechlorination Options.

It is evident from Table 136.2 that the best option, both economically and from a regulatory standpoint, is Option \#5 with a $\$ 5$ million investment and a 3-year lifetime. This is supported by the calculations performed in step four of the LCA. This option has the highest IRR and least payback period. However, the 3-year lifetime may be unrealistic, unless there were two extractors built at different locations (shown with the $\$ 10$ million investment, 3 year lifetime). The extraction and dechlorination option is better regardless of initial investment or length of the project. However, longer projects invariably decrease the savings. If some of the wastes cannot be extracted, and if the waste must be incinerated instead, the benefit of using 
supercritical carbon dioxide extraction for the extractable wastes is greatly diminished. If some other method were developed to destroy the PCB wastes that cannot be extracted, it may once again prove to be beneficial to extract the PCB wastes. It should also be noted that some options that yield a lower NPV but a quicker destruction time (i.e. having two extractors but shorter project lifetimes) may be preferable due to the hazards associated with the wastes. In general, the shorter the lifetime of the project, the smaller initial investment, and the more wastes that can be destroyed with alternate methods, the better the option is economically.

Due to the large volume of PCB waste contained within the DOE complex, the disposal of this waste should be a priority for all DOE sites. Six remediation options were evaluated: long term on-site storage (Option \#1), storage at the Waste Isolation Pilot Plant (Option \#2), incineration of total waste at the TSCA Oakridge Incinerator (Option \#3), supercritical CO2 extraction followed by incineration of extract at TSCA Oakridge Incinerator and landfill of clean waste (Option \#4), extraction followed by dechlorination of extract and landfill of clean waste (Option \#5), and supercritical CO2 extraction followed by supercritical water oxidation (Option \#6). A Life Cycle Analysis (LCA) was conducted to determine which of the six options is best, both economically and environmentally, for PCB waste disposal. Due to regulatory prohibitions and the scope of the waste accepted for storage at the WIPP, Options \# 1and \#2 were eliminated as possible disposal methods.

The first step of a LCA is setting the boundaries of the process. The boundaries of this assessment were set to incorporate the waste and disposal methods. Life Cycle Inventory (LCI), the second step of LCA, includes all the PCB waste contained within the DOE complex (19,000m3). Life Cycle Impact Assessment (LCIA) is the third step. PCBs are toxic and probable human carcinogens. Because TSCA requires that the PCB wastes be disposed of within one year of generation, further impact analyses were not required.

The fourth step of LCA is Improvement Analysis. Improvement Analysis was the focus of this paper. Transport and incineration of the total waste volume (Option \#3) would cost at least $\$ 15.6$ million. This option is heavily regulated by TSCA, RCRA, HMTA, and AEA. Furthermore, the possible closure of the TSCA Oakridge Incinerator may eliminate this as an option before all waste can be incinerated. Extraction and incineration (Option \#4) of the waste is also heavily regulated and still requires costly transport. However, extraction reduces the volume of waste to $1 / 10$ of the original volume. Therefore, the cost of transport and incineration is reduced by the same factor. The extraction process would have to be constructed which adds capital cost to this option. There is also a landfill cost associated with this option. The total costs of Option \#4 are between $\$ 5.2$ and $\$ 13.3$ million. The high-end cost of this option is still at least \$2 million less than the previous option. As with Option \#3, the pending closure of the Oak Ridge incinerator may prevent this option from being executable. Option \#5 involves extraction of waste and then dechlorination of extract using the Safety Kleen method. Since this dechlorination method can be performed on-site, expensive transportation costs are eliminated (assuming the extractor can be transported to the site, as well). Furthermore, the regulations applicable to transport and incineration do not apply. The total costs of Option \#5 are between $\$ 4.6$ and \$12.6 million, depending on the capital costs of building the extractor. The total cost of Option \#6, extraction followed by supercritical water oxidation, is approximately $\$ 7.8$ million. 
If this process could be brought on-site, there would be no transport costs, and therefore makes this an economically viable option. Furthermore, it has environmental benefits over incineration of the waste. In conclusion, Option \#5 (extraction followed by dechlorination) and Option \#6 (supercritical water oxidation) are the most economically and environmentally sound options for the destruction of PCB wastes contained at the DOE sites. 
Figure 13.1. Process Diagram for Incineration of total PCB waste (Option \#3)

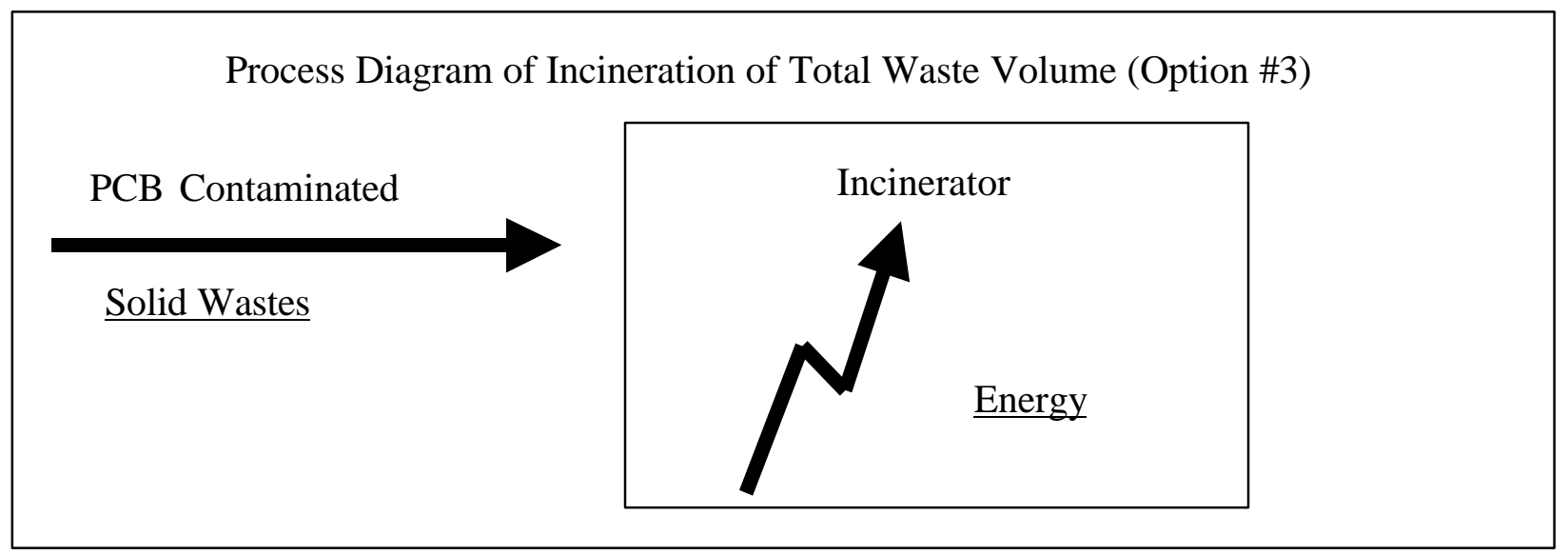

Figure 13.2. Process Diagram for Supercritical Carbon Dioxide Extraction plus Incineration of PCB extract (Option \#4)

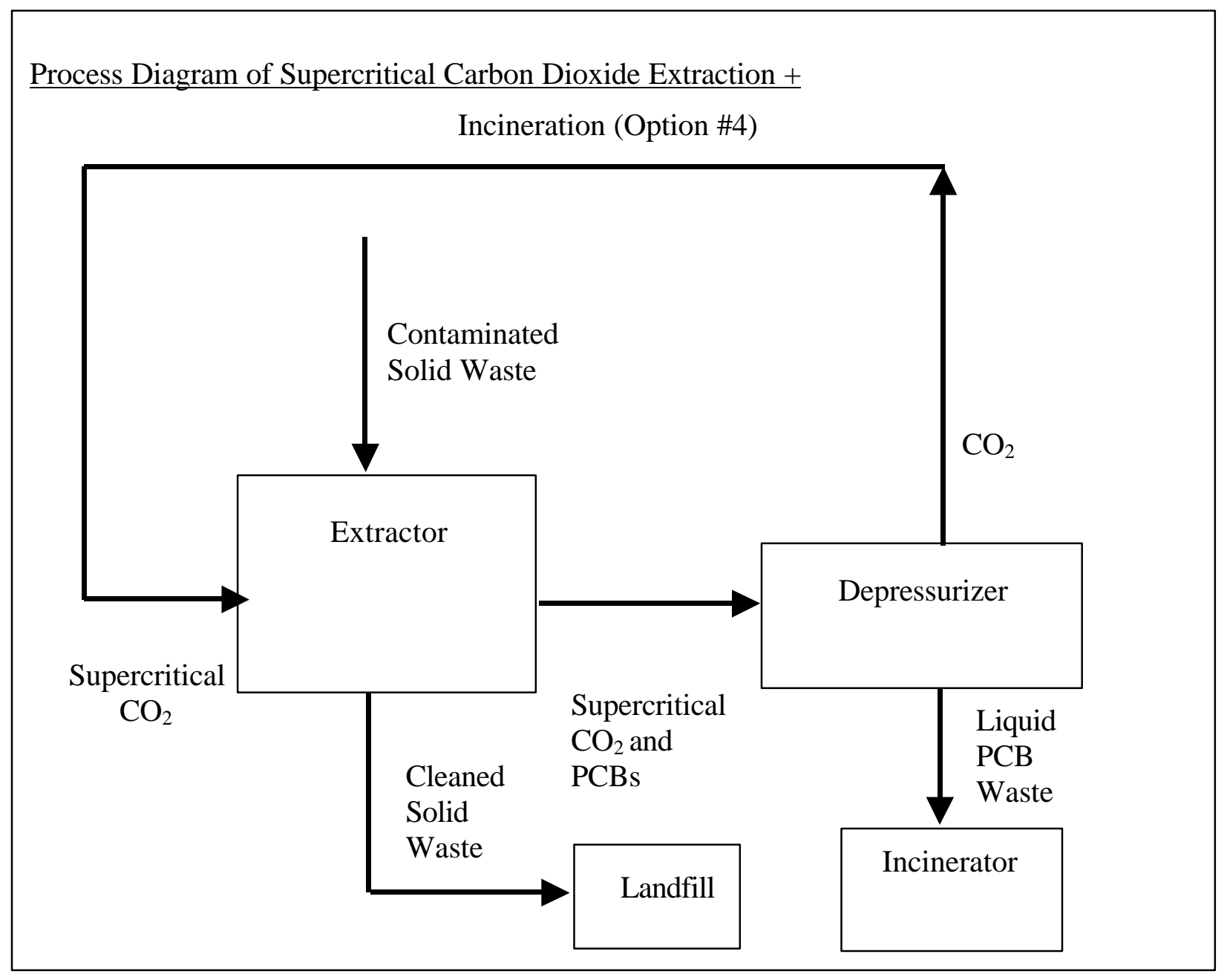


Figure 13.3. Process Diagram for Supercritical Carbon Dioxide Extraction plus Dechlorination of PCB extract (Option \#5)

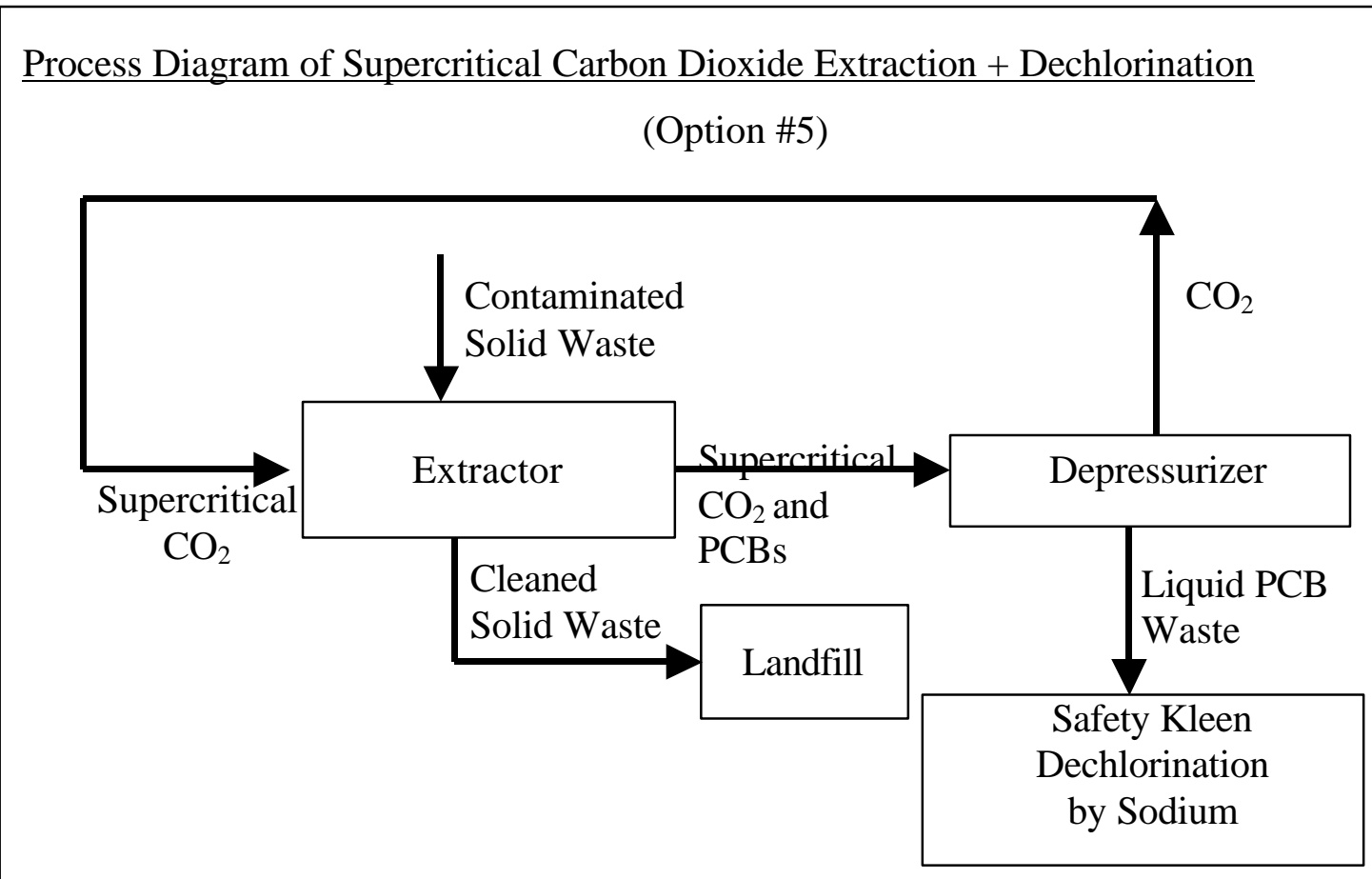

Figure 13.4. Process Diagram for Supercritical Carbon Dioxide Extraction plus Supercritical Water Oxidation of PCB extract

(Option \#5)

Process Diagram of Supercritical Carbon Dioxide Extraction + Supercritical Water Oxidation (Option \#6)

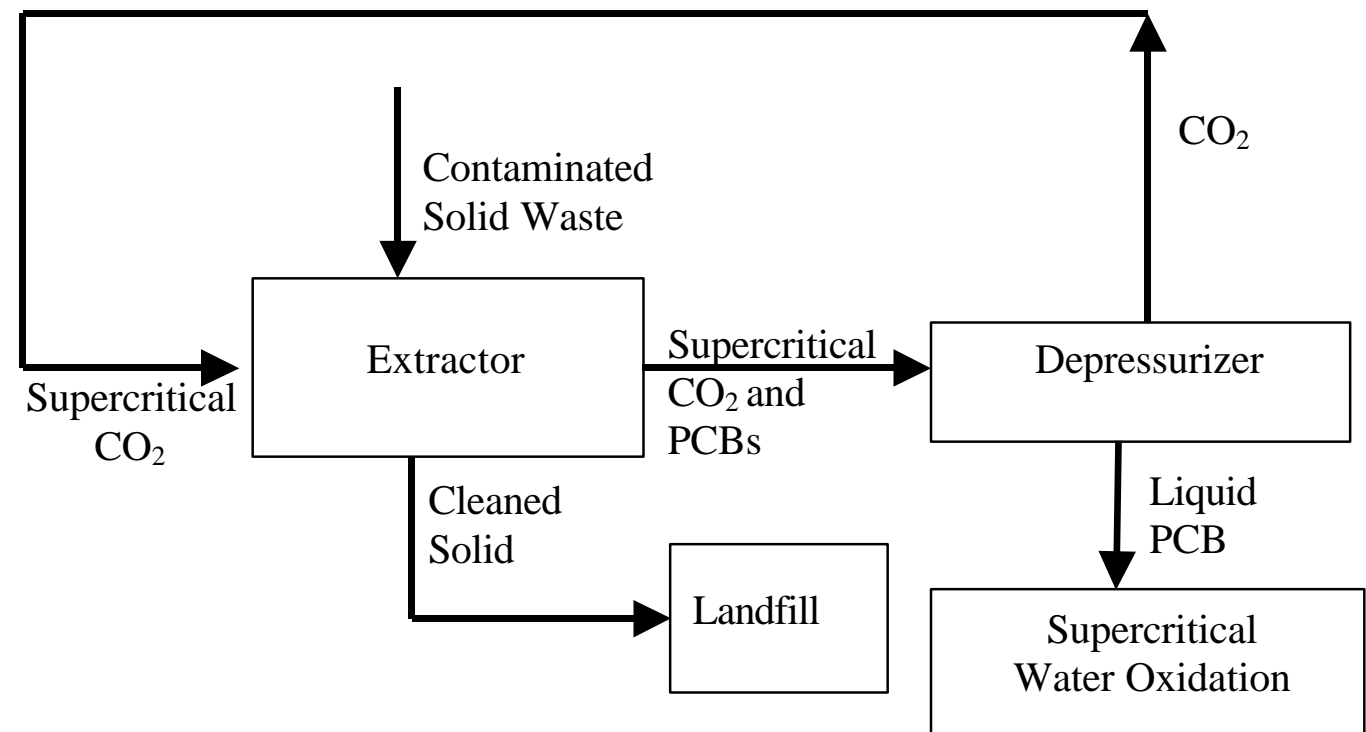




\section{Work Cited:}

Abraham, M.A. et al. "An Economic Evaluation of Catalytic Supercritical Water Oxidation: Comparison with Alternative Waste Treatment Technologies." Environmental Progress, 17 (4) 1998: 246-255.

Lowry, M.J. et al. "Development of Disposal Path for Non-Incinerable LowLevel Radioactive Waste Contaminated with PCBs: Pursuing, Obtaining, and Implementing Regulatory Solutions.” 1999. 20 February 2001.

<http://irmsrv02.srs.gov/general/sci-tech/fulltext/ms9900548/ms9900548.html>

Matthews, M.A., et al. "Recycling Steel from Grinding Swarf." Waste Management. 1998.

Mulholland, K.L., and J.A. Dyer. Pollution Prevention: Methodology, Technology, and Practices. New York: American Institute of Chemical Engineers. 1999.

United Nations Environmental Programme. "Survey of Currently Available NonIncineration PCB Destruction Technologies.” 2000. 2 March 2001.

<www.environmental-center.com/articles/article883/article883.htm>

U.S. Army Corps of Engineers. "Report on Treatment, Storage, and Disposal Facilities (TSDF) for Hazardous, Toxic, and Radioactive Waste (HTRW)." 1998.1 March 2001. <http://www.environmental.usace.army.mil/>

U.S. Department of Energy. Office of Environmental Policy and Assistance. Guidance Booklet on Storage and Disposal of Polychlorinated Biphenyl (PCB) Waste. DOE/EH-413-9914. Washington: GPO, 1999. <http://www.tis.eh.doe.gov/oepa/guidance/tsca/PCBGuid4.pdf>

WIPP Information Center. "WIPP: A critical step towards solving the nuclear waste problem." 2000. 3 March 2001. <http://www.wipp.carlsbad.nm.us/wipp.htm>

Code of Federal Regulations:

40 CFR 761.61 "PCB Remediation Waste"

40 CFR 761.7 "Incineration of PCB Waste"

48 CFR 970 
49 CFR 171-179

49 CFR 5101

S.C. Regulations

SC Regulation 61-83 “Transportation of Radioactive Waste Into or Within South 